\title{
SAFETY AND TECHNO-ECONOMIC ANALYSIS OF ETHYLENE
}

TECHNOLOGIES

\author{
A Thesis \\ by \\ PREETHA THIRUVENKATASWAMY
Submitted to the Office of Graduate and Professional Studies of Texas A\&M University
in partial fulfillment of the requirements for the degree of
MASTER OF SCIENCE

$\begin{array}{ll}\text { Chair of Committee, } & \text { Mahmoud El-Halwagi } \\ \text { Committee Members, } & \begin{array}{l}\text { M. Sam Mannan } \\ \text { Hisham Nasr-El-Din }\end{array} \\ \text { Head of Department, } & \text { M. Nazmul Karim }\end{array}$

May 2015

Major Subject: Safety Engineering

Copyright 2015 Preetha Thiruvenkataswamy 


\begin{abstract}
Inherent safety is a concept that enables risk reduction through elimination or reduction of hazards at the grass root level of a process development cycle. This proactive approach aids in achieving effective risk management while minimizing fixed and operating cost. Several indices which quantify the measures of inherent safety have been identified and by applying these techniques on conceptual design stage, an estimate of the inherent risk and additional safety cost measures can be developed. This approach facilitates easy decision making in an early stage, for choosing the best process that is superior in process, economic and safety performance. Yet, these quantitative techniques are not being used effectively in process industries. In this thesis, a comparative approach was developed wherein, two different process technologies producing same chemical were compared through techno-economic and safety analysis, to identify the superior process.
\end{abstract}

Recent advancements in shale gas monetization have contributed to the growth and expansion of large number of petrochemical plants, particularly the ethylene industry. For this thesis, the production of ethylene through two process technologies were considered, such that one route is the primary process route while other is a novel process that is still in development stage. The process routes identified were ethane steam cracking, a well-established process and "ECLAIRS" (Ethylene from Concentrated Liquid phase Acetylene- Integrated, Rapid and Safe), an emerging Gas to ethylene process. A top level analysis was performed using key quantitative indicators of 
process, cost and inherent safety. The results show that the state of art technology of ethane cracking has an attractive process and economic potential, while the gas to ethylene technology is more inherently safer. The areas of improvement were identified and critical analysis of metrics was carried out. 


\section{DEDICATION}

To

My Parents 


\section{ACKNOWLEDGEMENTS}

First of all, I would like to thank my committee chair, Dr. Mahmoud El-Halwagi for providing continuous, positive support and guidance throughout the course of this research. I would also like to thank my committee members and other department faculty for sharing their knowledge and expertise in the field of chemical engineering. I would also like express my gratitude to Dr. Fadwa El-Jack from Qatar University, for providing valuable inputs on ethylene processes. I sincerely believe that this learning experience has strengthened my fundamental understanding and helped me appreciate new concepts in the field of process safety and chemical engineering.

I would like to acknowledge the assistance provided by Nitin Roy, P.V.K. Srikanth, Sunder Janardhan and Narendra Kumar in the field of process safety, reaction engineering, thermodynamics and Aspen simulation. I am also thankful to my seniors Mohamed Noureldin, Kerron Gabriel and Kamrava Serveh for providing valuable guidance throughout my course of research. I would specially like to thank my friend Saurabh Maduskar, for providing positive support and inspiration to undertake this course. Thanks also go to my friends, colleagues and the department staff for making my time at Texas A\&M University a great experience. Finally, thanks to my family for their encouragement and support throughout my course of learning. 


\section{TABLE OF CONTENTS}

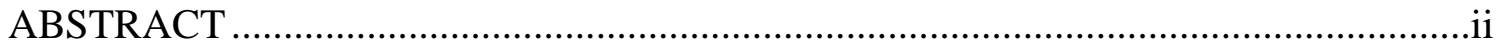

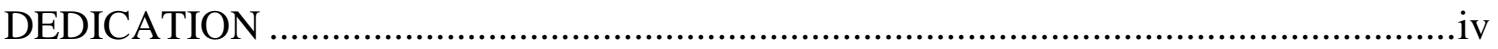

ACKNOWLEDGEMENTS ………………………………………………………v

TABLE OF CONTENTS …………………………...............................................

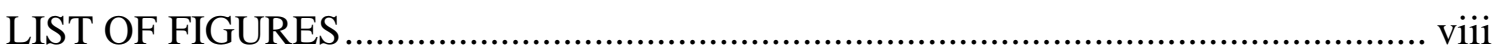

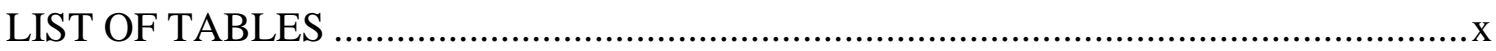

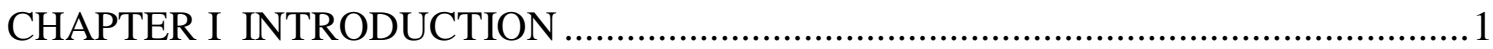

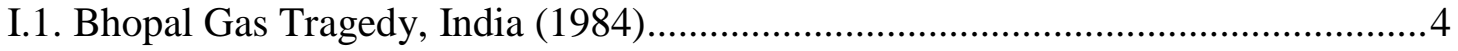

I.2. Flixborough, UK (1974) …………………………………………………6

CHAPTER II LITERATURE REVIEW ………………..............................................

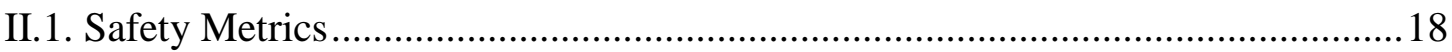

II.1.1. Dow Fire and Explosion Index ………………........................................ 18

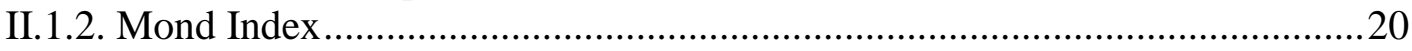

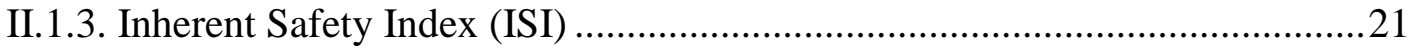

II.1.4. Safety Weighted Hazard Index (SWeHI) ...................................................22

II.1.5. Hazard Identification and Ranking System (HIRA)......................................24

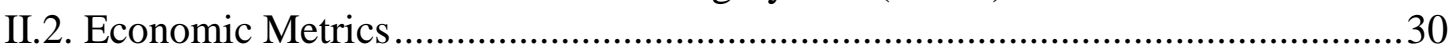

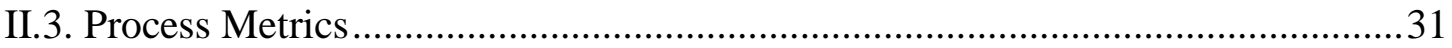

CHAPTER III PROCESS ANALYSIS.........................................................................

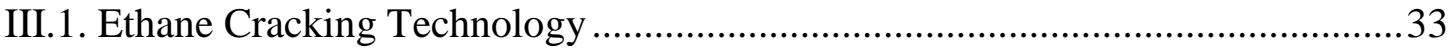

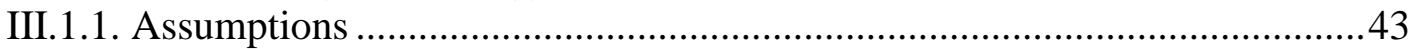

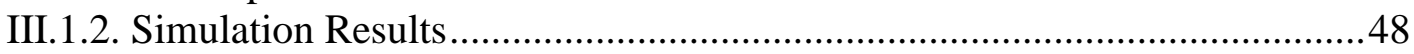

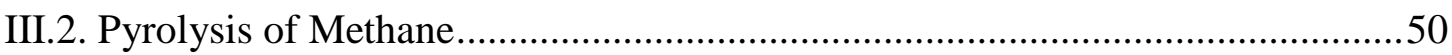

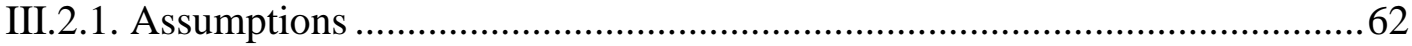

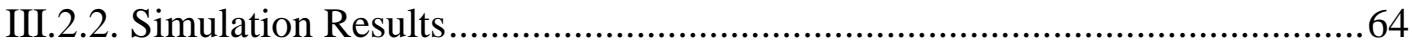

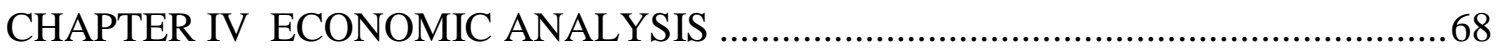




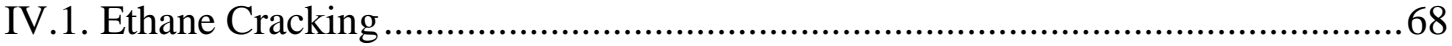

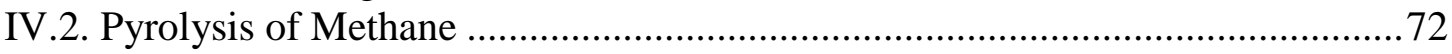

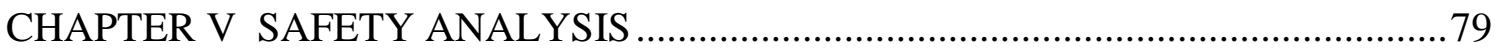

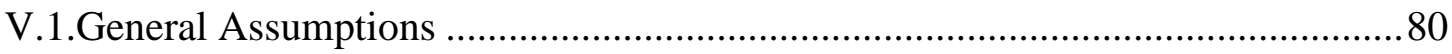

V.1.1 Units with Chemical Reactions and Physical Operations ............................81

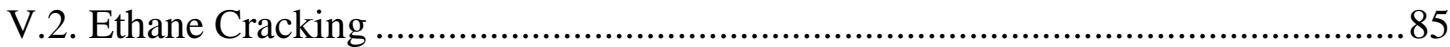

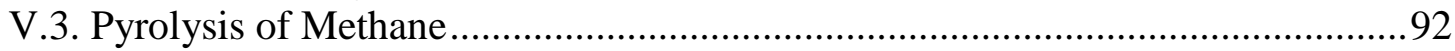

CHAPTER VI RESULTS AND DISCUSSION ................................................. 99

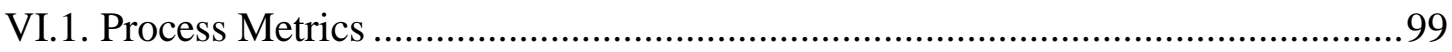

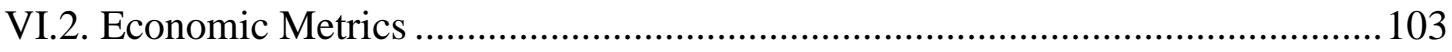

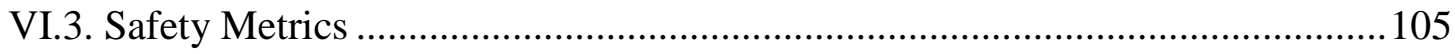

CHAPTER VII CONCLUSION AND RECOMMENDATIONS ..............................110

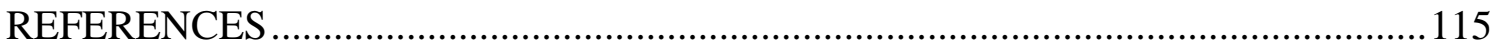

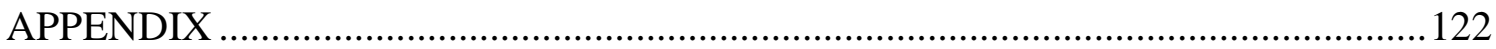




\section{LIST OF FIGURES}

Page

Figure 1: Typical Layers of Protection in a chemical process ..................................... 8

Figure 2: Stages of Chemical Process Development ............................................. 10

Figure 3: Approach methodology of techno-economic and safety analysis. ..................13

Figure 4: Ethylene supply and demand change .................................................. 16

Figure 5: Yield patterns of different steam cracking feed stocks ............................... 17

Figure 6: Factors affecting Damage potential.................................................. 27

Figure 7: Block diagram of ethane steam cracking process using front end demethanizer scheme

Figure 8: Process flow diagram of ethane steam cracking process..............................42

Figure 9: Specific energy consumption of major sections- ethane cracking process.......49

Figure 10: Major energy contributors- ethane cracking process...................................50

Figure 11: Block diagram of methane pyrolysis using partial oxidation method of heat transfer.

Figure 12: Process flow diagram of methane pyrolysis process. .................................56

Figure 13: Scheme 1 and scheme 2 for solvent separation. .....................................57

Figure 14: Scheme 3 proposed for solvent separation. .............................................58

Figure 15: Specific energy consumption of major sections- methane pyrolysis.............66

Figure 16: Major contributors to energy consumption- methane pyrolysis...................67

Figure 17: Distribution of equipment under various ranges of damage radius- Ethane

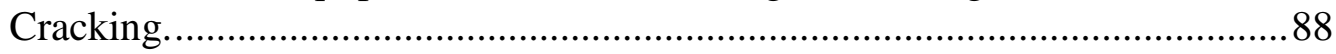

Figure 18: Semi-quantitative ranking based on HIRA method- Ethane Cracking...........89

Figure 19: Section wise ranking of FEDI- Ethane Cracking. .......................................91

viii 
Figure 20: Overall block diagram of inherent safety levels- Ethane cracking.

Figure 21: Distribution of equipment under various ranges of danage radius- Methane pyrolysis. 95

Figure 22: Semi-quantitative ranking based on HIRA method- Methane pyrolysis .95

Figure 23: Section wise ranking of FEDI- Methane Pyrolysis. .96

Figure 24: Overall block diagram of inherent safety levels- Methane pyrolysis. .98

Figure 25: Comparison of section-wise energy consumption. 101

Figure 26: Comparison of utility consumption. 102

Figure 27: ASPEN Flowsheet- Ethane Cracking - Overall Process..... 123

Figure 28: ASPEN Flowsheet: Ethane Cracking- Compression Section 124

Figure 29: ASPEN Flowsheet- Ethane Cracking- Cooling train. 125

Figure 30: ASPEN Flowsheet- Ethane Cracking- Separation Section 126

Figure 31: ASPEN Flowsheet- Gas to Ethylene - Pyrolysis and Compression Section 127 Figure 32: ASPEN Flowsheet - Gas to Ethylene- Solvent Separation and Product Separation Section 128 


\section{LIST OF TABLES}

Page

Table 1: Proposed additions of U.S. ethylene production capacity, 2013-2020 .............15

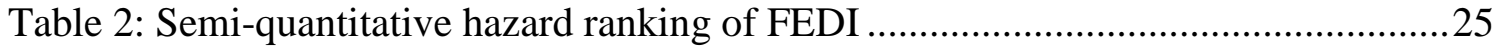

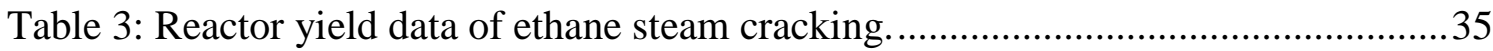

Table 4: Conversions assumed for ethane cracking reactions.................................... 35

Table 5: List of utilities and utility operating conditions.........................................46

Table 6: Process efficiency values of utilities.................................................. 46

Table 7: List of energy consuming equipment and their consumption rates- ethane

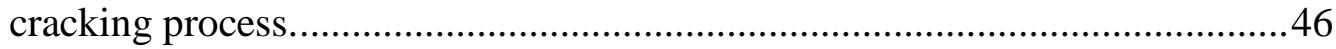

Table 8: Simulation results- ethane cracking process. ...........................................48

Table 9: Reactor yield mole composition- methane pyrolysis...................................53

Table 10: Conversions of methane pyrolysis reaction using partial oxidation method. ..53

Table 11: Comparison of different schemes proposed for solvent separation. ...............59

Table 12: List of energy consuming equipment and rate of energy consumptions-

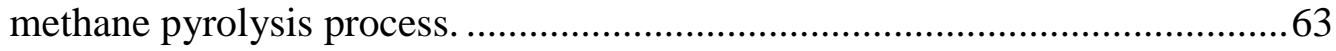

Table 13: Simulation results - methane pyrolysis process. .........................................66

Table 14: Estimation of raw material cost - Ethane steam cracking..............................69

Table 15: Consolidated cost data- Ethane cracking process. ......................................69

Table 16: Operating cost of equipment- ethane cracking ....................................... 70

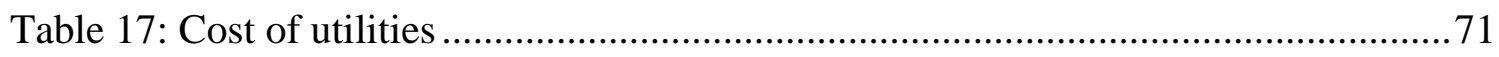

Table 18: Estimation of raw material cost- methane pyrolysis................................. 73

Table 19: Consolidated cost data- methane pyrolysis process. .................................. 74 
Table 20: Operating cost of equipment- methane pyrolysis. ....................................75

Table 21: Capital investment of equipment- Methane pyrolysis. ..................................77

Table 22: Equipment ranking based on FEDI values- Ethane cracking process..............85

Table 23: Equipment ranking based on FEDI values- Methane Pyrolysis. ....................99

Table 24: Comparison of process performance metrics........................................... 100

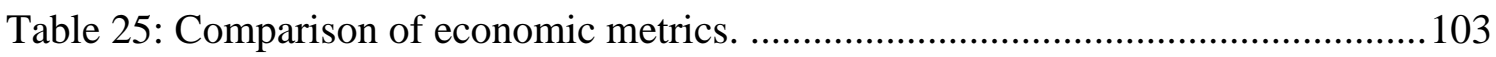

Table 26: Comparison of inherent safety levels.................................................. 105

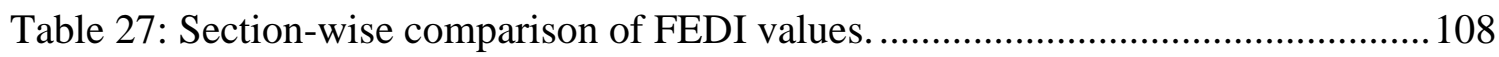

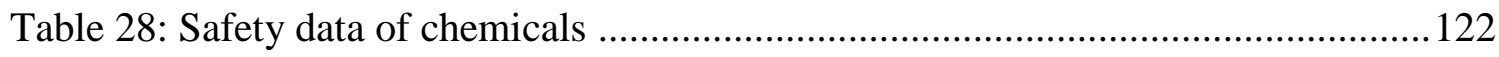

Table 29: Safety calculation sheet of physical units- Ethane Cracking ........................129

Table 30: Safety calculation sheet of physical units- Methane Pyrolysis .....................130

Table 31: Safety calculation of reactors- Ethane Cracking ....................................... 132

Table 32: Safety calculation of reactors- Methane Pyrolysis..................................... 132 


\section{CHAPTER I}

\section{INTRODUCTION}

Process risk management is a fundamental concept of chemical process safety that involves identifying, reducing and managing risks in chemical processes.(Center for Chemical Process, 2008b) Risk is a function of consequence and likelihood of a hazard, where hazard is defined as a potential harm caused by a condition. (Center for Chemical Process, 2008b) In order to effectively manage risks, a thorough hazard analysis must be done to identify all possible hazards produced in a process. Followed by identification, efforts should be taken to reduce those hazards that have high consequences as well as a large likelihood of occurrence. Since, it is impossible to eliminate all the hazards completely in a process, the risk levels should be maintained at a minimum level by continual improvement and effective management. One of those powerful ways of reducing risk is done by eliminating the root cause of hazards in a process. (Center for Chemical Process, 2008b) The approach of identifying the source of hazard and developing methods to eliminate or reduce impact of source is termed as inherent safety approach. (Center for Chemical Process, 2008b)

Hazards of a chemical process are inherent in nature, caused predominantly due to operating conditions, quantities of chemicals, characteristics of chemicals, size and location of unit operations. Consequence of a hazard arising out of an abnormal condition increases with increase in intensity of the above mentioned factors. In addition to these factors there are several other types of hazards such as mechanical hazards of 
rotary equipment, electrical hazards, safety hazards and few other that can attribute to further severity of hazard consequence.

In order to effectively neutralize the consequence of a hazard, the probability of an abnormal condition is thwarted by following risk reduction in four levels.(Center for Chemical Process, 2008a)

i. Inherent - Reducing or eliminating hazards that are present in the process condition or chemicals involved in processes.

ii. Passive - Eliminating hazards by subduing the impact of an abnormal condition without the use of any human initiated controls or automatic device activation.

iii. Active - Eliminating hazards by thwarting the occurrence of a hazard by initiating manual controls or automatic device activation.

iv. Procedural - Implementing policies, training and other managerial regulations that can effectively help in early identification of a hazard and abnormal situation management, thus preventing an accident from occurring. (Center for Chemical Process, 2008a)

The above mentioned approaches are used in all stages of process development and they seek to address all the hazards present in a process. Though all the methods contribute in increasing overall safety, inherent and passive ways are proven to be the most effective way of risk reduction because they don't involve any manual or automatic intervention.(Dennis, 2012) Hence, they are considered reliable and robust techniques of risk management.(Dennis, 2012) Inherent safety approach is one such method that can 
be applied at any stage of a chemical process with ease. However, basic safety of the process is enhanced on implementing the inherent safety approach at the preliminary level of a chemical process life cycle.(Kletz, 1985) This approach is a fundamental and logical way of eliminating risks by removing materials or reducing intensity of process variables that cause significant impact on safety. (Kletz, 1985)

Inherent Safety as defined by CCPS (Center for Chemical Process Safety) is given by: "A chemical manufacturing process is inherently safer if it reduces or eliminates the hazards associated with materials and operations used in the process and this reduction or elimination is permanent and inseparable." (Center for Chemical Process, 2008a) The concept of inherent safety was first introduced by Trevor Kletz, who suggested change in basic technology to remove hazards, rather than adding additional layers to protect the inherent hazards.(Kletz, 1985) Effective inherent safety is achieved with the change or modification done starting from process chemistry followed by change in intensive process parameters and design of equipment. The four main guiding principles of inherent safety approach are defined as follows:(Kletz, 1985)

i. Minimization: Minimizing the inventory of the material, size of equipment, pipeline size can reduce the risk of an incident significantly.

ii. Substitution: Substituting the more hazardous chemical with a less hazardous chemical that gives same or better performance is an effective method of risk reduction. A process that produces more hazardous intermediates or by products that require additional separation processes can be substituted by a less dangerous technology. 
iii. Moderation: Moderating the intensity of process parameters such as reduced temperatures and pressure favor in enhancement of safety.

iv. Simplification: A simplified process that has minimum number of equipment not only reduces fixed and operating cost but also enhances safety.

Inherent safety gained importance after the occurrence of two major accidents in chemical industry: Bhopal Gas tragedy, India (1984) and Explosion at Flixborough, UK.(Kletz, 1985) Both these incidents depict lack of sound process design and illustrate the need for inherently safer design at the initial stage. Following these incidents, continuous efforts have been taken to popularize the concept of Inherently Safer Designs (ISD) and thus improve safety at all levels of a process development. The brief details of the cause and consequence of these two accidents are explained below to understand the need of inherent safety approach.

\section{I.1. Bhopal Gas Tragedy, India (1984)}

On December 3, 1984, near Bhopal, India, approximately 41 tonnes of a toxic chemical named Methyl Iso-Cyanate leaked from a chemical plant manufacturing Carbaryl, a pesticide.(Gupta, 2002) This disaster caused approximately 3000+ fatalities and 300,000 injuries.(Gupta, 2002) Methyl Iso-Cyanate, was stored as a chemical intermediate in the process of manufacturing Carbaryl. On the day of the incident, a storage tank containing large quantities of Methyl Iso-Cyanate got contaminated with water which led to an exothermic runaway reaction, causing sudden rise in temperature 
and pressure.(Kletz, 1985) Increase in pressure caused the pressure relief valve to rupture, causing the toxic gas to be leaked through the flare system.

The release of the toxic gas has been attributed to improper maintenance of safety equipment, lack of proper controls and emergency response, and improper knowledge of chemical.(Browning, 1993) Investigations revealed that the refrigeration system that was designed to cool the storage tank was non-operational as a cost-cutting measure for saving refrigerant. (Browning, 1993) The pressure relief valve of the storage tank was connected to a vent gas scrubber system, followed by a flare system. It was later found that the scrubber system and the flare system were taken offline for maintenance. (Browning, 1993)In addition to negligent use of safety system, the plant personnel were not properly trained to manage emergencies. (Browning, 1993)

This incident is a perfect example of a Swiss-cheese model. When loopholes in each layer of protection align together, then the occurrence of incident is unpreventable. The disadvantage of adding additional layer of protection and the need of more reliable protection is demonstrated in this incident. Studies reveal that Carbaryl can be produced by the same reactants as used in Bhopal chemical plant, but in a different order that avoids the formation of MIC.(Kletz, 2006) Also, if the inventory levels of the plant were reduced, then the disaster could have been possibly avoided. This demonstrates that by applying the key strategies of inherent safety, effective risk management can be achieved. 


\section{I.2. Flixborough, UK (1974)}

On June 1, 1974, an explosion occurred in a plant manufacturing nylon near Flixborough, UK.(Kletz, 2006) The cause of explosion came from the unit containing six reactors connected in series, in which cyclohexane reacted with oxygen to form cyclohexanol and cyclohexanone mixture.(Kletz, 2006) The reactors were stacked in such as fashion to facilitate the flow of liquid cyclohexane from one reactor to other through gravity.(Kletz, 2006) Leakage of one of the reactors led to removal of that equipment for maintenance. A temporary pipeline was fitted to connect the remaining two reactors in order to keep the production running, but it was not mechanically designed to withstand the sudden rise in pressures in the reactors.(Kletz, 2006) On the day of the incident, the pipeline ruptured and led to a sudden release of flammable cyclohexane in huge quantities that ignited, causing a violent explosion. The explosion killed 28 plant personnel and destroyed the entire plant.(Kletz, 2006) The cause of explosion was attributed to poor mechanical design of the temporary pipeline.(Kletz, 2006) The other underlying reasons of this huge explosion is attributed to large inventory of flammable liquid and the inventory is due to poor conversion rates of each reactor.(Kletz, 2006) This is yet another example showing the need for a different technology that minimizes the use of hazardous materials while increasing or maintaining same production. Studies reveal that by reacting cyclohexane with water and oxygen, a better conversion can be achieved to manufacture the same chemical.(Kletz, 2006) This will ensure reduction in volume of the unit as well as specific consumption of hazardous chemical. 
The above mentioned accidents demonstrate how poor process design and inefficient operations affect safety. Soon after these incidents, chemical industries adopted different approaches for replacement of a safer technology to produce the same chemical compound. The lesson to be inferred is that hazards caused by the physical and chemical conditions of materials has to be identified earlier and reduced or modified to attenuate the impact, than by adding additional layers of protection. However, layers of protection are vital in reducing risk and hence, proper and reliable layer of protection is to be used.

The typical layers of protection in a chemical process development stage are illustrated below in Figure 1. (S2S-A Gateway for Plant and Process Safety, 2003) Layers of protection provide additional safety measures to suppress the effect of the potential hazards. (Center for Chemical Process, 2008a) These add-on layers do not intend to eliminate hazards, but instead they prevent and control the incidents from happening using manual, automatic and administrative controls. (Center for Chemical Process, 2008a) Every additional layer added reduces the overall risk, but also introduces the need for more reliable equipment. As reliability of equipment increases cost of equipment increases thus, causing a major impact on the fixed and operating cost of the plant. Addition of too many equipment also causes complexity in the process and this increases chances of human and operational error. In order to optimize the reliability and cost of safety, it is important to choose a process that is inherently safe designed so that, safety is ensured with minimal cost of operation and more reliability. 


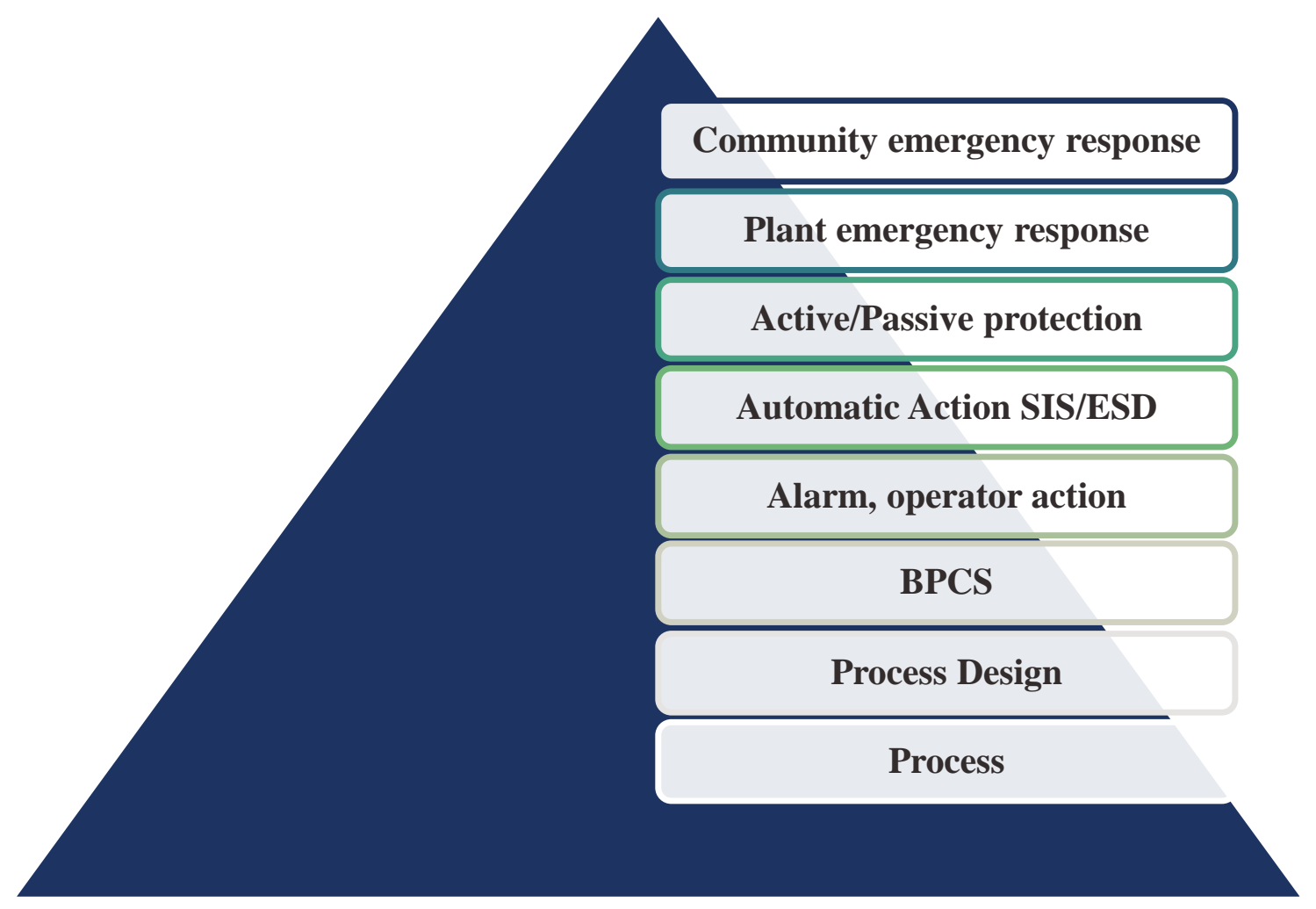

Figure 1: Typical Layers of Protection in a chemical process. Adapted from (S2S-A Gateway for Plant and Process Safety, 2003) 
A chemical process development lifecycle is illustrated below in Figure 2.

Inherently Safer Design approach is applied at all levels of process development but is cost effective to apply in research and development and conceptual design stage.(Dennis, 2012) This is because in the conceptual design stage after having identified the hazards, there are more opportunities to substitute or modify a process that is not designed and constructed.(Dennis, 2012) In the basic engineering stage, a better picture of process economics and process flow diagram is retrieved, including piping and instrumentation diagram, plant layout, process variables and Layers Of Protection Analysis (LOPA).(Maher, Norton, \& Surmeli, 2012) At this stage there are still better opportunities of modification since, more information about the process is obtained. A preliminary Hazards Operability (HAZOP) study identifies all possible hazards and efforts should be taken to reduce the imminent danger in the process than adding layers of protection.(Maher et al., 2012) From the above discussion, it is inferred that the above mentioned process development levels are crucial for determining the safety levels and additional cost of safety to be invested. Applying ISD approach in the later stages can cause time delays, additional cost of redesign and also reduces opportunities of modification.(Dennis, 2012) Nevertheless, ISD can still be applied at all stages such that a good, if not the best process design can be constructed.

Though the concept of ISD clearly carries a lot of benefits, it is not being followed by most of the chemical industries. The reasons are attributed to companies' focus on more productivity, restrictive attitude of exploring new technologies, lack of clarity, ignorance and less time spent on HAZOP in the preliminary stages of 
design.(Kletz, 1985) Other reasons include conflicting interest between safety and process yield, environmental concerns or economics.(Khan \& Amyotte, 2003)

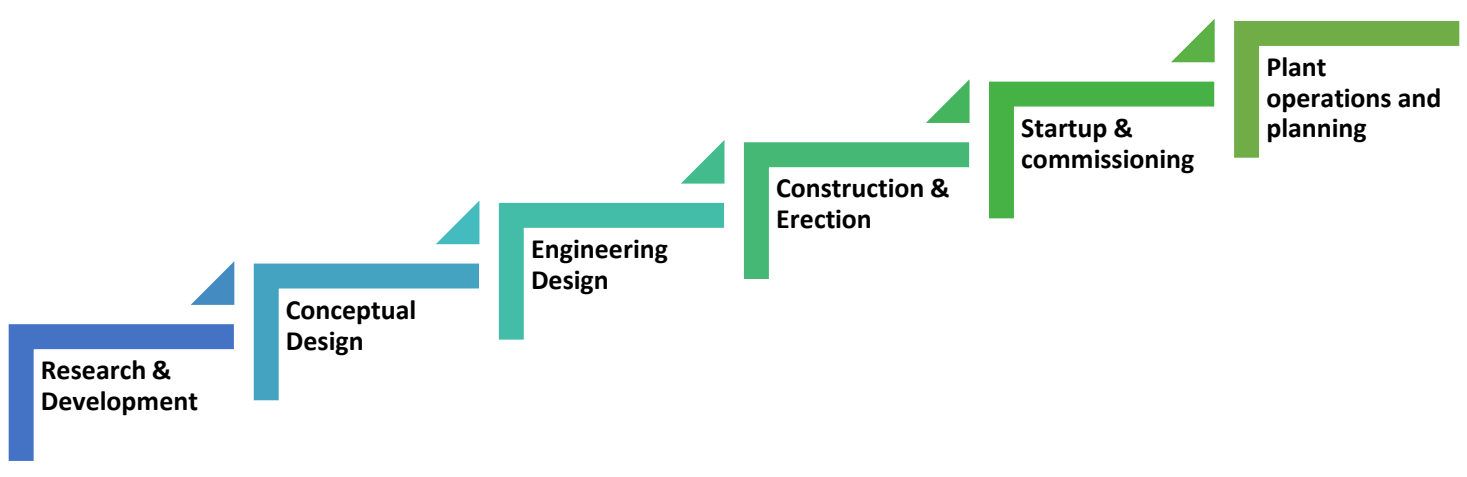

Figure 2: Stages of Chemical Process Development. Adapted from (Bauer \& Maciel Filho, 2004)

The above introduction to the concept of inherent safety provides a new route to deal with the hazards identified in a process. This approach provides a wide array of benefits including cost reduction while managing risks and also increase reliability. Yet, the approach is adapted only by a few companies in an effective way. This necessitates development of a problem statement whose principle objective is to apply the inherent safety approach at the conceptual design stage, to demonstrate its merits and method of choosing a safe approach to design. The problem statement can be described as making an effective overall decision between two chemical process routes for producing same chemical compound by analyzing the process technologies, economics of operation and 
inherent safety levels of the processes. Quantitative measures of all the three key performance factors are evaluated and a top level analysis is performed to select the process having minimum risk at basic level without addition of any layers of protection. The base case product chosen for the study is ethylene and the processes are identified such that one route is a well-established, state of art technology while the other one is a novel technology, that is yet to be commercialized.(Wood, Nwaoha, \& Towler, 2012)

The aim of this thesis is to illustrate the idea of inherent safety by doing a toplevel quantitative analysis of safety on the base case and comparing the safety levels with the process economics and technology. This study aims to analyze the inherent safety levels of two different process routes producing the same chemical compound and decide on the inherently safer process subject to cost and technological factors. There are several indices that can be used to measure inherent safety and these indices represent the magnitude of potential impact of a process. Another objective of this analysis is to identify areas of process improvement that can help in improving process efficiency as well as safety. This analysis also helps in comparing the operating cost with safety of the plant, so that decisions can be made that are equally beneficial to both the factors. The final aim is to rank all the major equipment/ sections of the plant that impact safety and provide possible recommendations for risk reduction.

The general approach to the problem statement can be illustrated by the Figure 3 . Initially, chemical kinetics and general process flow data for both the process technologies are collected from literature. Using this data, a steady state process simulation is carried out with the aid of computational software. From the simulation 
results, the process parameters, heating and cooling requirements of each unit are calculated. From these results, fixed and operating costs of both the plants are calculated. Energy costs and raw material costs are extracted based on the current prices of natural gas, natural gas liquids and oil. (ICIS, 2015)Following calculation of economic metrics, a basic design analysis is carried out to extract data on size and capacity of unit operations.

After preliminary review of different quantitative hazard indices available, a suitable index is chosen that accounts for intensity of operating conditions and characteristics of chemicals handled. Since ethylene is a derivative of hydrocarbons, a fire and explosion index based on Hazard Identification and Ranking System is chosen as the safety metric.(Khan \& Abbasi, 1998) The scope of the safety analysis is restricted to only the process technology (i.e. only process conditions and main stream process flow). Hence the physical location of units and external safety hazards are not considered for analysis. After applying safety metrics on all process units, the indices are ranked according to their level of potential damage or hazard. The economic metrics and safety metrics are compared for each process to identify the process that is inherently safe while being economically beneficial. 


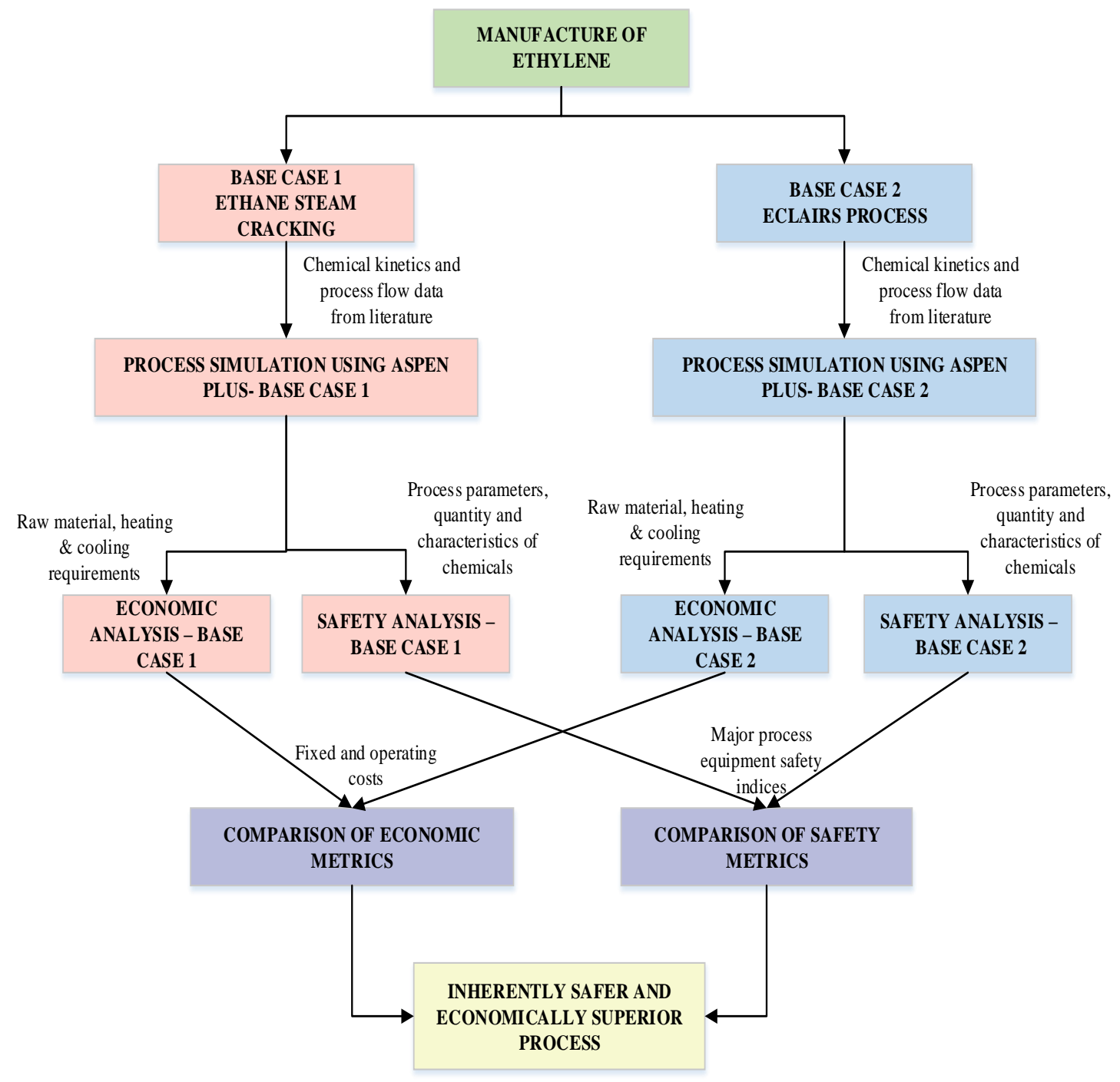

Figure 3: Approach methodology of techno-economic and safety analysis. 


\section{CHAPTER II}

\section{LITERATURE REVIEW}

Recent advancements made in extracting more natural gas from untapped shale gas reserves have opened the door for huge opportunities of shale gas monetization in the petrochemical market. Natural Gas Liquid (NGL) reserves have also increased significantly along with shale gas recoveries and this has led to exploration of opportunities that use NGLs such as ethane, propane and butane as raw materials.(Thomas K. Swift, Martha G. Moore, \& Sanchez, 2011) Studies show that ethane, one of the primary components recovered from NGL has a huge market for producing petrochemical intermediates rather than being burnt as a fuel. (Thomas K. Swift et al., 2011)These shale gas developments have led to a $25 \%$ increase of ethane supply. (Thomas K. Swift et al., 2011) This increase has created a major growth in petrochemical production capacities, investment in chemical industries, taxes, revenue and economic output.(True, 2013)

One of those petrochemical industry that is undergoing a great deal of expansion is the ethylene industry. Ethylene is a primary petrochemical compound that is used in the manufacture of polyethylene, ethylene dichloride, ethylene oxide, ethyl benzene, vinyl acetate and other miscellaneous chemicals. (Thomas K. Swift et al., 2011) The shale gas boom has led to announcement of 10 new projects to produce ethylene. Table 1 given below shows the major projects announced for expansion of ethylene. 
Table 1: Proposed additions of U.S. ethylene production capacity, 2013-2020. (True, 2013)

\begin{tabular}{|l|l|r|}
\hline Company & Location & $\begin{array}{l}\text { Proposed } \\
\text { capacity in } \\
\text { million metric } \\
\text { tons per year }\end{array}$ \\
\hline Chevron Phillips & Baytown, TX & 1.5 \\
\hline Exxon Mobil & Baytown, TX & 1.5 \\
\hline Sasol & Lake Charles, LA & 1.4 \\
\hline Dow & Freeport, TX & 1.4 \\
\hline Shell & Beaver Co, PA & 1.3 \\
\hline Formosa & Point Comfort, TX & 0.8 \\
\hline Occidental/Mexichem & Ingleside, TX & 0.5 \\
\hline Dow & St. Charles, LA & 0.4 \\
\hline LyondellBasell & Laporte, TX & 0.4 \\
\hline Aither Chemicals & Kanawha, WV & 0.3 \\
\hline Williams/Sabic JV & Geismar, LA & 0.2 \\
\hline Ineos & Alvin, TX & 0.2 \\
\hline Westlake & Lake Charles, LA & 0.2 \\
\hline Williams/Sabic JV & Geismer, LA & 0.1 \\
\hline Total & & $\mathbf{1 0 . 1}$ \\
\hline
\end{tabular}

The new projects encompass an additional capacity of 12.5 million tonnes/year, leading to $52 \%$ increase in current US ethylene capacity.(Chang, 2014) This has in turn led to increase in production capacities of important intermediates such as polyethylene, polyvinyl chloride and ethylene glycol. (Chang, 2014) The result of expansion is aimed at meeting the demand for ethylene, and the figure below explains the yearly trend of ethylene production, consumption and demand. From Figure 4 which represents ethylene supply and demand, it is clear that from the year 2013 the capacities of ethylene complexes will be high and the production will be sufficient to meet the demand. 


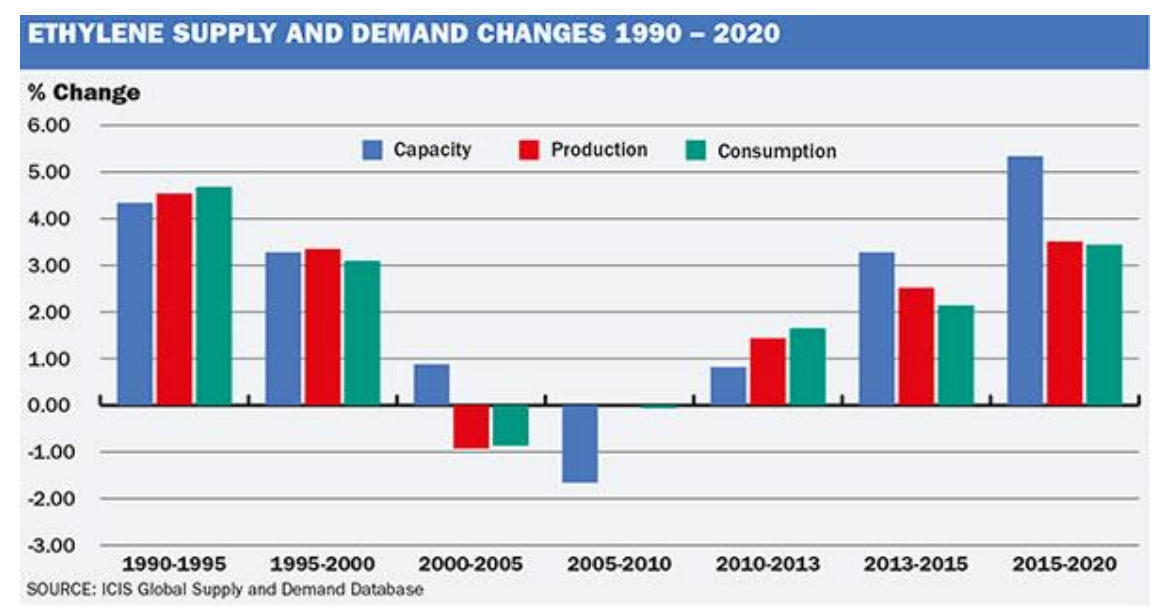

Figure 4: Ethylene supply and demand change. (ICIS, 2015)

Ethylene is primarily manufactured through steam cracking of naphtha or ethane, and this is the oldest and most established technology for producing ethylene. (Thomas K. Swift et al., 2011) Over $85 \%$ of ethylene is derived from ethane feedstock. (Thomas K. Swift et al., 2011) With more availability of ethane, steam cracking of ethane is gaining more importance. Moreover, the excess supply has made prices of ethane cheaper than naphtha and hence, a lot of projects are already underway to convert naphtha crackers to gas crackers.(True, 2013) Literature studies also reveal that specific consumption of ethane is much lower than that of naphtha.(Ren, Patel, \& Blok, 2006) Other advantages of using ethane feedstock are low $\mathrm{CO} 2$ emission, high ethylene and hydrogen yield and less heaviers.(Ren et al., 2006) The Figure 5 shown below illustrates the comparison of different feed stocks of cracker. Since ethane cracking is already a fully matured technology, it offers less of a chance for exploring modifications in the 
process for improving safety. Hence, this base case will serve as an excellent basis for comparison of other new technologies.

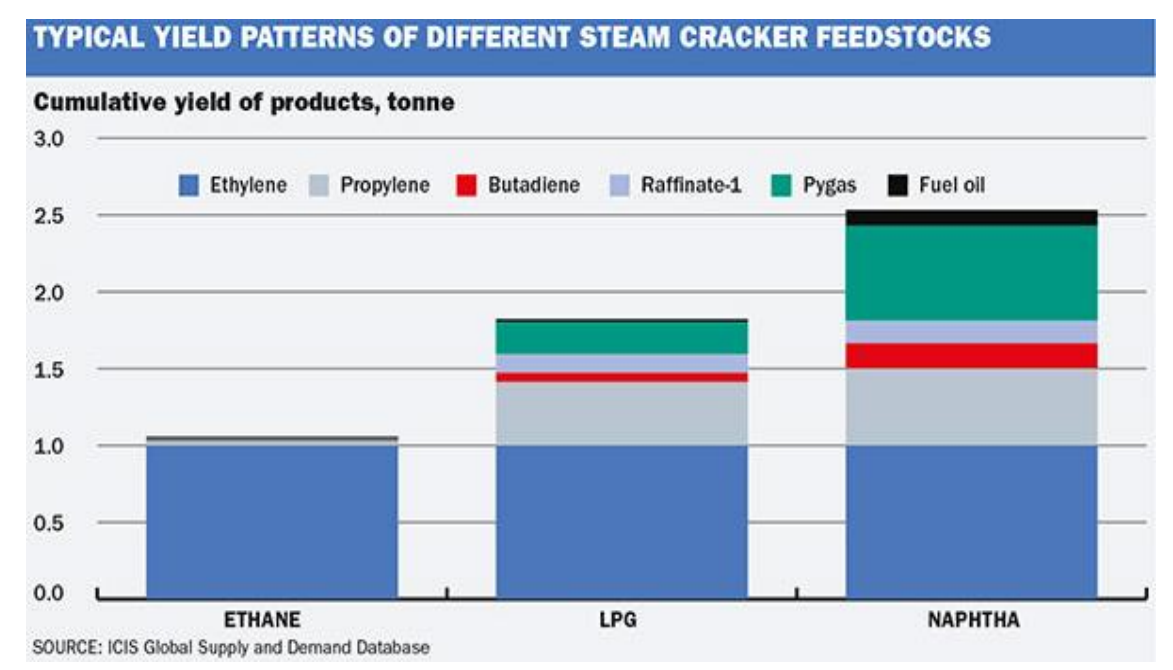

Figure 5: Yield patterns of different steam cracking feed stocks. (ICIS, 2015)

Another competing technology is a novice technology called "ECLAIRS," which involves usage of natural gas as the raw material.(Gattis, Peterson, \& Johnson, 2004) Natural gas also serves as an excellent raw material due to the abundant supply and cheap price. Pyrolysis of methane to acetylene, followed by selective hydrogenation to ethylene is the main chemistry.(Gattis et al., 2004) This new gas to ethylene technology is currently designed and operated by Synfuels International Inc. at a test scale level.(Gattis et al., 2004) Since it is a new technology, more opportunities exist to identify areas that lack safety and demonstrate the idea of inherent safety effectively. Hence, a safety techno-economic comparison of this process with the state of art ethane 
cracking technology will help in identifying dark areas and will deliver clear benefits of choosing one over the other.

\section{II.1. Safety Metrics}

Literature review shows a wide array of systematic quantitative tools adopted for measuring the risk and inherent safety of a process. Quantitative metrics are objective based and are more effective since they represent the magnitude of impact. Moreover, the scale of improvement achieved by modifying a process or operating variables is well interpreted by a quantitative measure such as a safety or a hazard index and this facilitates continual improvement. Thus, these indices can be useful in capturing the application of inherent safety design principles. Safety indices are simple to use in the early stage of design for hazard identification since they do not require detailed process information and are also cheaper than the more traditional approaches such as HAZOP, FTA (Fault Tree Analysis) and FMEA (Failure Mode and Effect Analysis).(Khan, Sadiq, \& Amyotte, 2003) They are easy to calculate and enable easy comparison between processes.(Khan et al., 2003) A list of most commonly used safety metrics is discussed below.

\section{II.1.1. Dow Fire and Explosion Index}

Dow fire and explosion index is the most commonly used index in chemical industries.(Khan et al., 2003) This index has been revised seven times with the latest published in 1994.(Khan et al., 2003) This index is primarily calculated after the basic 
engineering stage when all the design parameters, layout, spacing, controls and detection systems are added.(AichE, 1994) The information needed for evaluating fire and explosion index are plot plan, process flow diagram, replacement cost data of equipment and details of all layers of protection.(AichE, 1994). Initially, a parameter called Material Factor (MF) which measures the hazard potential in terms of flammable and reactive characteristics of the material is calculated.(AichE, 1994) This is followed by calculation of general and special process hazards. General process hazards (F1) account for penalties due to exothermic and endothermic reactions, material transfer, access, enclosed units and drainage and spill control of chemical.(AichE, 1994) Special process hazards (F2) include penalties for hazardous operating conditions, process parameters, quantity, corrosion and types of equipment used in operation.(AichE, 1994) The above mentioned process hazards are multiplied to get process unit hazards factor $(\mathrm{F} 3)$, which is again multiplied with material factor to get the fire \& explosion index.(AichE, 1994) Later, Loss Control Credit Factor (LCCF) is calculated by multiplying credits assigned on the basis of availability of process controls, material isolation techniques and fire protection added.(AichE, 1994) Finally, from the calculated Fire and Explosion Damage Index (FEDI), a radius of exposure, area exposed to the hazard and the replacement cost of all equipment in that area are calculated.(AichE, 1994)

Damage radius $=0.84 * \mathrm{FEDI}$

Additional factor called a damage factor, which represents the degree of loss exposure is calculated based on MF and F3. This damage factor multiplied with value of area exposed gives base Maximum Probable Property Damage (MPPD).(AichE, 1994) 
By applying loss credit factor to this value, the actual MPPD is determined.

Subsequently, maximum probable day's outage and the business interruption in terms of monetary value are calculated.(AichE, 1994) The penalties and credits are based on designated ranges of parameters calculated using expert-based knowledge. The advantage of using this index is that it accounts for all design details and correlates the damage incurred to monetary value. But, from the above calculation method, it is clear that Dow index is a very comprehensive and laborious process of hazard identification. It is also expensive due to the amount of data required and additionally, it requires technical expertise to decide on the penalty and credit values.

\section{II.1.2. Mond Index}

The Mond fire, explosion and toxicity index was developed by Mond division at ICI.(Khan et al., 2003) The approach and principles of calculation are similar to Dow index, except that Mond index includes additional hazards.(Khan et al., 2003) The major changes incorporated in Mond index are that it includes a wider range of storage and process facilities, processing of explosive chemicals, toxicity hazards index, deviating effects of good design, extended plant layout, indices to account for fire, aerial and internal explosion.(Lewis, 1979) The initial procedure of hazard assessment due to fire and explosion are the same as Dow index except for some additional factors included in the assessment. An additional toxicity index is included, which is based on toxic characteristics of the chemical, quantity in use and health implications.(Khan et al., 2003) Fire, explosion and toxicity indices calculated are analyzed and compared with the 
acceptable risk standards.(Lewis, 1979) Following this, reviews of the hazard factors namely the general and special process hazards are done to implement design changes that would reduce the risk levels.(Lewis, 1979) Finally, credits for implementation of preventive control features are accounted and final indices are recalculated.(Lewis, 1979) Thus, this index carries an additional advantage of accounting for special hazard considerations. However, it carries the same disadvantage as that of Dow index because this procedure is also time-consuming and comprehensive.

\section{II.1.3. Inherent Safety Index (ISI)}

Inherent safety index is used for measuring the inherent safety potential of a

process. ISI is a modified version of Prototype Index of Inherent Safety (PIIS).(Heikkilä, Hurme, \& Järveläinen, 1996) The PIIS introduced by Edward \& Lawrence was mainly reaction-oriented and failed to include other processes into consideration.(Edwards \& Lawrence, 1993) ISI accounts for all the process attributes combined with the chemical characteristics.(Heikkilä et al., 1996) This index is effective for making business decisions for choosing process alternatives producing the same product. The total inherent safety is represented by the below mentioned formula:(Heikkilä et al., 1996) $\mathrm{I}_{\mathrm{TI}}=\mathrm{I}_{\mathrm{CI}}+\mathrm{I}_{\mathrm{PI}}$

$\mathrm{I}_{\mathrm{CI}}$ (chemical inherent safety index) represents the value contributed by chemicals and chemical characteristics while $\mathrm{I}_{\mathrm{PI}}$ (Physical inherent safety index) represents process parameters and other physical factors.(Heikkilä et al., 1996) The addition of these subindices form the total inherent safety index $\left(\mathrm{I}_{\mathrm{TI}}\right)$ which depicts the basic hazard potential 
of the process.(Heikkilä et al., 1996) The chemical inherent safety index is addition of individual scores assigned to 7 categories, namely heat of reaction, heat of side reaction, flammability, toxicity, explosiveness, corrosiveness and chemical interactions.(Heikkilä et al., 1996) The process inherent safety is the addition of individual scores assigned to five categories namely inventory, pressure, temperature, equipment safety and safety of process structure.(Heikkilä et al., 1996) The approach uses different databanks for each sub-category to extract information about them.(Heikkilä et al., 1996) The scores are based on experienced based ranges of values for each sub-category. The scale of score varies such that the smaller score represents a highly safe process and vice versa.(Heikkilä et al., 1996) Hence, the process with higher $\mathrm{I}_{\mathrm{TI}}$ value indicates that it is more hazardous. The advantage of using this index is that due to the requirement of basic information on chemicals and process, it can be easily applied during the conceptual stage of design for choosing better alternatives. The disadvantage is that the index is subjective type and is based on a semi-quantitative scoring pattern which might yield different results for different users based on their experience.

\section{II.1.4. Safety Weighted Hazard Index (SWeHI)}

SWeHI is an advanced and modified version of its predecessor index, HIRA (Hazard Identification and Ranking). This index aims to capture the entire picture of a process by including all factors such as process, environment and society and how they impact safety.(Khan, Husain, \& Abbasi, 2001) Quantitatively, it represents the radius of area that is hazardous, caused due to operating and environmental conditions of a 
particular unit/ section.(Khan et al., 2001) The formula for calculating the SWeHI index is given as follows:(Khan et al., 2001)

$\mathrm{SWeHI}=\mathrm{B} / \mathrm{A}$

In the above formula, B represents the damage caused due to fire, explosion or toxic release of a particular unit under the assumption of a $50 \%$ probability of damage. 'A' represents the credits gained due to the safety measures and controls adopted for either preventing occurrence of an accident or reducing the frequency.(Khan et al., 2001) Thus, if the control measures are low, the value of index will be high suggesting that the unit or process is not safe. This type of analysis is best suited for identifying, comparing and ranking different units within a process, so that maximum focus can be given on the more hazardous equipment for safety improvement. The method of approach and calculation of B is identical to the calculation of the HIRA index except for addition of two penalties; one accounts for external factors such as earthquakes and floods while the other accounts for vulnerability of surroundings such as accident and societal clashes.(Khan et al., 2001) The calculation of A is done by considering two subgroups: one that measures the controls adopted and the other that reduces the frequency of occurrence. The general formula is given by:(Khan et al., 2001) $\mathrm{A}=0.15^{*} \sum(1+\mathrm{cr})$

In the above mentioned formula, credits are included to account for emergency response planning, disaster management planning, other control measures such as foam, water and fire extinguishing materials available, control systems, detecting systems, emergency control measures, human error and human reliability.(Khan et al., 2001) Each 
of these categories is further divided into sub categories that are additive and the final number is calculated by using the above mentioned formula. All the quantification methods used in the calculation of B are derived from thermodynamic, empirical models, National Fire Protection Agency (NFPA) rankings, American Petroleum Institute (API) standards, process safety design codes, storage area classification guidelines and Dow index.(Khan et al., 2001) The calculation of $\mathrm{A}$ is based on expert decisions, literature studies on controls, detection and human error.(Khan et al., 2001) Thus, this index has attempted to quantify factors predominantly based on objective type data. Hence, it is reliable and is very effective in specifically identifying areas where safety controls need to be added. However, the disadvantage of this index is that it can be applied only for a fully designed or an existing plant, thus failing to fetch opportunities of improving the actual process.

\section{II.1.5. Hazard Identification and Ranking System (HIRA)}

The Hazard Identification and Ranking System introduced by Khan and Abbasi in the year 1998 is a systematic and comprehensive methodology of hazard identification.(Khan \& Abbasi, 1998) This method aims to be more sensitive to process parameters and is accurate since the quantification is made using thermodynamic and fluid dynamics models. The index accounts for impact of hazards posed by a unit at elevated temperatures due to environmental factors and surroundings.(Khan \& Abbasi, 1998) Hence, it is accurate in describing the hazard potential of a unit. This index is unique from other indices such that it considers different classes of equipment according 
to the hazards specific to it, thus accounting for all kinds of hazards of each unit.(Khan \& Abbasi, 1998) The various units that are classified based on their special hazards are:(Khan \& Abbasi, 1998)

i. Storage units

ii. Physical units with operations such as pumping, mass and heat transfer and compression.

iii. Unit having chemical reactions

iv. Transportation units

v. Other hazardous units such as boilers, furnaces and fired heaters

The HIRA index is a combination of two other indices: Fire and Explosion Damage Index (FEDI) and Toxicity Damage Index (TDI).(Khan \& Abbasi, 1998) The estimation of FEDI is based on several penalties and energy factors. Finally, a damage potential is calculated from which the FEDI is estimated using the following formula:(Khan \& Abbasi, 1998)

FEDI $=4.76 *(\text { Damage potential })^{1 / 3}$

FEDI is the damage radii represented in meters. The semi-quantitative ranking is given by Table 2 .

Table 2: Semi-quantitative hazard ranking of FEDI. (Khan \& Abbasi, 1998)

\begin{tabular}{|l|l|}
\hline Fire and Explosion damage Index (FEDI) & \multicolumn{1}{c|}{ Hazard Characterization } \\
\hline FEDI $>500$ & Extremely hazardous \\
\hline $500>\mathrm{FEDI}>400$ & Highly hazardous \\
\hline $400>\mathrm{FEDI}>200$ & Hazardous \\
\hline $200>\mathrm{FEDI}>100$ & Moderately hazardous \\
\hline
\end{tabular}


Table 2: Continued.

\begin{tabular}{|l|l|}
\hline Fire and Explosion damage Index (FEDI) & \multicolumn{1}{|c|}{ Hazard Characterization } \\
\hline $100>$ FEDI $>20$ & Less hazardous \\
\hline else & No hazard \\
\hline
\end{tabular}

An illustrative diagram describing the various penalties and energy factors is given in Figure 6. The algorithm for calculating temperature and pressure penalties for different classes of units vary depending on the equipment class specific guidelines. Other penalties calculated include that for location of nearest hazardous units, capacity, characteristics of chemicals, density of units, physical state of chemical during transport, quantity of fuel used in furnaces, type of reaction and probability of side or runaway reactions.(Khan \& Abbasi, 1998) These penalties are included in the estimation of FEDI depending on their applicability to that particular class of equipment. All the values of penalties obtained are from thermodynamic, empirical models, API standards, NFPA rankings, Dow index and other quantitative relationships derived from literature studies.(Khan \& Abbasi, 1998) 


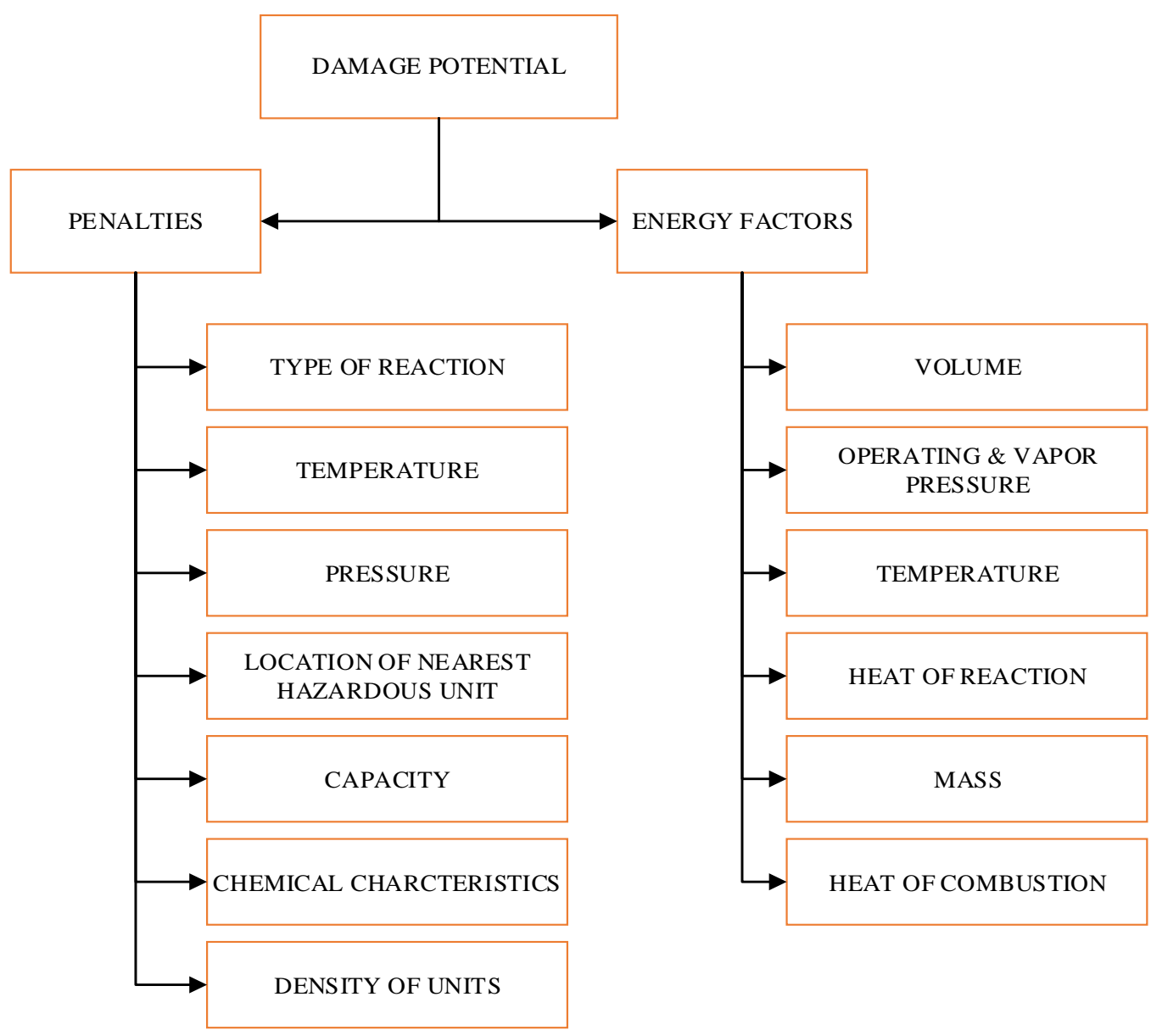

Figure 6: Factors affecting Damage potential.

The toxic damage index methodology is devised to calculate the measure of toxic load that is lethal over an area.(Khan \& Abbasi, 1998) It is derived using transport phenomena and empirical models depending on quantity, its toxicity, physical state of chemical, operating conditions and site characteristics.(Khan \& Abbasi, 1998) An assumption of slightly stable atmospheric condition is made for dispersion calculations. The calculation of TDI is done by considering a $\mathrm{G}$ factor and several other penalties.(Khan \& Abbasi, 1998) G factor considers situations such as release of 
superheated liquid that cause vapor flash and pool of liquid, release of gas leading to dispersion into atmosphere, liquefied gas having two-phase release and pyrophilic solids giving toxic vapors.(Khan \& Abbasi, 1998) The formula is given by:(Khan \& Abbasi, 1998)

$\mathrm{G}=\mathrm{A} * \mathrm{~m}$

In the above formula, $\mathrm{A}$ is a function of release conditions and $\mathrm{m}$ is the mass released in $\mathrm{kg} / \mathrm{s}$. The penalties calculated account for operating pressure, temperature, toxicity of chemical, vapor density and site characteristics.(Khan \& Abbasi, 1998) The formula for calculating TDI is given by:(Khan \& Abbasi, 1998)

$\mathrm{TDI}=25.35^{*}\left(\mathrm{G}^{*} \prod \text { penalties }\right)^{0.425}$

The advantage of using the HIRA methodology of hazard identification is that most of the penalties and energy factors calculated are directly from empirical relations and literature studies. This makes it a more reliable quantification and further enables easy interpretation of results. In addition to this, the concept of addressing unit specific hazards based on the different units involved in an industry facilitates accurate calculation of hazard potential. The semi-quantitative ranking enables us to focus on those areas that are extremely hazardous. The disadvantages of this index include the calculation procedure being comprehensive and requirement of detailed design with equipment layout and plot plan. Another drawback of this index is that it does not take into account any credit for control systems or preventive measures taken in the plant thus, giving an overestimated magnitude of impact.(Khan et al., 2001) 
Comprehensive tools such as Dow, Mond index are applied in industries extensively after the detailed engineering phase. However, the availability of indices that can accurately measure the amount of inherent safety during the conceptual stage of design are less in number. This is one of the reason why industries do not adopt inherent safety assessment at early stages. From literature review, it is concluded that in this thesis, the hazard identification and ranking system will be adopted for analyzing inherent safety on the ethylene base plants. This is because HIRA index is based on fundamental thermodynamic models which makes the quantification more objectivebased. Further, it is flexible in choosing what penalties can be included, depending upon the available amount of information. Since, it does not account for control systems and prevention systems, it is easy to identify the factor that directly impacts the inherent safety of the unit. Otherwise, the general tendency is to add more protection devices than identifying the root cause of the hazard.

Hence, this index is highly suitable for determination of actual inherent safety. In this thesis, penalties accounting for location of nearest hazardous unit and space occupied by the unit will be neglected. This proves to be a valid assumption, since the objective is to compare different units and rank them based on inherent safety. Also, since ethylene is primarily a hydrocarbon compound, only the fire and explosion index will be determined. The scope of this analysis is restricted only to the main process stream and hence other external hazards that impact the unit will not be considered. 


\section{II.2. Economic Metrics}

Economics of operation plays a crucial role in selecting alternative process routes. Cost of building a plant is influenced by several factors. Some of those factors include process efficiency, process yield, availability of cheap raw material, equipment cost, utility consumption, profit, environmental emissions and safety measures of plant. The main economic metrics that dictate the decision making process are fixed and operating cost. Fixed cost of equipment for two identical well-established technologies having literature data for capacities and capital cost are determined using the correlation:(El-Halwagi, 2012)

$\mathrm{FCI}_{\mathrm{B}}=\mathrm{FCI}_{\mathrm{A}} *(\text { Capacity of } \mathrm{B} / \text { Capacity of } \mathrm{A})^{0.6}$

In the above formula, FCI is the Fixed Capital Investment. Another method for calculating the fixed capital investment is based on the cost of delivered equipment. This method includes a factor that incorporates a collective term for cost of installation, piping \& instrumentation and other engineering installations.(El-Halwagi, 2012) This method known as Lang method is given by the following formula:(El-Halwagi, 2012) FCI $=$ FCI Lang factor $*$ Delivered equipment cost

The value of Lang factor depends on the type of material processed. Operating cost or Working Capital Investment (WCI) constitutes of cost of energy, catalysts, raw materials, labor and maintenance.(El-Halwagi, 2012) Utility cost includes cost of steam, power, fuel, cooling water and nitrogen.(El-Halwagi, 2012) Cost of utility depends on the complexity of process and studies show that safety is directly related to the cost of energy. Hence, a safer process tends to have less operating cost thus, leading to greater 
profits. The sum of FCI and WCI constitutes the total capital investment, which is cost of the entire project.(El-Halwagi, 2012)

Another important parameter that dictates the feasibility of a project is the economic gross potential. This is calculated to assess if the proposed project is feasible considering raw material costing and products costing.(El-Halwagi, 2012) Economic Gross Potential $(\mathrm{EGP})=\sum$ Annual production rate of products* cost of products - $\sum$ Annual consumption rate of raw material * cost of raw material.

If EGP is greater than one, then project is deemed economically feasible and further studies are carried out to find the actual net profit. If EGP is lesser than one, the project is economically not feasible and shall not be considered for further analysis.(ElHalwagi, 2012)

\section{II.3. Process Metrics}

Process technology of manufacturing a product dictates the cost of the project, environmental impact as well as the safety. The chemistry of the process and the separation processes involved to achieve product purity that satisfies customer's requirement is crucial in determining process route. Factors that affect the decision making process are product yield, conversion, specific consumption of the raw material, energy consumption involved in the process, degree of separation processes and process complexity. In this thesis, all of the above mentioned factors are determined to make effective comparison between different process routes by performing a process simulation using Aspen Plus. Aspen Plus is a steady state chemical process simulation 
software that entails a wide array of rigorous thermodynamic property package specific to each case study. The inputs to the simulation software were given from chemical kinetics and process flow data available from the literature. 


\section{CHAPTER III}

\section{PROCESS ANALYSIS}

In this chapter, a detailed description of the process technology, simulation techniques used, assumptions made and finally the results of steady state simulation are obtained. Only major equipment involved in the main process stream flow were considered for developing the process. ASPEN PLUS version 7.8.2 was used to carry out steady state simulation of the base case plants. A print screen picture of the aspen flow models are attached in the appendix. Peng Robinson was used as the base thermodynamic method for simulation of both the plants. All reactors were simulated using RSTOIC model while all distillation columns, absorption and quench towers were simulated using RADFRAC.

\section{III.1. Ethane Cracking Technology}

Steam cracking is the most widely used, established technology for producing ethylene.(Takaoka, 1967) Due to increase in shale gas reserves, ethane supply is found to have increased by $25 \%$ making it a suitable raw material for producing ethylene. (Thomas K. Swift et al., 2011) Over $85 \%$ of ethylene is manufactured from natural gas liquids obtained along with the shale gas. (Thomas K. Swift et al., 2011) Since ethane is not easily transportable, most of the time it is considered as stranded gas and therefore is burnt in flares or used as fuel. But now, ethylene industries are shifting from conventional liquid crackers processing naphtha to gas crackers that process ethane due 
to cheap raw material cost and higher product yield of ethane. Hence, this process analysis helps in understanding the underlying safety and economic benefits of using ethane as feedstock.

The process chemistry of thermal steam cracking of ethane can be explained by a complex set of reactions that are based on free radical mechanism.(Froment, Van de Steene, Van Damme, Narayanan, \& Goossens, 1976) There are number of literature studies done on the thermal cracking of ethane to analyze the product yield patterns and conversion of ethane along the length of reactor.(Froment et al., 1976) On subjecting ethane to high temperatures at low pressures, it undergoes dehydrogenation reaction to primarily form ethylene and hydrogen. Other primary products obtained are methane, acetylene, propylene, propane and butadiene. The products are obtained as result of complex combination of 42 free radical mechanisms.(Sundaram \& Froment, 1977) Out of these reactions, only 8 main reactions that adequately define the net effect of the chemistry have been considered for the case study.(Sundaram \& Froment, 1977) They are given as follows:
i. $\quad \mathrm{C}_{2} \mathrm{H}_{6} \leftarrow$
ii. $\quad 2 \mathrm{C}_{2} \mathrm{H}_{6}-----------\rightarrow \mathrm{C}_{3} \mathrm{H}_{8}+\mathrm{CH}_{4}$
iii. $\quad \mathrm{C}_{3} \mathrm{H}_{8}---------\rightarrow \mathrm{C}_{3} \mathrm{H}_{6}+\mathrm{H}_{2}$
iv. $\mathrm{C}_{3} \mathrm{H}_{8}----------\rightarrow \mathrm{C}_{2} \mathrm{H}_{4}+\mathrm{CH}_{4}$
v. $\mathrm{C}_{3} \mathrm{H}_{6} \leftarrow---------\rightarrow \mathrm{C}_{2} \mathrm{H}_{2}+\mathrm{CH}_{4}$
vi. $\mathrm{C}_{2} \mathrm{H}_{2}+\mathrm{C}_{2} \mathrm{H}_{4}-----------\rightarrow \mathrm{C}_{4} \mathrm{H}_{6}$
vii. $\quad 2 \mathrm{C}_{2} \mathrm{H}_{6}---------\rightarrow \mathrm{C}_{2} \mathrm{H}_{4}+2 \mathrm{CH}_{4}$ 
viii. $\mathrm{C}_{2} \mathrm{H}_{6}+\mathrm{C}_{2} \mathrm{H}_{4}-----------\rightarrow \mathrm{C}_{3} \mathrm{H}_{6}+\mathrm{CH}_{4}$

Table 3: Reactor yield data of ethane steam cracking.

\begin{tabular}{|l|l|}
\hline \multicolumn{1}{|c|}{ Components } & Reactor yield mass \% \\
\hline Hydrogen & 3.8 \\
\hline Methane & 2.6 \\
\hline Acetylene & 0.08 \\
\hline Ethane & 40 \\
\hline Ethylene & 52.4 \\
\hline Propylene & 1.1 \\
\hline Propane & 0.03 \\
\hline Butadiene & 1.04 \\
\hline
\end{tabular}

Table 4: Conversions assumed for ethane cracking reactions.

\begin{tabular}{|c|c|l|}
\hline $\begin{array}{c}\text { Reaction } \\
\text { Number }\end{array}$ & Conversion $\%$ & $\begin{array}{c}\text { Conversion of limiting } \\
\text { reactant }\end{array}$ \\
\hline i & 56 & Ethane \\
\hline ii & 1.4 & Ethane \\
\hline iii & 35 & Propane \\
\hline iv & 39.3 & Propane \\
\hline v & 65 & Propylene \\
\hline vi & 40 & Acetylene \\
\hline vii & 35.8 & Ethane \\
\hline viii & 2 & Ethane \\
\hline
\end{tabular}

The net effect of these reactions are endothermic hence, in order to increase yield of ethylene, external energy has to be supplied to maintain the temperature of the reactor. This is accomplished by indirect fired heater, where heat release from 
combustion of fuel is used to heat the reaction mixture that passes through tubes, fixed along the walls of furnace.(Takaoka, 1967) The main dehydrogenation reaction takes place in the temperature range of $750-850{ }^{0} \mathrm{C}$ at low pressures of about $1.5-3.5$ bar.(Takaoka, 1967) The residence time of the reaction mixture in the cracker coils are about 0.1-0.5 seconds.(Takaoka, 1967) Steam is injected along with ethane, since it reduces the partial pressure of hydrocarbons which in turn reduces the rate of decomposition of hydrocarbon products to coke at high temperatures.(Takaoka, 1967) Steam to hydrocarbon ratio of range $0.3-0.45$ is considered for the process.(Sundaram \& Froment, 1977) A $60 \%$ single- pass conversion of ethane is assumed, which is in accordance with the literature.(Froment et al., 1976) The cracker yields obtained are shown above in Table 3 and the values are matched with the literature data.(Froment et al., 1976) These values are used for simulating the cracker reactor using RSTOIC. The percentage conversions calculated from reaction kinetic data for the above eight reactions are also shown above in Table 4. Ethane cracker is considered as the heart of the ethylene process plant. Cracker has the maximum energy consumption since endothermicity of the reactions are very high.

The entire process is separated into three major sections: Pyrolysis, Compression and Cooling \& Separation. The pyrolysis section comprises of the cracker, where the ethylene product is formed by subjecting ethane feed to high temperature at low pressure. Cooled cracker products exiting the pyrolysis section are compressed in stages to desired pressure in order to effectively separate the ethylene from other compounds. In the compression section, acid gases are removed using caustic scrubbing and any 
residual moisture is also removed.(Takaoka, 1967) This is done before cooling section to avoid formation of solid $\mathrm{CO} 2$ or ice at cryogenic conditions since, they can block equipment and pipelines.(Takaoka, 1967) Following the compression section, the tail gas is cooled in a series of heat exchangers using refrigerants to effectively separate hydrogen from rest of the product gases, which passes to the separation section.(Takaoka, 1967) The separation scheme used in this analysis is Front-end DeMethanizer and Tail-end Acetylene Hydrogenation.(Takaoka, 1967) In this separation scheme, methane and residual hydrogen are removed initially, followed by which heaviers are removed. Acetylene present in residual stream is hydrogenated back to get ethylene following which ethylene is separated as product. The product purity of ethylene obtained is $99.9 \mathrm{wt} \%$.

The process begins with fresh and recycled ethane feed being preheated in the convection section of the cracker by the flue gas up to a temperature of about $775^{0} \mathrm{C}$. The reaction takes place at a low pressure of $1.5 \mathrm{bar}$ and temperature of about $775{ }^{\circ} \mathrm{C}$ in the radiation section of the cracker furnace. Low pressure steam is injected at a steam/ hydrocarbon ratio of 0.35 . The reaction products exit the cracker furnace at a temperature of $840{ }^{\circ} \mathrm{C}$ and 1 bar pressure. The reaction products have to be immediately quenched to stop the further formation of acetylene which is an undesired by-product. This is done by rapid cooling of the reaction products to $380{ }^{\circ} \mathrm{C}$ with cooling water in a series of transfer line heat exchangers.(Takaoka, 1967) Following the transfer line exchangers, the products are further quenched in quench towers to about $42{ }^{\circ} \mathrm{C}$, 
operating at 1 bar pressure. The cooling medium used in quench towers are cooling water.

The cooled gas is now compressed in three stages of compression. Each stage comprises of a compressor, a cooling water heat exchanger (to cool the compressed gases to $40{ }^{\circ} \mathrm{C}$ ) and a flash (to separate the gases from the condensed liquid). In the first compression stage, pressure is increased to $2.4 \mathrm{bar}$, followed by second stage where pressure is increased to about 6 bar. This is again followed by third stage of compression where the final pressure is around 15 bar. The cooled compressed gases from the third stage of compression is now passed into a caustic scrubber containing 27 trays, where 8 wt $\%$ sodium hydroxide is used a solvent to remove any acid gases such as carbon dioxide or sulfur present in the gas.(Hammond \& Ham, 2009) The sweet gas exiting the caustic scrubber is compressed again to about 36 bar in a $4^{\text {th }}$ stage of compression subsequently. The cooled product gas at $40{ }^{0} \mathrm{C}$ from the $4^{\text {th }}$ stage compressor is further cooled to about $15{ }^{\circ} \mathrm{C}$ using propylene refrigerant. The gas is sent to adsorption tower/dryer to remove any residual moisture in the gas stream, since the stream will be subjected to cryogenic conditions downstream.(Takaoka, 1967) After achieving a dew point of around $-73{ }^{\circ} \mathrm{C}$ in the gas stream, the tail end gas from dryer is directed to cooling train. The cooling train consists of 3 stages of cooling, where each stage comprises of three heat exchangers and one flash drum. The heat exchangers in each stage are integrated with two other streams in two exchangers. The remaining heat duty is removed by a propylene refrigerant in parallel exchangers. In the first stage of cooling, the gas is cooled to $-29^{\circ} \mathrm{C}$ and flashed in a flash drum. This is followed by second stage 
of cooling to $-74{ }^{0} \mathrm{C}$ and third stage where the exit gas from third stage flash drum is at around $-124{ }^{0} \mathrm{C}$. The 95 mol \% hydrogen gas stream exiting the third flash at $-124{ }^{0} \mathrm{C}$ is one of the stream that is pinched with three heat exchangers of each stage. After passing through the integrated exchangers, a part of it is regulated back to acetylene hydrogenation reactor while the rest is used as fuel utility.

All the liquids collected from the three flash drums of the cooling train are then regulated into de-methanizer column of 30 trays that operates at 30 bar pressure, top and bottom temperature of $-113{ }^{0} \mathrm{C}$ and $-4{ }^{0} \mathrm{C}$ respectively. The vapor distillate from the column containing 61 mole $\%$ methane is expanded and used for heat integration in the cooling train. After passing through series of exchangers in cooling train, the gas is used as utility fuel. The bottoms from de-methanizer column is regulated into de-ethanizer column of 45 trays operating at 26 bar, where all $\mathrm{C} 3+$ heaviers are removed from the bottom at temperature of $80{ }^{\circ} \mathrm{C}$. The top of column consisting of $\mathrm{C} 2$ and lighter compounds exits the column at $-11{ }^{0} \mathrm{C}$. This overhead stream is heated to around $35{ }^{0} \mathrm{C}$ and then sent into the acetylene hydrogenation reactor operating at 25 bar.

In the acetylene hydrogenation reactor, the residual acetylene remaining in the gas is reacted with hydrogen and converted back to ethylene using a suitable catalyst. The gas phase hydrogenation reaction is given by following reaction mechanism.(Bond \& Wells, 1966)

$$
\mathrm{C}_{2} \mathrm{H}_{2}+\mathrm{H}_{2} \leftarrow--\cdot------\rightarrow \mathrm{C}_{2} \mathrm{H}_{4}
$$

The net effect of the reaction is exothermic. The major undesired by-product formed in this reaction is ethane.(Bond \& Wells, 1966) Formation of ethane from 
ethylene will significantly reduce the process yield. Hence, by controlling the rate of hydrogen flowing into the reactor, ethane formation can be reduced. For this case study, acetylene conversion of $100 \%$ and $0 \%$ ethane formation are assumed. The reactor products now containing only $\mathrm{C} 2$ compounds exits at $75{ }^{\circ} \mathrm{C}$ and enters $\mathrm{C} 2$ splitter columns. C2 splitter columns contains 100 trays and operates at pressure of 19 bar with top temperature of $-31{ }^{0} \mathrm{C}$ and bottom temperature of $-9{ }^{0} \mathrm{C}$. Ethylene is separated from top with product purity of $99.99 \mathrm{wt} \%$ while ethane removed from bottom is recycled back as cracker feed. The reboiler duties of all column in the separation section are given by 6 bar saturated steam while the condenser duties are taken by propylene refrigerant at different temperatures. The block diagram of the ethane cracking process using front-end de-methanizer scheme is shown below in Figure 7. 


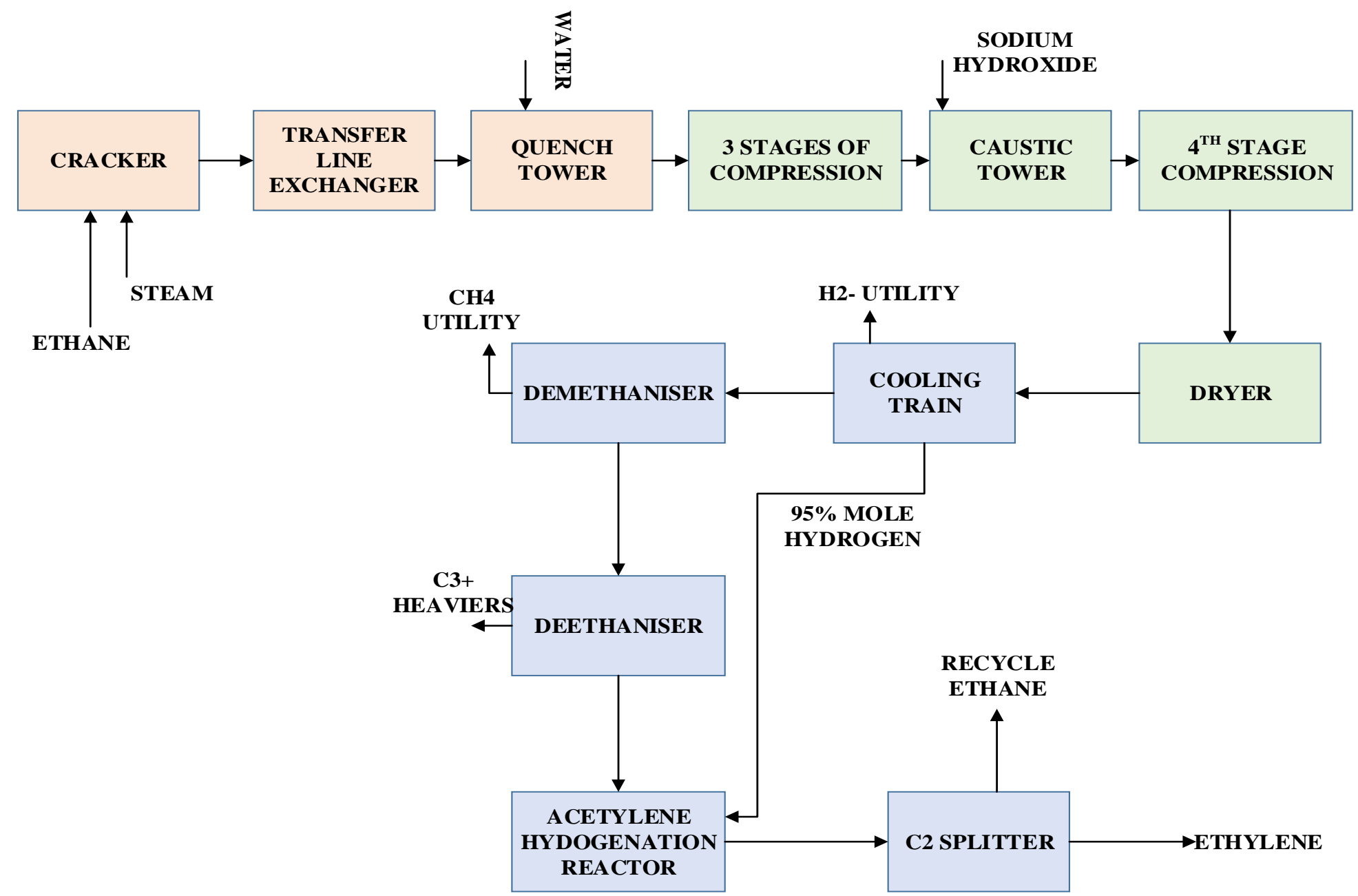

Figure 7: Block diagram of ethane steam cracking process using front end de-methanizer scheme. 


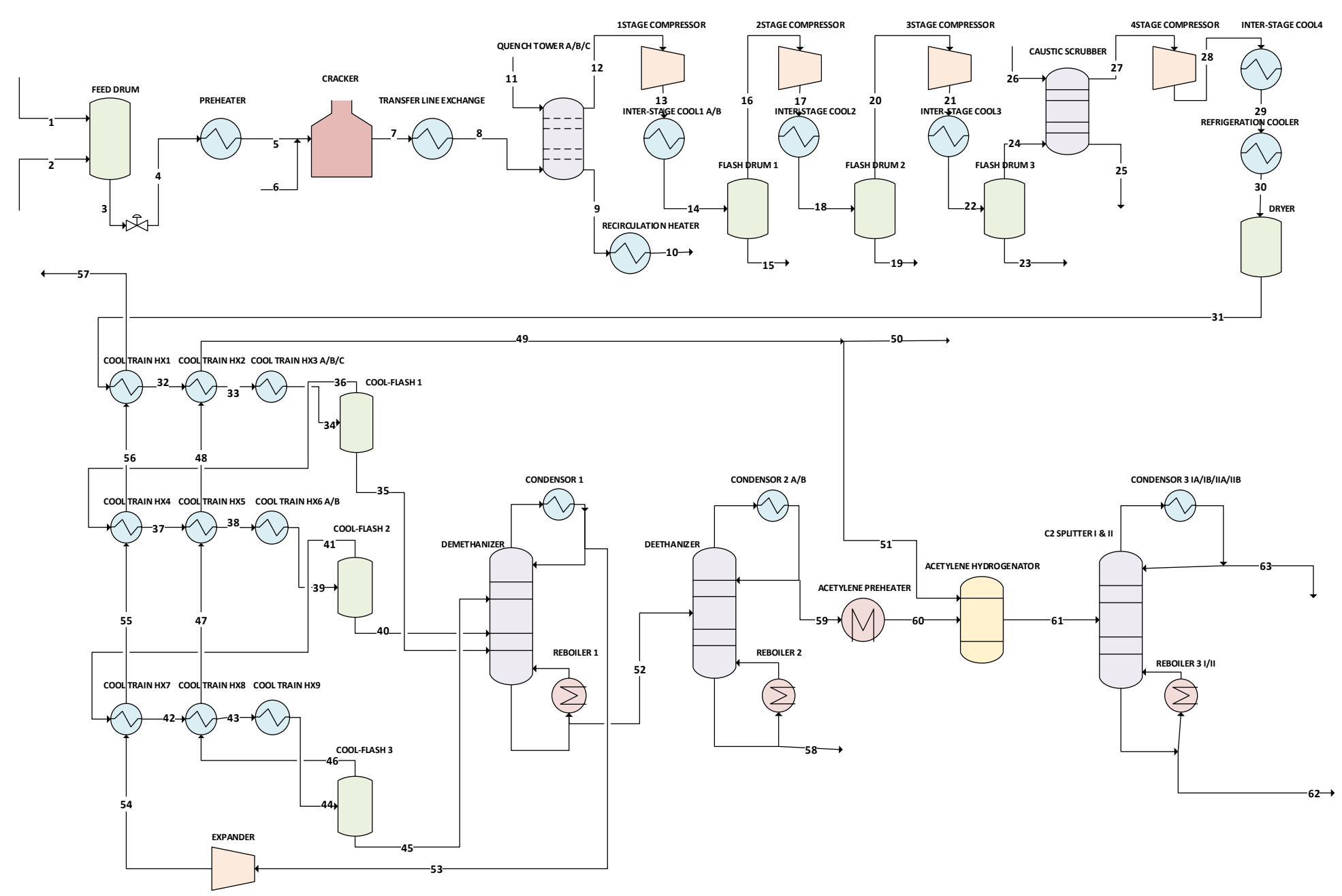

Figure 8: Process flow diagram of ethane steam cracking process. 
The process flow diagram of the ethane cracking process obtained after ASPEN simulation is given above in Figure 8. Along with process simulation data, design specifications were also given for each class of equipment. All equipment were simulated and optimized to account for balanced energy consumption, product purity, operation, design and safety considerations. Design of equipment was done using a top level analysis. For columns, compressors and heat exchangers, primary design data were fetched from ASPEN models. The assumptions made for design of certain class of equipment are listed below.

\section{III.1.1. Assumptions}

i. A pressure drop of 0.5 bar is assumed for all heat exchangers.

ii. The convection and radiation section of the furnace are shown in separate blocks: preheater for convection and RSTOIC models for reactor.

iii. Ethane fresh feed is assumed to contain only $0.1 \mathrm{wt} \%$ of carbon dioxide as impurity and is available at $25{ }^{\circ} \mathrm{C}$ and 19 bar pressure.

iv. The off-gas generated in the process is considered in the form of equivalent amount of natural gas required for heating and is balanced in the final energy of fuel required.

v. Caustic scrubbing was modeled as a RSTOIC reactor where $100 \%$ conversion of carbon dioxide is assumed. Design of caustic scrubber was done based on 27 trays separately in RADFRAC. 
vi. All heat exchangers are assumed to be shell and tube type. Heat transfer areas were calculated from ASPEN PLUS. A minimum temperature approach of $5{ }^{0} \mathrm{C}$ is assumed for refrigeration operations and $7{ }^{0} \mathrm{C}$ for other exchangers. Heat exchanger volume was determined by assuming a surface area density of 100.(Shah \& Sekulić, 2003) The formula for calculating volume is given by: (Shah \& Sekulić, 2003) Volume $=$ Heat transfer area / surface area density

vii. The rule of thumb for maximum heat transfer area is $1000 \mathrm{~m}^{2}$.(Branan, 2012) Any heat exchanger exceeding this value was split accordingly into parallel heat exchangers.

viii. Similarly the maximum allowable column diameter was assumed to be 6 . Any column exceeding this value was split accordingly into parallel columns.

ix. Volume of reactors are found using literature value for residence time. Liquid residence time for half full flash vessels is assumed to be $5 \mathrm{~min}$ according rule of thumb.(Coker, 2007) Approximate volume of column is calculated using the formula:

Volume $=\pi *(\text { Column diameter })^{2} *$ Height of column $/ 4$

Height of column $=$ No of trays $*$ tray spacing +10 feet

Default tray spacing of $0.6096 \mathrm{~m}$ was assumed for columns.(Chuang \& Nandakumar, 2000) 
x. All products recovered from distillation are based on minimum $99 \%$ mass recovery.

xi. Compression ratio of compressors was assumed in such a way so as to not exceed compressor outlet temperature greater than $150{ }^{\circ} \mathrm{C}$, to avoid formation of polymers that plug equipment.(Takaoka, 1967)

xii. Alumina is assumed to be used for adsorption of moisture and a residence time of $5 \mathrm{sec}$ is assumed for dryer. (Olivier Ducreux \& Nedez, 2011)

xiii. Heating duties are provided by steam except for preheater and cracker reactor; Cooling duties are provided by cooling water except for cooling $\&$ separation section; Propylene refrigerant is used for cooling purposes in cooling and separation section. Natural gas is assumed to be fuel used in furnace. The operating conditions of the utilities are given below in Table 5. The operating efficiencies of utilities are given in Table 6.

xiv. Caustic scrubbing is exothermic reactive absorption, but since the solvent is only $8 \mathrm{wt} \%$ of caustic soda, there will be no significant temperature rise, considering only $0.1 \mathrm{wt} \%$ of $\mathrm{CO} 2$ in the feed.(Hammond \& Ham, 2009) Similarly acetylene hydrogenation, which is also exothermic is assumed to be adiabatic, hence the outlet temperature of reactor is high.(Bond \& Wells, 1966)

$\mathrm{xv}$. A list of energy consuming equipment in each section and their consumption rates are given below in Table 7. 
Table 5: List of utilities and utility operating conditions.

\begin{tabular}{|c|l|c|c|}
\hline S. No & \multicolumn{1}{|c|}{ Utility } & Temperature & Pressure \\
\hline & & Deg C & bar \\
\hline 1 & Steam & 158 & 6 \\
\hline 2 & Natural Gas & 25 & 2 \\
\hline 3 & Propylene refrigerant & -45 & - \\
\hline 4 & Propylene refrigerant & -101 & - \\
\hline 5 & Propylene refrigerant & -156 & - \\
\hline 6 & Cooling water & 30 & - \\
\hline 7 & Chilled water & 15 & - \\
\hline
\end{tabular}

Table 6: Process efficiency values of utilities.

\begin{tabular}{|l|c|}
\hline \multicolumn{2}{|c|}{ Process Efficiency Assumptions } \\
\hline Natural Gas - Thermal efficiency & $\mathbf{6 0 \%}$ \\
\hline Cooling water- Cooling efficiency & $\mathbf{1 0 0 \%}$ \\
\hline Compressor- shaft efficiency & $\mathbf{4 5 \%}$ \\
\hline Total compressor efficiency - shaft power from natural gas & $\mathbf{2 7 \%}$ \\
\hline Refrigeration efficiency & $\mathbf{1 0 0 \%}$ \\
\hline Steam- Heating efficiency- Produced from natural gas & $\mathbf{6 0 \%}$ \\
\hline
\end{tabular}

Table 7: List of energy consuming equipment and their consumption rates- ethane cracking process.

\begin{tabular}{|c|c|c|c|c|}
\hline $\begin{array}{l}\text { S. } \\
\text { NO }\end{array}$ & SECTION & Units named in PFD & $\begin{array}{l}\text { Type of utility } \\
\text { used }\end{array}$ & $\begin{array}{c}\text { Actual } \\
\text { energy } \\
\text { require } \\
\text { ments }\end{array}$ \\
\hline & & & & $\begin{array}{c}\text { MMBt } \\
\text { u/hr }\end{array}$ \\
\hline 1 & \multirow{3}{*}{$\begin{array}{c}\text { PYROLY } \\
\text { SIS }\end{array}$} & PREHEATER & Natural gas & 699 \\
\hline 2 & & CRACKER & Natural gas & 697 \\
\hline 3 & & TRANSFER LINE EXCHANGE & cooling water & 388 \\
\hline 4 & & RECIRCULATION HEATER & cooling water & 272 \\
\hline 5 & & INTERSTAGE COOL1-A & cooling water & 32 \\
\hline
\end{tabular}


Table 7: Continued.

\begin{tabular}{|c|c|c|c|c|}
\hline $\begin{array}{l}\text { S. } \\
\text { NO }\end{array}$ & SECTION & Units named in PFD & $\begin{array}{c}\text { Type of utility } \\
\text { used }\end{array}$ & $\begin{array}{c}\text { Actual } \\
\text { energy } \\
\text { require } \\
\text { ments }\end{array}$ \\
\hline & & & & $\begin{array}{c}\text { MMBt } \\
\text { u/hr }\end{array}$ \\
\hline 6 & \multirow{8}{*}{$\begin{array}{l}\text { COMPRES } \\
\text { SION } \\
\text { SECTION }\end{array}$} & INTERSTAGE COOL1-B & cooling water & 32 \\
\hline 7 & & INTERSTAGE COOL2 & cooling water & 40 \\
\hline 8 & & INTERSTAGE COOL3 & cooling water & 35 \\
\hline 9 & & INTERSTAGE COOL4 & cooling water & 36 \\
\hline 10 & & 1ST STAGE COMPRESSOR & Power & 131 \\
\hline 11 & & 2ND STAGE COMPRESSOR & Power & 126 \\
\hline 12 & & 3RD STAGE COMPRESSOR & Power & 124 \\
\hline 13 & & 4TH STAGE COMPRESSOR & Power & 117 \\
\hline 14 & \multirow{19}{*}{$\begin{array}{c}\text { SEPARATI } \\
\text { ON } \\
\text { SECTION }\end{array}$} & REFRIGERATION COOLER & Chilled water & 14 \\
\hline 15 & & COOL TRAIN HX3-A & refrigerant & 10 \\
\hline 16 & & COOL TRAIN HX3-B & refrigerant & 10 \\
\hline 17 & & COOL TRAIN HX3-C & refrigerant & 10 \\
\hline 18 & & COOL TRAIN HX6-A & refrigerant & 24 \\
\hline 19 & & COOL TRAIN HX6-A & refrigerant & 24 \\
\hline 20 & & COOL TRAIN HX9 & refrigerant & 8 \\
\hline 21 & & CONDENSOR 1 & refrigerant & 5 \\
\hline 22 & & REBOILER 1 & Steam & 57 \\
\hline 23 & & CONDENSOR 2-A & refrigerant & 41 \\
\hline 24 & & CONDENSOR 2-B & refrigerant & 41 \\
\hline 25 & & REBOILER 2 & Steam & 133 \\
\hline 26 & & ACETYLENE PREHEATER & Steam & 102 \\
\hline 27 & & CONDENSOR 3-I-A & refrigerant & 45 \\
\hline 28 & & CONDENSOR 3-I-B & refrigerant & 45 \\
\hline 29 & & CONDENSOR 3-II-A & refrigerant & 45 \\
\hline 30 & & CONDENSOR 3-II-B & refrigerant & 45 \\
\hline 31 & & REBOILER 3-I & Steam & 83 \\
\hline 32 & & REBOILER 3-II & Steam & 83 \\
\hline & & & Total & 3551 \\
\hline
\end{tabular}




\section{III.1.2. Simulation Results}

The results of the process analysis using ASPEN PLUS were found to be in agreement with the literature. The process metrics are summarized below in Table 8 . From results, we can see the energy consumption of individual equipment in each section. Depending on this data, it can be concluded that the highest energy consumer is furnace (preheater + cracker), followed by compressors in the second place and then Transfer line exchange. Figure 9 illustrates the contribution of each section to specific energy consumption. The section that has largest specific energy consumption is pyrolysis followed by compression section and then separation. These results are then analyzed with its safety and economics to find areas of concern. But from these results, it is apparent that equipment such as furnace, compressors and transfer line exchanger need more process improvement in terms of energy. At this stage opportunities for heat integration or another less intensive process can be explored. Heat integration enables reduction in energy consumption as well reduces the number of equipment required thus indirectly enhancing safety. Off gas generated from the process is accounted in the cost analysis. The energy reduction achieved by utilizing off gas as utility fuel is considered to be $100 \%$. The major energy contributors along with consumption rates are illustrated in Figure 10.

Table 8: Simulation results- ethane cracking process.

\begin{tabular}{|l|c|c|}
\hline \multicolumn{1}{|c|}{ Parameter } & Value & UOM \\
\hline Annual Production rate of ethylene & 830,132 & Tonnes/yr \\
\hline Product purity & 99.90 & wt $\%$ \\
\hline Annual Ethane Feed rate & 978,492 & Tonnes/yr \\
\hline
\end{tabular}


Table 8: Continued.

\begin{tabular}{|l|c|c|}
\hline \multicolumn{1}{|c|}{ Parameter } & Value & UOM \\
\hline Process yield of ethylene & 85 & $\%$ \\
\hline Cracker single-pass conversion & 60 & wt \% \\
\hline Cracker yield of ethylene & 51 & MMBtu/hr \\
\hline Minimum energy requirements & 2,446 & MMBtu/tonne of ethylene \\
\hline $\begin{array}{l}\text { Minimum Specific Energy } \\
\text { Consumption }\end{array}$ & 26 & $\begin{array}{c}\text { Tonne of ethylene/ tonne } \\
\text { of ethane }\end{array}$ \\
\hline Specific consumption of raw material & 1.2 & \\
\hline
\end{tabular}

\section{Specific Energy Consumption}

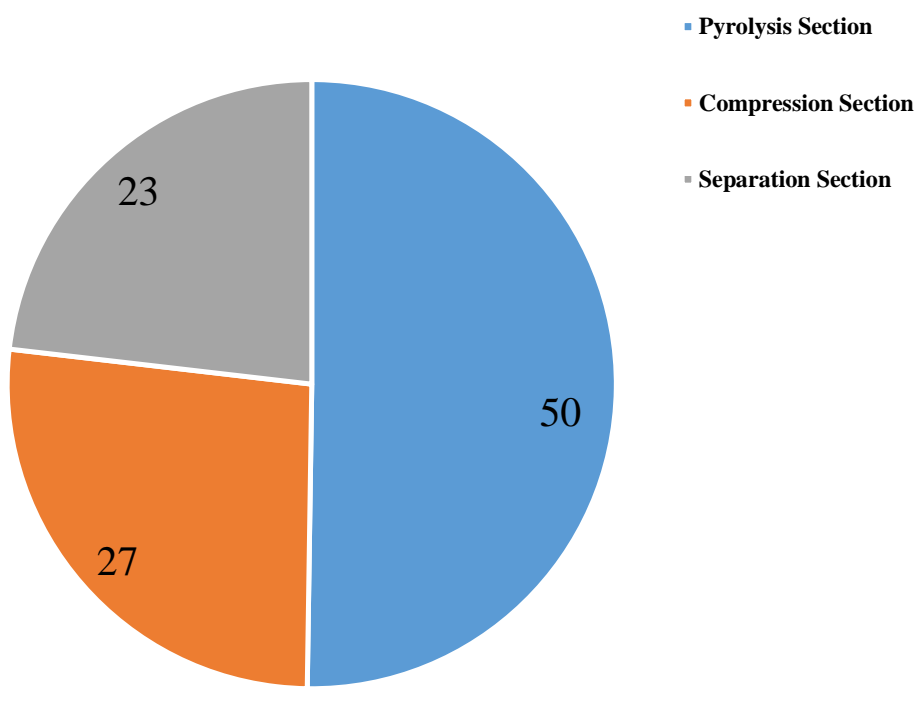

Figure 9: Specific energy consumption of major sections- ethane cracking process. 


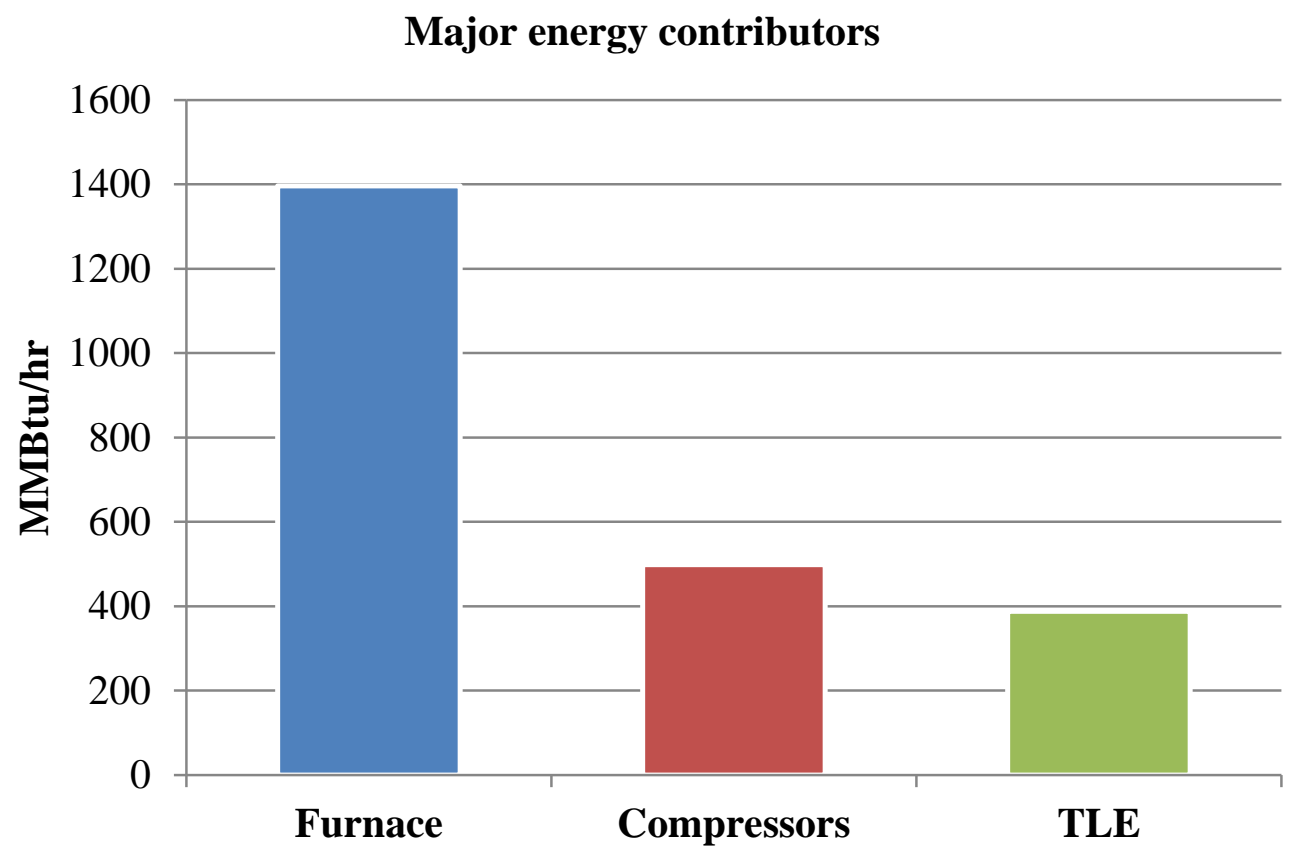

Figure 10: Major energy contributors- ethane cracking process.

\section{III.2. Pyrolysis of Methane}

Natural gas is a clean source of energy and is available in abundance. The increase in reserves and low cost of natural gas have paved way for exploration of new methods of converting methane to valuable chemicals rather than using it as fuel.(Cantrell, Bullin, McIntyre, Butts, \& Cheatham, 2013) Also, transportation of natural gas by liquefaction is expensive and tougher. Hence, opportunities that directly convert gas to petrochemicals are gaining more focus. One such new technology of that kind is the Gas to Ethylene Technology or ECLAIRS (Ethylene from concentrated liquid phase acetylene- Integrated rapid and safe).(Hall, 2005) This new technology utilizes natural gas to convert it into acetylene, a stable petrochemical intermediate and 
converting the same into ethylene through liquid phase hydrogenation.(Hall, 2005) The technology is still not commercialized and it is in pilot plant scale. This process claims to be economical for low gas feed rates as low as $30 \mathrm{kSCMD}$ up to any further larger scale when compared to traditional GTL processes (Fischer Tropsch), that require larger gas feed rates of the order of 300 MMSCFD to be economical.(Hall, 2005) Application of safety and economic evaluation techniques on such a novel process can render useful in justifying the replacement of one technology over the other. The intermediate acetylene is produced primarily by subjecting methane to high temperatures at low pressures. The process called as pyrolysis of methane is a widely used technology adopted in the manufacture of acetylene and syngas.(Holmen, Olsvik, \& Rokstad, 1995) Since the methane pyrolysis reaction is highly endothermic, and in order to maintain high reaction temperature heat is supplied to cracker in many different ways such as partial oxidation of methane, indirect heating in furnace, electric arc furnace and Wullf pyrolysis process.(Holmen et al., 1995) For our case study, partial oxidation of methane to acetylene is considered. Partial oxidation method was chosen since it is a practically feasible, well established process and detailed literature data on chemical kinetics are available.

The process chemistry of natural gas pyrolysis is explained by the below mentioned reactions. At high temperatures in the range of $2500 \mathrm{~K}$ and low pressures of about 1 bar, methane undergoes dehydrogenation consequently to form acetylene, a much stable compound than ethylene at those temperature.(Holmen et al., 1995) The residence time required for the reaction is as low as 0.01 seconds since, decomposition 
of acetylene to carbon has to be stopped. Hence, the hot product gases are immediately quenched using cooling water or quench oil.(Holmen, 2009) Partial oxidation of methane employs a direct medium of heat transfer by burning part of natural gas feed with oxygen to produce enough heat to crack the rest of the feed.(Holmen et al., 1995) A methane to oxygen ratio of 1.65 moles is usually selected, by which approximately $60 \%$ of methane is burned to produce combustion products while $30 \%$ is converted to acetylene. (Wolf, 1992)

$$
\begin{array}{ll}
\text { i. } & 2 \mathrm{CH}_{4} \leftarrow--------\rightarrow \mathrm{C}_{2} \mathrm{H}_{4}+2 \mathrm{H}_{2} \\
\text { ii. } & 2 \mathrm{CH}_{4} \leftarrow--------\rightarrow \mathrm{C}_{2} \mathrm{H}_{2}+3 \mathrm{H}_{2} \\
\text { iii. } & \mathrm{CH}_{4}+\mathrm{O}_{2}--------\rightarrow \mathrm{CO}+\mathrm{H}_{2}+\mathrm{H}_{2} \mathrm{O} \text { (incomplete combustion) } \\
\text { iv. } & \mathrm{CO}+\mathrm{H}_{2} \mathrm{O} \leftarrow------\rightarrow \mathrm{CO}_{2}+\mathrm{H}_{2} \\
\text { v. } & \mathrm{C}_{2} \mathrm{H}_{2}+\mathrm{CH}_{4} \leftarrow-----\rightarrow \mathrm{C}_{3} \mathrm{H}_{4}+\mathrm{H}_{2} \\
\text { vi. } & \mathrm{CH}_{4}+2 \mathrm{O}_{2}-------\rightarrow \mathrm{CO}_{2}+2 \mathrm{H}_{2} \mathrm{O}
\end{array}
$$

The main products formed in the partial oxidation method are hydrogen, acetylene, carbon dioxide, carbon monoxide, ethylene, methane and heaviers.(Pässler et al., 2012) The products formed are immediately quenched in order of 0.02 milliseconds to prevent formation of carbon.(Ries, 1966) The reactor yield and feed conversion values were assumed based on the values given in literatures. (Pässler et al., 2012) The cracker was simulated using RSTOIC by taking conversion values from chemical reaction kinetic data and literature studies. The dry gas composition of pyrolysis reactor outlet is given in Table 9. The conversion values assumed for the above mentioned reactions are listed in Table 10. 
Table 9: Reactor yield mole composition- methane pyrolysis.

\begin{tabular}{|l|l|}
\hline \multicolumn{1}{|c|}{ Components } & Reactor yield mol \% \\
\hline Hydrogen & 54.7 \\
\hline Methane & 4.9 \\
\hline Acetylene & 8.4 \\
\hline Carbon dioxide & 4.8 \\
\hline Ethylene & 0.4 \\
\hline $\begin{array}{l}\text { Carbon } \\
\text { monoxide }\end{array}$ & 26.4 \\
\hline Propadiene & 0.4 \\
\hline
\end{tabular}

Table 10: Conversions of methane pyrolysis reaction using partial oxidation method.

\begin{tabular}{|c|l|l|}
\hline $\begin{array}{c}\text { Reaction } \\
\text { Number }\end{array}$ & Conversion \% & $\begin{array}{c}\text { Conversion of limiting } \\
\text { reactant }\end{array}$ \\
\hline i & 1.3 & Methane \\
\hline ii & 32 & Methane \\
\hline iii & 56 & Methane \\
\hline iv & 1.8 & Carbon monoxide \\
\hline v & 4 & Acetylene \\
\hline vi. & 9 & Methane \\
\hline
\end{tabular}

The entire process is divided into 4 main sections namely; pyrolysis, compression, solvent separation and product separation. In the pyrolysis section, preheated natural gas and oxygen undergoes partial oxidation at high temperature in the cracker to form acetylene and combustion products, which are immediately quenched using quench water. The quenched gas is further cooled and consequently compressed in stages to pressures of about 12 bar. Carbon dioxide present in the cooled gas is removed 
in an amine sweetening unit between two compressor stages. The sweet gas exiting the compression section is sent into an absorption column where $\mathrm{N}$ methyl 2- Pyrrolidine is used as solvent for absorbing acetylene.(Tabe-Mohammadi, Villaluenga, Kim, Chan, \& Rauw, 2001) The solvent laden acetylene enters into hydrogenation reactor where acetylene is converted to ethylene. The tail gas from NMP absorption tower is partially regulated into a pressure swing adsorption to extract pure hydrogen for using in hydrogenation reactor.(Peramanu, Cox, \& Pruden, 1999) The rest of tail gas is used as utility fuel. The solvent containing ethylene is now regulated into a series of flash network for separating solvent from hydrocarbon product mixture and solvent is recycled back into absorption tower.(Abedi, 2007) The remaining hydrocarbon gas is compressed again in two stages and sent to two distillation columns, where lighters and heavier are separated and ethylene product is obtained with $99.99 \mathrm{wt} \%$ purity.

The block diagram of methane pyrolysis of natural gas using partial oxidation method is shown in Figure 11. The process flow diagram obtained from Aspen simulation is illustrated below in Figure 12. 


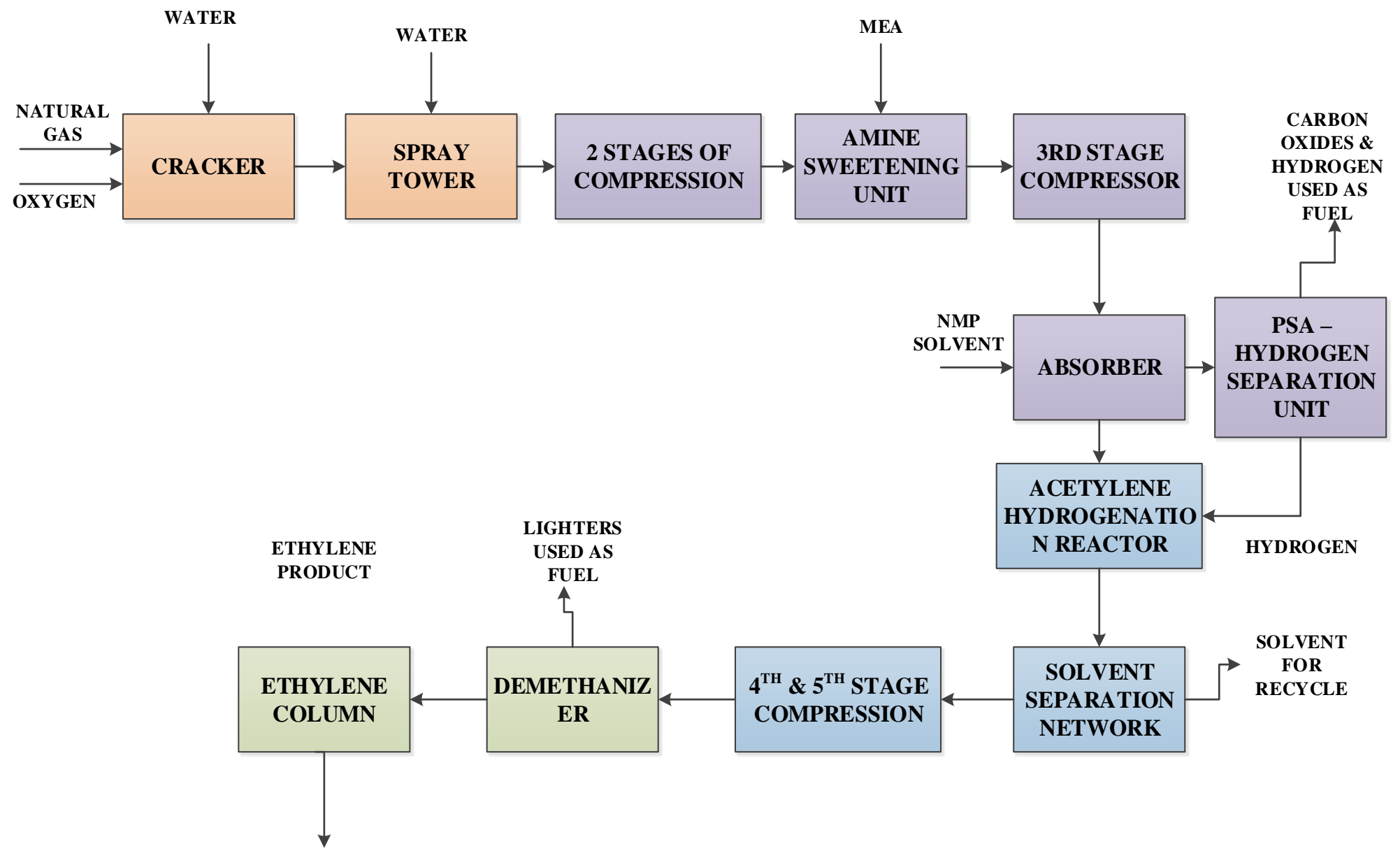

Figure 11: Block diagram of methane pyrolysis using partial oxidation method of heat transfer. 


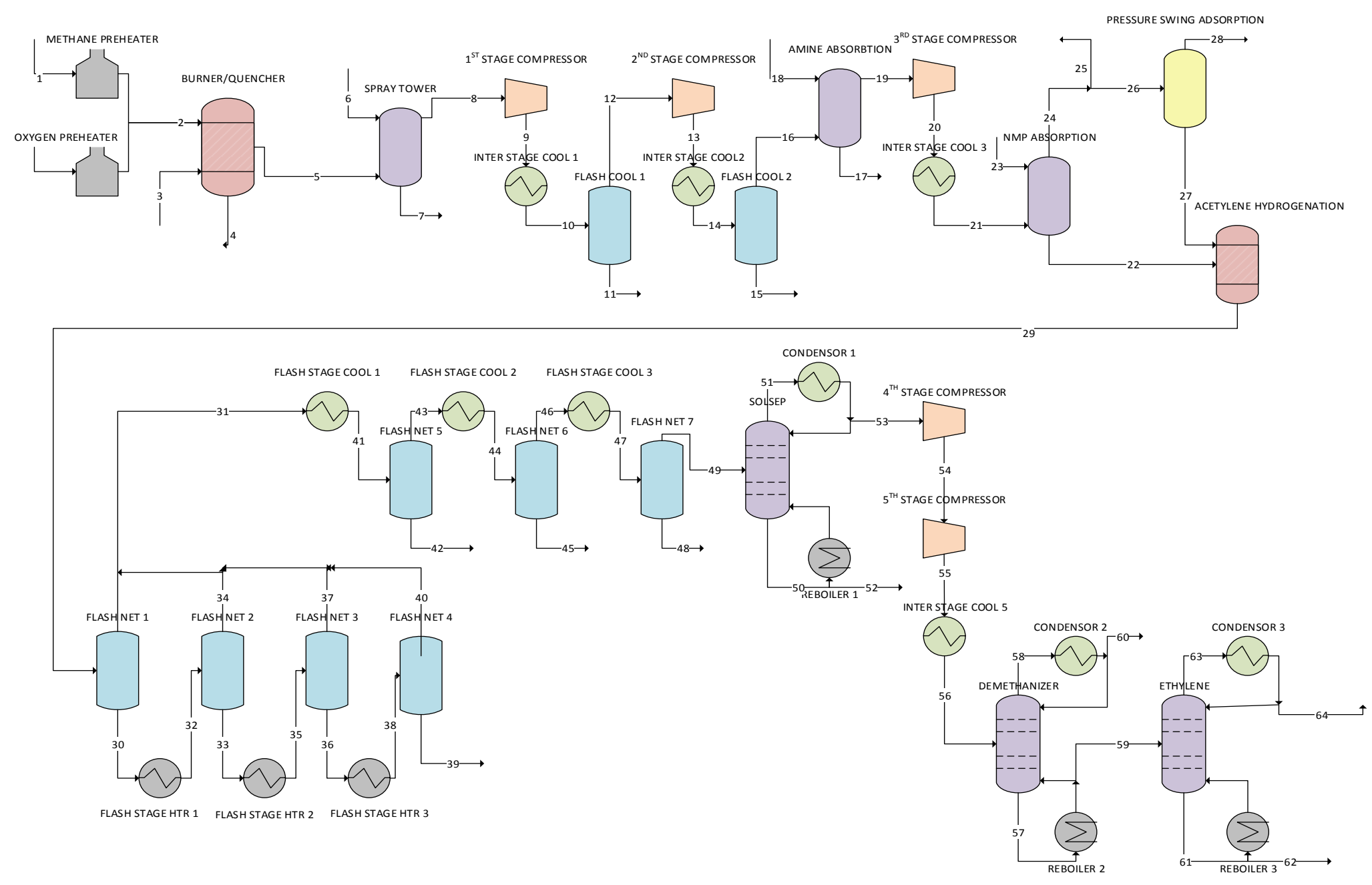

Figure 12: Process flow diagram of methane pyrolysis process. 


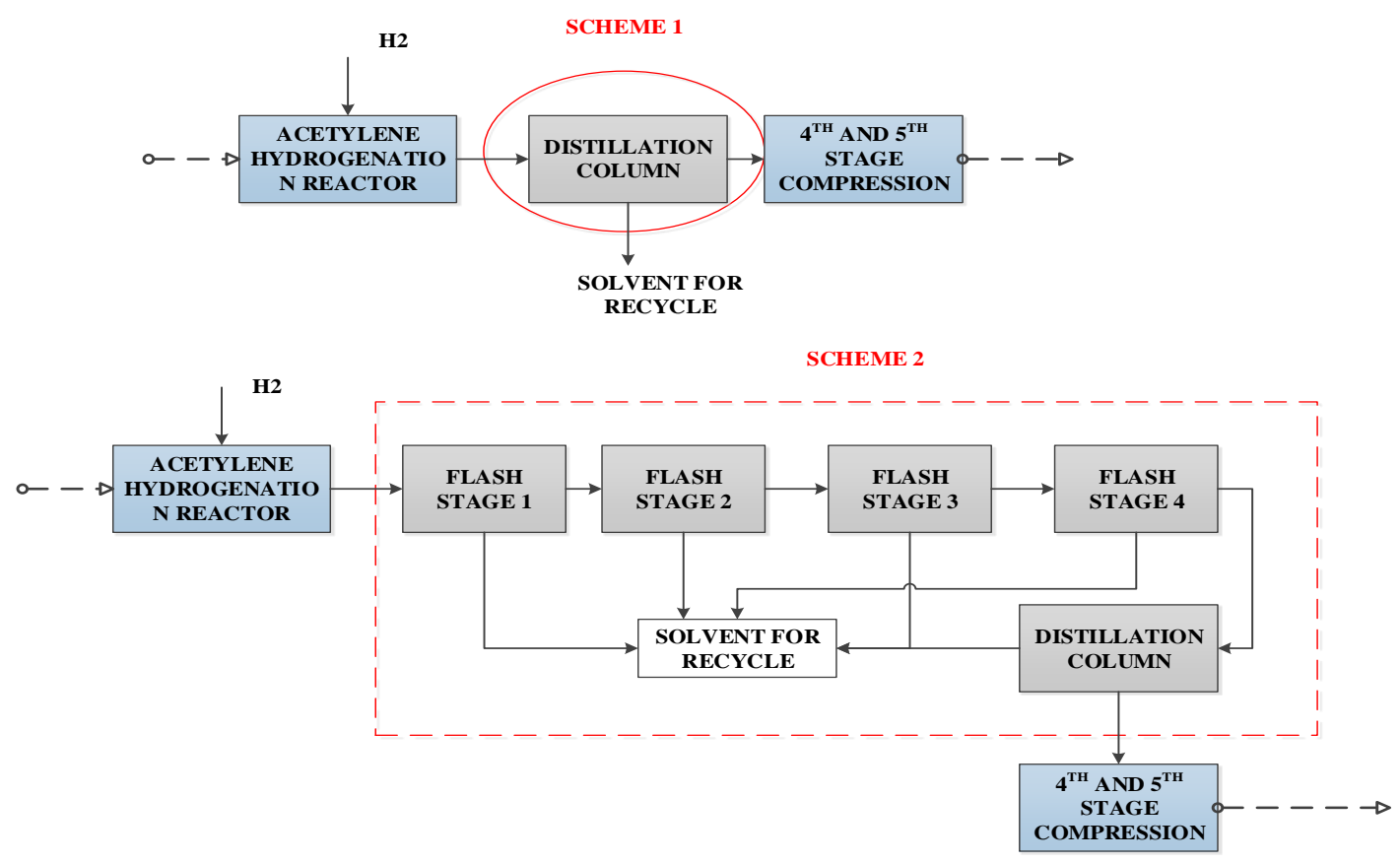

Figure 13: Scheme 1 and scheme 2 for solvent separation.

In the solvent separation section, three solvent separation schemes were proposed and analyzed for feasibility. Scheme 1 and 2 for solvent separation is depicted by Figure 13. The $1^{\text {st }}$ scheme involves using distillation column to separate hydrocarbons from solvent. Though a complete separation is effected with minimal loss of solvent and product, the energy duties and capital cost required for the columns were very high, making it an infeasible solution. The scheme 2 involves using a series of 4 flash vessels where pressure is reduced subsequently along with intermediate heating, to remove majority of the solvent. The vapors from all flash vessels were fed into distillation column to study separation. This scheme also had the disadvantage of utilizing high 
energies in reboilers and condensers and also required huge capital investment and hence, this scheme was not selected.

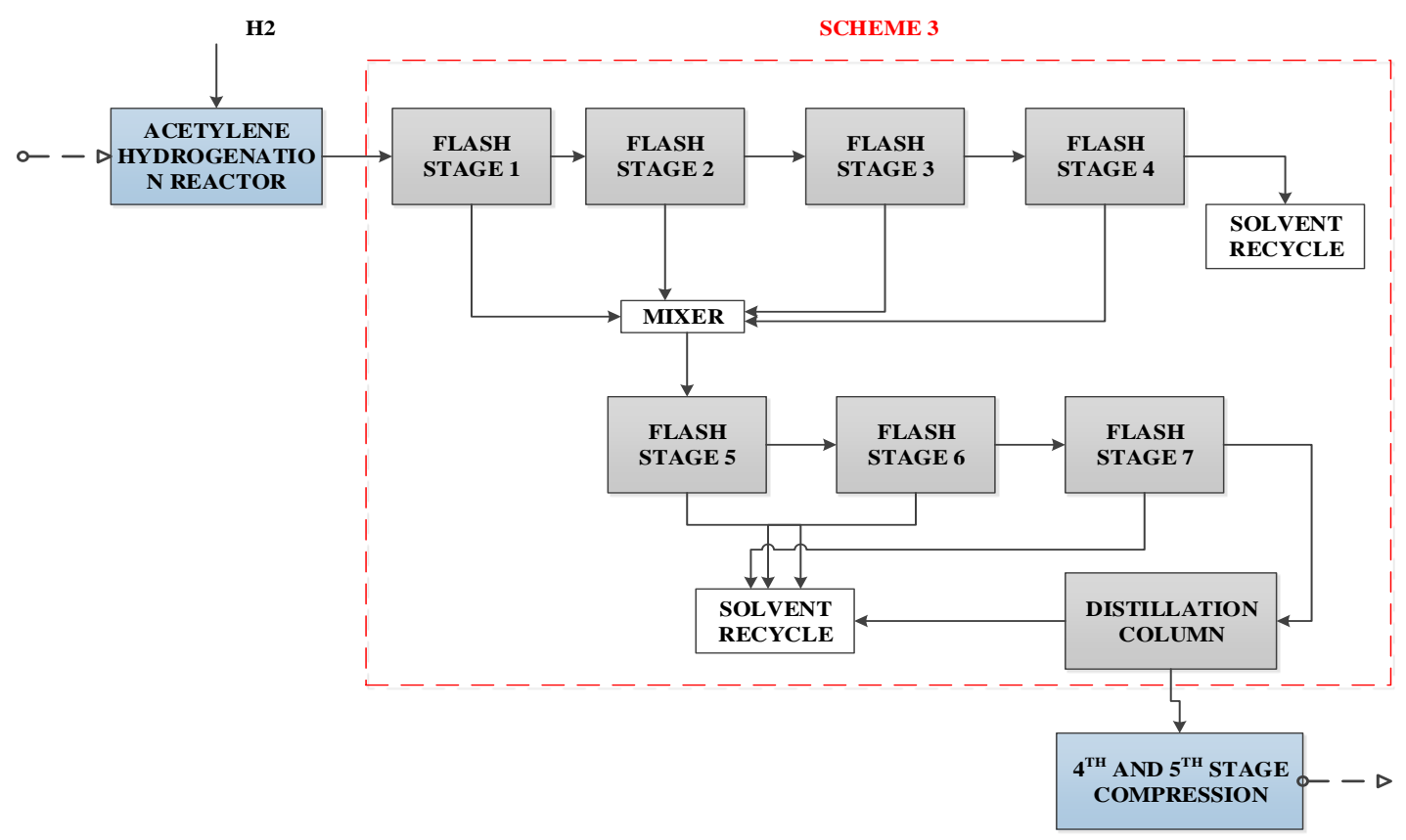

Figure 14: Scheme 3 proposed for solvent separation.

Scheme 3 of solvent separation is shown in Figure 14. Scheme 3 is a continuation of scheme 2, where the vapors collected from 4 flash vessels are cooled in 3 stages of flash vessels and finally when the hydrocarbon to solvent composition is about 50 mole $\%$, a distillation column is used to separate the same. This scheme proved to be energy efficient and also reduced the capital cost. Hence, this scheme is selected for developing process flow diagram. A comparison chart of 3 schemes are shown below in Table 11. 
Table 11: Comparison of different schemes proposed for solvent separation.

\begin{tabular}{|l|c|c|c|}
\hline \multicolumn{1}{|c|}{ PARAMETERS } & SCHEME 1 & SCHEME 2 & SCHEME 3 \\
\hline No of flash vessels & 0 & 4 & 7 \\
\hline $\begin{array}{l}\text { Distillation column condenser duty, } \\
\text { MMBtu/hr }\end{array}$ & 1084 & 96.04 & 68 \\
\hline $\begin{array}{l}\text { Distillation column reboiler duty, } \\
\text { MMBtu/hr }\end{array}$ & 915 & 712.99 & 17 \\
\hline
\end{tabular}

The process flow starts with methane and oxygen being preheated separately to $600{ }^{0} \mathrm{C}$, followed by which they are mixed in ratio of $1: 1.65$ moles of methane to oxygen and fed into burners.(Ries, 1966) About 56\% of methane is burned at 1 bar pressure, producing large amounts of heat required to crack the remaining methane into various products. The cracked gas at around $1500{ }^{0} \mathrm{C}$ is immediately quenched in burners using quench water to $80{ }^{\circ} \mathrm{C}$ to prevent decomposition to coke. The quenched gas is further cooled in a spray tower to $30^{\circ} \mathrm{C}$. The cooled gas is consequently sent to two stage of compression where in each stage, the gas is compressed, cooled and then flashed again to compress the vapors. The product gas is compressed to 2 bar in $1^{\text {st }}$ stage and then to 5 bar in second stage. The compression ratios were chosen in such a way not to exceed acetylene partial pressure of 1.4 MPa for safety considerations.(Ries, 1966) The gas exiting the second stage is passed into a amine sweetening unit where $31 \mathrm{wt} \%$ solution of MEA(Mono EthanolAmine) is used a solvent for absorbing carbon dioxide.(Burr \& Lyddon, 2008) A 100\% percent removal of carbon dioxide is assumed. The sweet gas exiting the amine sweetening unit is then sent to third stage of compression where it is compressed further to 12 bar. The compressed gas now enters 
into absorption tower where chilled solvent, $\mathrm{N}$ methyl 2- Pyrrolidine at $-50{ }^{0} \mathrm{C}$ is used for absorbing acetylene.(Gattis et al., 2004) A 95\% mass recovery of acetylene is assumed to optimize the capital cost and operating cost of the tower. The tail gas devoid of acetylene is separated into two streams where one stream is sent to utility for fuel use while other stream is sent to pressure swing adsorption for extracting $99.9 \%$ pure hydrogen. The pure hydrogen stream is regulated back into acetylene hydrogenation reactor while the remaining off gas is sent as utility fuel.

The solvent laden acetylene enters the acetylene hydrogenation reactor, where acetylene is converted into ethylene in the presence of catalyst at liquid phase.(Gattis et al., 2004) The reaction chemistry is same as gas phase hydrogenation. The product exiting the reactor is at $88{ }^{\circ} \mathrm{C}$ and 11 bar pressure and this is regulated into solvent separation section. The solvent laden product is a mixed phase and hence is flashed in 4 flash columns with a pressure reduction of 2 bar for each flash vessels along with intermediate heating. The stream had to be heated due to the presence of large amount of solvent. Flash vessels $1,2,3$ and 4 are operated at a temperature of $88{ }^{0} \mathrm{C}, 100{ }^{0} \mathrm{C}, 110{ }^{0} \mathrm{C}$ and $120{ }^{\circ} \mathrm{C}$, and pressures of 10 bar, 8 bar, 6 bar and 4 bar respectively. The liquid from each flash were regulated to subsequent flash drums and finally the liquid collected from the 4th flash vessel that contain approximately $99.5 \mathrm{wt} \%$ solvent are assumed to be directly recycled. The vapors from all 4 flash drums are mixed, cooled and flashed in three stages. These vapors are cooled in these stages because the solvent concentration has reduced significantly. Flash vessel 5, 6 and 7 are operated at temperatures $102{ }^{\circ} \mathrm{C}, 95$ ${ }^{0} \mathrm{C}$ and $85{ }^{0} \mathrm{C}$ with no significant pressure reduction. 
The vapors from each flash drum is regulated to subsequent flash drums and the final vapor exiting flash 7 is sent into distillation column, SOLSEP operating at 3 bar with top temperature of $-72{ }^{\circ} \mathrm{C}$ and bottom temperature of $19{ }^{\circ} \mathrm{C}$. The liquids collected from all the three flash drums 5, 6 and 7 contain $99.5 \mathrm{wt} \%$ of solvent and are recycled. The vapor distillate from SOLSEP column is regulated into two $4^{\text {th }}$ and $5^{\text {th }}$ stage of compression in order to prepare for effective separation in product separation section. Meanwhile the bottoms of SOLSEP containing $99.99 \mathrm{wt} \%$ of solvent is again recycled back to NMP absorption tower. The product gas is compressed to 12 bar in $4^{\text {th }}$ stage and 30 bar in $5^{\text {th }}$ stage. The hot gas exiting $5^{\text {th }}$ stage compressor is then cooled in a cooling water heat exchanger and sent into de-methanizer column.

The de-methanizer column operates at $30 \mathrm{bar}$, with top temperature at $-116{ }^{0} \mathrm{C}$ and bottom temperature of $-12{ }^{\circ} \mathrm{C}$. The vapor distillate containing predominantly methane, carbon monoxide and hydrogen are used as utility fuel. The bottoms of demethanizer column are then regulated into ethylene column where ethylene is removed as liquid distillate, while heaviers are removed at bottom. The column operates at 25 bar pressure with top temperature of $-20{ }^{\circ} \mathrm{C}$ and bottom temperature of $77{ }^{\circ} \mathrm{C}$. A product purity of $99.99 \mathrm{wt} \%$ is obtained. The heating utilities for the columns and heat exchangers are supplied by saturated steam at 6 bar pressure. The cooling utilities for inter-stage cooling exchangers are supplied by cooling water, while propylene refrigerant is used for condensers in columns. The process efficiencies and utilities used are same as those used for ethane cracking technology. All equipment were simulated to 
give optimized values of energy consumption. The general assumptions considered for this process are given below.

\section{III.2.1. Assumptions}

i. The natural gas feed is assumed to be sweet and contain $100 \%$ methane.

ii. $\quad 100 \%$ pure oxygen is assumed to be available as feed.

iii. Heat duties of methane and oxygen preheaters are rendered by indirect heating furnaces using natural gas as utility fuel.

iv. Amine sweetening tower was modeled by using RSTOIC and $100 \%$ conversion of $\mathrm{CO} 2$ is assumed. The design of amine absorber was done separately by assuming 20 trays in RADFRAC.

v. Acetylene conversion to ethylene in acetylene hydrogenation reactor was assumed to be $100 \%$. The reactor is considered adiabatic and owing to exothermic reaction of acetylene hydrogenation, the reactor outlet temperature increases.

vi. All distillation columns were simulated for more than $99 \%$ mass recovery of products.

vii. Residence time of 200 seconds is assumed for pressure swing adsorption cycle.(Jain, Moharir, Li, \& Wozny, 2003)

viii. Residence time of both gas phase and liquid phase acetylene hydrogenation reaction is assumed to be 20 seconds. (Anderson, 1967) 
ix. Only the main stream process equipment were considered hence, the recovery units and utility treatment units were not considered for evaluation of energy consumption.

x. A list of energy consuming equipment in each section and their consumption rates are given below in Table 12.

Table 12: List of energy consuming equipment and rate of energy consumptionsmethane pyrolysis process.

\begin{tabular}{|c|c|c|c|c|}
\hline $\begin{array}{l}\text { S. } \\
\text { NO }\end{array}$ & SECTION & Units named in PFD & $\begin{array}{c}\text { Type of } \\
\text { utility used }\end{array}$ & $\begin{array}{c}\text { Actual } \\
\text { heat } \\
\text { requirem } \\
\text { ents }\end{array}$ \\
\hline & & & & $\begin{array}{c}\text { MMBtu/h } \\
\mathbf{r} \\
\end{array}$ \\
\hline 1 & \multirow{4}{*}{$\begin{array}{c}\text { PYROLYSI } \\
\mathbf{S}\end{array}$} & METHANE PREHEATER & Natural gas & 1105 \\
\hline 2 & & OXYGEN PREHEATER & Natural gas & 445 \\
\hline 3 & & REACTOR QUENCHER & cooling water & 2239 \\
\hline 4 & & SPRAY TOWER COOLER & cooling water & 1441 \\
\hline 5 & \multirow{14}{*}{$\begin{array}{c}\text { COMPRES } \\
\text { SION }\end{array}$} & INTERCOOL STAGE 1-A & cooling water & 51 \\
\hline 6 & & INTERCOOL STAGE 1-B & cooling water & 50 \\
\hline 7 & & INTERCOOL STAGE 1-C & cooling water & 50 \\
\hline 8 & & INTERCOOL STAGE 1-D & cooling water & 50 \\
\hline 9 & & INTERCOOL STAGE 2-A & cooling water & 55 \\
\hline 10 & & INTERCOOL STAGE 2-B & cooling water & 55 \\
\hline 11 & & INTERCOOL STAGE 2-C & cooling water & 57 \\
\hline 12 & & INTERCOOL STAGE 3-A & cooling water & 72 \\
\hline 13 & & INTERCOOL STAGE 3-B & cooling water & 72 \\
\hline 14 & & 1ST STAGE COMPRESSOR & Power & 550 \\
\hline 15 & & 2ND STAGE COMPRESSOR & Power & 536 \\
\hline 16 & & 3RD STAGE COMPRESSOR & Power & 531 \\
\hline 17 & & 4TH STAGE COMPRESSOR & Power & 50 \\
\hline 18 & & 5TH STAGE COMPRESSOR & Power & 45 \\
\hline 19 & & FLASH STAGE 1 HTR & Steam & 130 \\
\hline
\end{tabular}


Table 12: Continued.

\begin{tabular}{|c|c|c|c|c|}
\hline $\begin{array}{l}\text { S. } \\
\text { NO }\end{array}$ & SECTION & Units named in PFD & $\begin{array}{c}\text { Type of } \\
\text { utility used }\end{array}$ & $\begin{array}{l}\text { Actual } \\
\text { heat } \\
\text { requirem } \\
\text { ents }\end{array}$ \\
\hline & & & & $\begin{array}{c}\text { MMBtu/h } \\
\mathbf{r}\end{array}$ \\
\hline 20 & \multirow{10}{*}{$\begin{array}{l}\text { SOLVENT } \\
\text { SEPARATI } \\
\text { ON }\end{array}$} & FLASH STAGE 2 HTR & Steam & 116 \\
\hline 21 & & FLASH STAGE 3 HTR & Steam & 132 \\
\hline 22 & & FLASH STAGE 4 COOL & cooling water & 36 \\
\hline 23 & & FLASH STAGE 5 COOL & cooling water & 47 \\
\hline 24 & & FLASH STAGE 6 COOL & cooling water & 47 \\
\hline 25 & & SOLSEP REBOILER & steam & 30 \\
\hline 26 & & SOLSEP CONDENSOR-A & refrigerant & 34 \\
\hline 27 & & SOLSEP CONDENSOR-B & refrigerant & 34 \\
\hline 28 & & SOLSEP CONDENSOR-C & refrigerant & 33 \\
\hline 29 & & INTERCOOL STAGE 5 & cooling water & 14 \\
\hline 30 & \multirow{6}{*}{$\begin{array}{c}\text { PRODUCT } \\
\text { SEPARATI } \\
\text { ON }\end{array}$} & DEMETHANIZER REBOILER & steam & 36 \\
\hline 31 & & $\begin{array}{l}\text { DEMETHANIZER } \\
\text { CONDENSOR-A }\end{array}$ & refrigerant & 29 \\
\hline 32 & & $\begin{array}{l}\text { DEMETHANIZER } \\
\text { CONDENSOR-B }\end{array}$ & refrigerant & 29 \\
\hline 33 & & ETHYLENE REBOILER & steam & 80 \\
\hline 34 & & ETHYLENE CONDENSOR-A & refrigerant & 25 \\
\hline 35 & & ETHYLENE CONDENSOR-B & refrigerant & 25 \\
\hline & & & Total & 8332 \\
\hline
\end{tabular}

\section{III.2.2. Simulation Results}

The simulation results calculated from ASPEN were used for calculating the energy requirements. From the simulation results, it can be seen that pyrolysis section is the largest energy consumer of the entire process. This is mainly attributed to the abundant supply of quench water required to quench the coke formation reaction. The 
energy consumption was calculated on basis of energy required to cool the exit quench water from reactor. It can also be seen that solvent and product separation energy consumptions are considerable low. Literature studies show different methods of heat recovery in acetylene cracker quench part by using different quench fluid such as oil or hydrocarbon such that effective utilization of the energy removed can be done.(Ries, 1966) In this case study water without heat recovery is analyzed. The process metrics that define the process technology are also shown below in Table 13. Following the reactor, compressors also contribute to large energy consumption, which is again followed by spray tower. Heat integration opportunities can be widely explored to reduce the minimum energy consumption in pyrolysis and compression section. One of the major limitations of using direct heat integration in pyrolysis section is the short residence time required for quench water. A total ethylene recovery of $95 \%$ is calculated based on the acetylene and ethylene available at reactor outlet compared to ethylene column product flow rate. The recovery is low because much of potential acetylene is lost in NMP absorption section. A large amount of off gas is generated in this process primarily constituting of hydrogen and carbon monoxide. This has been accounted in the cost analysis. Specific consumption is based on natural gas that is used for partial oxidation also. If methane that is utilized only for pyrolysis is considered, specific consumption will go down to 1.5 tonnes of methane/tonne of ethylene. Figure 15 shows the contribution of each section to specific energy consumption. Figure 16 shows the list of highest energy contributors along with their consumption rates. 
Table 13: Simulation results - methane pyrolysis process.

\begin{tabular}{|l|c|l|}
\hline \multicolumn{1}{|c|}{ Parameter } & Value & \multicolumn{1}{c|}{ UOM } \\
\hline Production rate of ethylene & 827,820 & Tonnes/yr \\
\hline Product purity & 99.99 & wt\% \\
\hline Feed rate of fresh methane & $3,320,040$ & Tonnes/yr \\
\hline Feed rate used only for pyrolysis reaction & $1,238,401$ & Tonnes/hr \\
\hline Process yield of ethylene-entire methane & 25 & $\%$ (mass basis) \\
\hline Process yield of ethylene-partial methane & 67 & $\%$ (mass basis) \\
\hline Pyrolysis single-pass conversion & 33 & $\%$ \\
\hline Ethylene recovery -total & 96 & $\%($ mass basis) \\
\hline Minimum energy requirements & 6253 & MMBtu/hr \\
\hline Minimum Specific Energy Consumption & 66 & $\begin{array}{l}\text { MMBtu/tonne of } \\
\text { ethylene }\end{array}$ \\
\hline Specific consumption of raw material & $\mathbf{4}$ & $\begin{array}{l}\text { Tonnes of } \\
\text { methane/tonne of } \\
\text { ethylene }\end{array}$ \\
\hline
\end{tabular}

\section{Specific Energy Consumption}

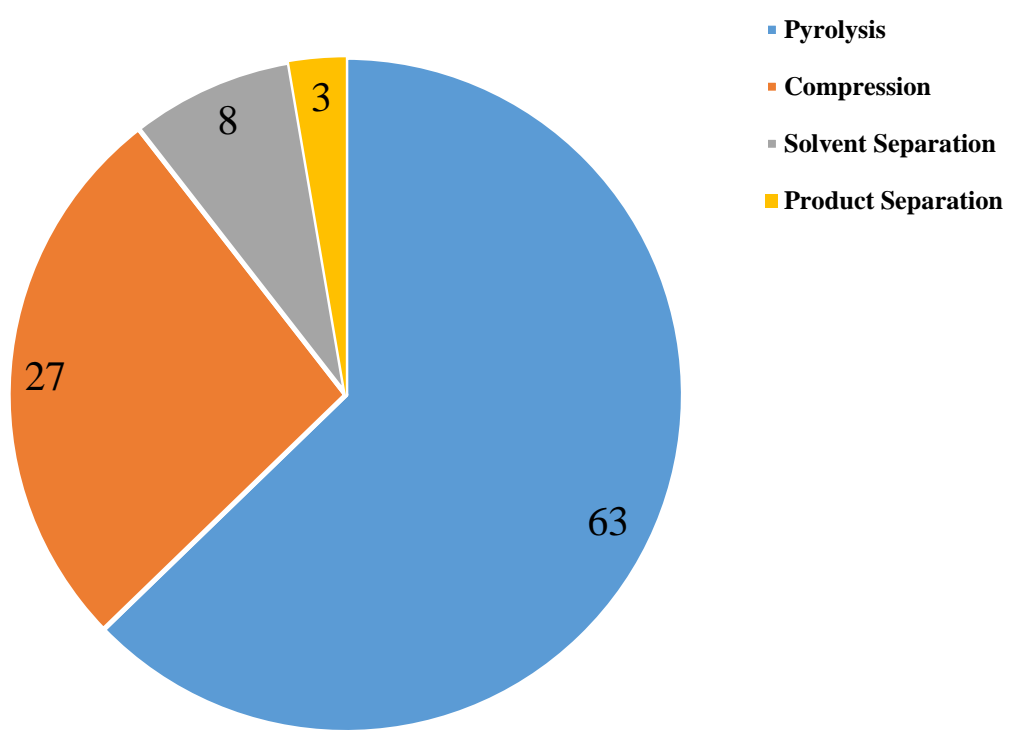

Figure 15: Specific energy consumption of major sections- methane pyrolysis. 


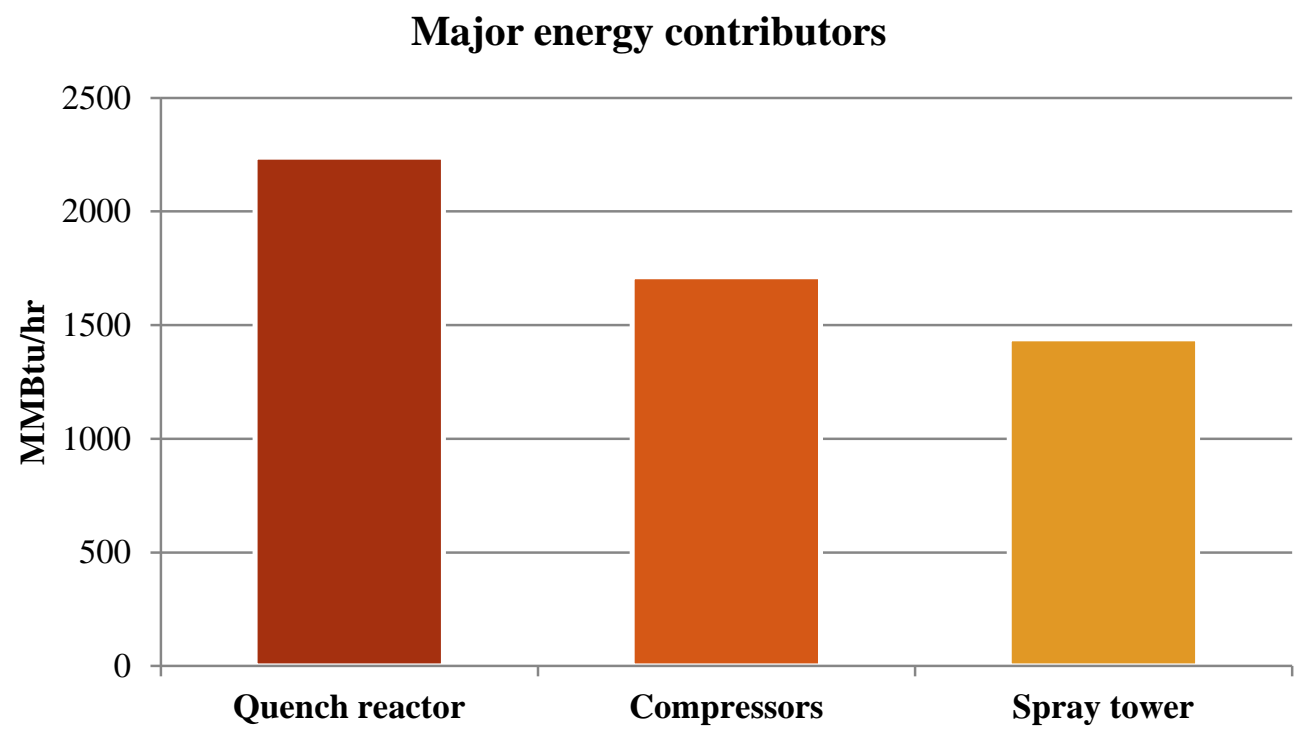

Figure 16: Major contributors to energy consumption- methane pyrolysis. 


\section{CHAPTER IV}

\section{ECONOMIC ANALYSIS}

In this chapter, a top level economic analysis using shortcut tools are used to evaluate the economics of operation of both the plants. Fixed and operating costs of the plants are calculated based on the production capacity of each plant, energy consumption and cost of raw material and utility. The cost of maintenance or labor will not be included as a part of the operating cost in this study. The utility assumptions made are in accordance to the general range of prices as given in the literature (El-Halwagi, 2012). The price of raw material is taken from energy information administration (EIA) and ICIS website.

\section{IV.1. Ethane Cracking}

In the ethane cracking process, the major raw material used is cracker feed ethane. The cost of ethane is found by taking an average of NGL- ethane trend from energy information association website. Table 14 shows the estimation of raw material cost. A comparison of price between naphtha and ethane is made to justify the use of ethane as feedstock. From the results, it can be found that the cost of ethane is 5 times higher than Naphtha price and hence, ethane is highly favorable than naphtha as feedstock for producing ethylene. The prices were taken as average value of predicted trend in EIA website. Table 15 shows the consolidated cost metrics obtained for the 
plant. Table 16 shows the operating cost of each equipment that was calculated according to the actual consumption in the plant.

Table 14: Estimation of raw material cost - Ethane steam cracking.

\begin{tabular}{|c|c|c|}
\hline Parameter & Value & UOM \\
\hline Specific gravity of Naptha & 0.75 & \\
\hline Density of Naphtha & 46.8 & $\mathrm{lb} / \mathrm{ft} 3$ \\
\hline Average Price of Gasoline & 3.5 & $\$ /$ gal \\
\hline Average Price of Crude Oil (barrell) & 100 & $\$ / b b l$ \\
\hline Average Price of Crude Oil (Gallon) & 2.3 & $\$ /$ gal \\
\hline Assuming price of Naphtha price & 3 & \$/gal \\
\hline Average Price of Naphtha (cubic foot) & 22 & $\$ / \mathrm{ft} 3$ \\
\hline Average Price of Naphtha (Pound basis) & 0.48 & $\$ / \mathrm{lb}$ \\
\hline Average Price of Naphtha $(\mathrm{kg})$ & 1.1 & \$/kg naphtha \\
\hline Specific Consumption of Naphtha to ethylene & 2.86 & $\mathrm{~kg} / \mathrm{kg}$ ethylene \\
\hline Amount of Naphtha required & 272 & Tonnes/hr \\
\hline Price of Naphtha & 288334 & $\$ / \mathrm{hr}$ \\
\hline Gross heating Value of ethane & 1783 & Btu/SCF \\
\hline Average Price of NGL - Ethane & 4 & \$/MMBtu \\
\hline Basis of 1 MMBtu (SCF) & 560.9 & SCF ethane \\
\hline Basis of 1 MMBtu $(\mathrm{kg})$ & 20.2 & $\mathrm{~kg}$ of ethane \\
\hline Average Price of NGL - Ethane (kg) & 0.2 & \$/kg ethane \\
\hline Amount of ethane required & 112 & Tonnes/hr \\
\hline Price of ethane & 22171 & $\$ / h r$ \\
\hline
\end{tabular}

Table 15: Consolidated cost data- Ethane cracking process.

\begin{tabular}{|l|c|c|}
\hline \multicolumn{1}{|c|}{ Parameter } & Value & UOM \\
\hline Cost of Energy & 526.6 & Million $\$ / \mathrm{yr}$ \\
\hline Cost of Raw material & 195.2 & Million $\$ / \mathrm{yr}$ \\
\hline Total Operating Cost & $\mathbf{7 2 1 . 8}$ & Million $\$ \mathbf{y r}$ \\
\hline Fixed Capital Cost & $\mathbf{8 7 0 . 8}$ & Million $\$ \mathbf{y r}$ \\
\hline Annual sales of product & 1336.2 & Million $\$ / \mathrm{yr}$ \\
\hline Economic Gross Potential & 1141 & Million $\$ / \mathrm{yr}$ \\
\hline
\end{tabular}


Table 16: Operating cost of equipment- ethane cracking.

\begin{tabular}{|c|c|c|}
\hline SECTION & Units named in PFD & $\begin{array}{l}\text { Total cost } \\
\text { of utility }\end{array}$ \\
\hline & & $\$ / \mathbf{h r}$ \\
\hline \multirow{3}{*}{ PYROLYSIS } & PREHEATER & 2797 \\
\hline & CRACKER & 2788 \\
\hline & TRANSFER LINE EXCHANGE & 775 \\
\hline \multirow{10}{*}{$\begin{array}{l}\text { COMPRESSION } \\
\text { SECTION }\end{array}$} & RECIRCULATION HEATER & 544 \\
\hline & INTERSTAGE COOL1-A & 64 \\
\hline & INTERSTAGE COOL1-B & 64 \\
\hline & INTERSTAGE COOL2 & 80 \\
\hline & INTERSTAGE COOL3 & 70 \\
\hline & INTERSTAGE COOL4 & 72 \\
\hline & 1ST STAGE COMPRESSOR & 523 \\
\hline & 2ND STAGE COMPRESSOR & 505 \\
\hline & 3RD STAGE COMPRESSOR & 495 \\
\hline & 4TH STAGE COMPRESSOR & 469 \\
\hline \multirow{20}{*}{$\begin{array}{l}\text { SEPARATION } \\
\text { SECTION }\end{array}$} & REFRIGERATION COOLER & 283 \\
\hline & COOL TRAIN HX3-A & 192 \\
\hline & COOL TRAIN HX3-B & 192 \\
\hline & COOL TRAIN HX3-C & 198 \\
\hline & COOL TRAIN HX6-A & 471 \\
\hline & COOL TRAIN HX6-A & 471 \\
\hline & COOL TRAIN HX9 & 164 \\
\hline & CONDENSOR 1 & 97 \\
\hline & REBOILER 1 & 9702 \\
\hline & CONDENSOR 2-A & 826 \\
\hline & CONDENSOR 2-B & 826 \\
\hline & REBOILER 2 & 17640 \\
\hline & ACETYLENE PREHEATER & 8820 \\
\hline & CONDENSOR 3-I-A & 898 \\
\hline & CONDENSOR 3-I-B & 898 \\
\hline & CONDENSOR 3-II-A & 898 \\
\hline & CONDENSOR 3-II-B & 898 \\
\hline & REBOILER 3-I & 11907 \\
\hline & REBOILER 3-II & 11907 \\
\hline & TOTAL OFF-GAS GENERATION & -4757 \\
\hline
\end{tabular}


Table 16: Continued.

\begin{tabular}{|c|c|r|}
\hline SECTION & Units named in PFD & $\begin{array}{c}\text { Total cost } \\
\text { of utility }\end{array}$ \\
\hline & DILUTION STEAM & \$/hr \\
\hline & Total & 60113 \\
\hline
\end{tabular}

Table 17: Cost of utilities. (El-Halwagi, 2012)

\begin{tabular}{|c|c|c|l|}
\hline Type of utility & Parameter & Value & \multicolumn{1}{|c|}{ UOM } \\
\hline \multirow{2}{*}{ Heating utility } & Steam & $\mathbf{4 . 4 1}$ & \$/tonne \\
\cline { 2 - 4 } & Natural gas & $\mathbf{4}$ & $\$ /$ MMBtu \\
\hline \multirow{2}{*}{ Cooling Utility } & Refrigeration & $\mathbf{2 0}$ & $\$ / \mathrm{MMBtu}$ \\
\cline { 2 - 4 } & Cooling water & $\mathbf{2}$ & $\$ / \mathrm{MMBtu}$ \\
\hline
\end{tabular}

The assumptions made for utility prices are given in Table 17. The total operating cost is sum of energy cost and raw material cost. The raw material cost includes the cost of ethane and cost of caustic since, caustic regeneration is not considered here. The price of caustic taken from ICIS website is found to be $\$ 545 /$ tonne. In this analysis, the cost of utility is assumed in terms of energy except for steam. The amount of steam consumed in each exchanger is calculated using ASPEN PLUS such that only latent heat is utilized by the process stream. It can also be seen that the credit for utilizing off gas generated in the plant as fuel for cracker can be reflected in terms of negative cost of natural gas saved in the furnace. The total off gas generated constitutes of $12,259 \mathrm{Kg} / \mathrm{hr}$ of light gases, whose composition is given by $54.79 \mathrm{~mol} \%$ of hydrogen, $6.8 \mathrm{~mol} \%$ of ethylene, $37 \mathrm{~mol} \%$ of methane and $1 \mathrm{~mol} \%$ of ethane. It 
produces a combined heat duty of around $1189 \mathrm{MMBtu} / \mathrm{hr}$, which when multiplied with natural gas thermal efficiency and the cost of natural gas gives the credit for off gas to energy cost. The cost of injecting dilution steam in the cracker for prevention of coke formation is also added in the operating costs. It can be seen from cost analysis table, that cost of energy is approximately $73 \%$ of the total operating cost.(Ren et al., 2006) Hence this proves that this process is highly energy intensive. The fixed cost is calculated using the formula:(El-Halwagi, 2012)

$\mathrm{FCI}_{\mathrm{B}}=\mathrm{FCI}_{\mathrm{A}} *$ (Capacity of $\mathrm{B} /$ Capacity of A) ${ }^{0.6}$

Where $\mathrm{FCI}_{\mathrm{A}}$ is found to be $691 \$ \mathrm{MM}$ for 568,000 annual rate of production of ethylene (Capacity).(El-Halwagi, 2012) Here, capacity of B is 832000 Tonnes per year (present case study).

\section{IV.2. Pyrolysis of Methane}

The basic raw materials involved in methane pyrolysis are natural gas and oxygen. To get pure oxygen, an air separation unit needs to be installed at the same process facility in order to be cost effective. In this case study, a cost of $0.021 \$ / \mathrm{kg}$ of oxygen is assumed as raw material price.(Noureldin, Elbashir, \& El-Halwagi, 2013) Similarly the amine absorber involving the usage of MEA requires installation of recovery system to recover MEA and recycle it back to the tower.(Chapel, Mariz, \& Ernest, 1999) In this case, capital and operating cost of MEA recovery units are included and shown separately in order to make reasonable comparison with ethane cracking process where no recovery system has been accounted. $\mathrm{N}$ methyl 2-pyrrolidine is 
considered to be almost fully recovered and recycled directly. The NMP make up to be added to the system according to simulation results is $549 \mathrm{~kg} / \mathrm{hr}$. The detailed cost estimation of raw materials is given below in table. It is assumed that MEA is fully recovered in the amine recovery unit hence, no makeup is accounted. The cost of utility is assumed to be same as that of ethane cracking technology. The raw material estimation is given below in Table 18.

Table 18: Estimation of raw material cost- methane pyrolysis.

\begin{tabular}{|c|c|c|}
\hline Parameter & Value & UOM \\
\hline Average Price of Natural Gas & 4 & \$/MMBtu \\
\hline Basis of 1 MMBtu (SCF) & 1000 & SCF methane \\
\hline Basis of 1 MMBtu $(\mathrm{kg})$ & 19.2 & $\mathrm{~kg}$ of methane \\
\hline Average Price of methane $(\mathrm{kg})$ & 0.21 & \$/kg methane \\
\hline Amount of methane required & 379 & Tonnes/hr \\
\hline Price of methane & 692975349 & \$/year \\
\hline NMP make up rate & 549 & $\mathrm{~kg} / \mathrm{hr}$ \\
\hline Value of NMP & 1.85 & $\$ / \mathrm{lb}$ \\
\hline Annual cost of NMP makeup & 19771320 & \$/year \\
\hline Cost of oxygen & 0.021 & \$/kg oxygen \\
\hline Amount of oxygen consumed & 491370 & $\mathrm{~kg} / \mathrm{hr}$ \\
\hline Annual cost of oxygen & 90392425 & \$/year \\
\hline Total raw material cost & 803.1 & $\$ \mathrm{M} /$ year \\
\hline
\end{tabular}

The cost of energy consumption on an annual basis is calculated using results derived from simulation. The cost of utilities namely steam, power, natural gas, refrigeration and cooling water are assumed to be same as that of ethane cracking plant. It can be seen from process simulation results that the maximum energy consumed was 
in the quench and spray tower where cooling water is the cooling medium. Though amount of cooling water required is high, the cost of cooling water is low per energy basis and hence, the energy cost is comparatively lesser than the previous process. From the raw material analysis, it can clearly be seen that cost of natural gas is very high when compared to other materials and this is due to high consumption of gas in the reactor. It is to be noted that only $33 \%$ of methane is converted to valuable intermediate, acetylene and hence, the economic gross potential is also low compared to previous process. The capital and operating cost of amine sweetening unit were calculated according to literature data. The consolidated cost metrics is shown below in Table 19.

Table 19: Consolidated cost data- methane pyrolysis process.

\begin{tabular}{|l|c|c|}
\hline \multicolumn{1}{|c|}{ Parameter } & Value & UOM \\
\hline Cost of Energy & 598.5 & Million \$/yr \\
\hline Cost of Raw material & 803.1 & Million \$/yr \\
\hline Total Operating Cost(without amine recovery ) & 1401.6 & Million \$/yr \\
\hline Operating cost of amine recovery unit & 20.1 & Million \$/yr \\
\hline Total Operating Cost(including amine recovery) & $\mathbf{1 4 2 1 . 7}$ & Million\$/year \\
\hline $\begin{array}{l}\text { Fixed Capital Cost (including amine recovery } \\
\text { units) }\end{array}$ & $\mathbf{3 8 5 . 1}$ & Million \$/yr \\
\hline Annual sales of product & 1336.2 & Million \$/yr \\
\hline Economic Gross Potential & 533.1 & Million \$/yr \\
\hline
\end{tabular}

The energy cost of each equipment is shown below in Table 20. The total operating cost is addition of raw material cost and utility cost. The amount of steam utilized in heat exchangers are obtained using ASPEN simulation. The total off gas generated from NMP absorption, Pressure swing adsorption and de-methanizer lighters 
accrue to a mass flow rate of 401.2 tonnes $/ \mathrm{hr}$. The composition of off gas is given by 60 mol $\%$ of hydrogen, 33.5 mole $\%$ of carbon monoxide, 6.2 mole $\%$ of methane and other hydrocarbons contribute to about 1 mole $\%$. The off gas generated is equivalent to 10676 MMBtu/hr of energy and this when multiplied with cost of natural gas gives the credit for energy. It can be seen from the energy cost table that $38 \%$ of the actual energy cost has been balanced by accounting for the energy consumed by off gas. It can also be seen that raw material accounts for $57 \%$ of the total operating cost.

Table 20: Operating cost of equipment- methane pyrolysis.

\begin{tabular}{|c|c|c|}
\hline SECTION & Units named in PFD & $\begin{array}{c}\text { Total cost of } \\
\text { utility }\end{array}$ \\
\hline & & $\$ / \mathrm{hr}$ \\
\hline \multirow{4}{*}{ PYROLYSIS } & METHANE PREHEATER & 4419 \\
\hline & OXYGEN PREHEATER & 1778 \\
\hline & REACTOR QUENCHER & 4477 \\
\hline & SPRAY TOWER COOLER & 2881 \\
\hline \multirow{14}{*}{ COMPRESSION } & INTERCOOL STAGE 1-A & 101 \\
\hline & INTERCOOL STAGE 1-B & 101 \\
\hline & INTERCOOL STAGE 1-C & 101 \\
\hline & INTERCOOL STAGE 1-D & 101 \\
\hline & INTERCOOL STAGE 2-A & 110 \\
\hline & INTERCOOL STAGE 2-B & 110 \\
\hline & INTERCOOL STAGE 2-C & 114 \\
\hline & INTERCOOL STAGE 3-A & 144 \\
\hline & INTERCOOL STAGE 3-B & 144 \\
\hline & 1ST STAGE COMPRESSOR & 2201 \\
\hline & 2ND STAGE COMPRESSOR & 2143 \\
\hline & 3RD STAGE COMPRESSOR & 2123 \\
\hline & 4TH STAGE COMPRESSOR & 200 \\
\hline & 5TH STAGE COMPRESSOR & 179 \\
\hline & FLASH STAGE 1 HTR & 22051 \\
\hline & FLASH STAGE 2 HTR & 22051 \\
\hline
\end{tabular}


Table 20: Continued.

\begin{tabular}{|c|c|c|}
\hline SECTION & Units named in PFD & $\begin{array}{c}\text { Total cost of } \\
\text { utility }\end{array}$ \\
\hline & & $\$ / \mathbf{h r}$ \\
\hline \multirow{9}{*}{$\begin{array}{c}\text { SOLVENT } \\
\text { SEPARATION }\end{array}$} & FLASH STAGE 3 HTR & 22051 \\
\hline & FLASH STAGE 4 COOL & 73 \\
\hline & FLASH STAGE 5 COOL & 95 \\
\hline & FLASH STAGE 6 COOL & 94 \\
\hline & SOLSEP REBOILER & 3087 \\
\hline & SOLSEP CONDENSOR-A & 680 \\
\hline & SOLSEP CONDENSOR-B & 680 \\
\hline & SOLSEP CONDENSOR-C & 660 \\
\hline & INTERCOOL STAGE 5 & 28 \\
\hline \multirow{8}{*}{$\begin{array}{c}\text { PRODUCT } \\
\text { SEPARATION }\end{array}$} & DEMETHANIZER REBOILER & 4851 \\
\hline & DEMETHANIZER CONDENSOR-A & 586 \\
\hline & DEMETHANIZER CONDENSOR-B & 586 \\
\hline & ETHYLENE REBOILER & 11025 \\
\hline & ETHYLENE CONDENSOR-A & 496 \\
\hline & ETHYLENE CONDENSOR-B & 496 \\
\hline & OFF GAS GENERATION & -42704 \\
\hline & Total & 68318 \\
\hline
\end{tabular}

The fixed capital cost of this plant is calculated by extracting equipment cost values obtained from ASPEN plus economic analyzer. For equipment namely methane and oxygen preheaters, cracker reactor, pressure swing absorption unit and amine sweetening unit, the capital cost was calculated based on literature values using six tenth factor rule. (Ries, 1966) (Peramanu et al., 1999) (Chapel et al., 1999) The equipment costs obtained from economic analyzer were then multiplied with a Lang factor of 5 to obtain the fixed capital cost.(El-Halwagi, 2012) For those values obtained from 
literature, six by tenth rule was applied to calculate the equipment cost at given capacity. The formula for scale factor of equipment cost is given by:

Equipment Cost ${ }_{\mathrm{B}}=$ Equipment Cost $_{\mathrm{A}} *(\text { Capacity of B/ Capacity of } \mathrm{A})^{\mathrm{x}}$

The value of $\mathrm{x}$ is determined depending on the type of equipment. For furnaces an exponent of 0.78 was used while for rest of the equipment a general value of 0.6 was used for calculation purposes. (El-Halwagi, 2012) Table 21 lists the fixed capital investment calculated for each equipment.

Table 21: Capital investment of equipment- Methane pyrolysis.

\begin{tabular}{|c|l|r|}
\hline S.No & Physical Units & \multirow{2}{*}{ FCI in USD } \\
\hline 1 & Methane preheater & 83553047 \\
\hline 2 & Oxygen preheater & 13806232.21 \\
\hline 3 & Cracker reactor & 22660000 \\
\hline 4 & Spray tower (10 nos.) & 45440000 \\
\hline 5 & 1st stage compressor & 3239000 \\
\hline 6 & Intercool stage 1 (4 nos.) & 1285000 \\
\hline 7 & Cool flash 1 & 44712814 \\
\hline 8 & 2nd stage compressor & 2197000 \\
\hline 9 & Intercool stage 2 (3 nos.) & 1219000 \\
\hline 10 & Cool flash 2 & 21876470 \\
\hline 11 & Amine sweetening unit (including recovery) & 65093500 \\
\hline 12 & 3rd stage compressor & 1490000 \\
\hline 13 & Intercool stage 3 (2 nos.) & 8026500 \\
\hline 14 & NMP absorption (3 nos.) & 8512069 \\
\hline 15 & Pressure swing absorption unit & 7160000 \\
\hline 16 & Acetylene hydrogenation & 2821500 \\
\hline 17 & Flash net 1 & 468000 \\
\hline 18 & Flash stage 1 heater & 2428000 \\
\hline 19 & Flash net 2 & 492500 \\
\hline 20 & Flash stage 2 heater & \\
\hline
\end{tabular}


Table 21: Continued.

\begin{tabular}{|r|l|r|}
\hline S.No & Physical Units & FCI in USD \\
\hline 21 & Flash net 3 & 2292500 \\
\hline 22 & Flash stage 3 heater & 749500 \\
\hline 23 & Flash net 4 & 1698500 \\
\hline 24 & Flash stage cool 4 & 213500 \\
\hline 25 & Flash net 5 & 574000 \\
\hline 26 & Flash stage cool 5 & 295500 \\
\hline 27 & Flash net 6 & 374000 \\
\hline 28 & Flash stage cool 6 & 328500 \\
\hline 29 & Flash net 7 & 330500 \\
\hline 30 & Solsep column & 1958500 \\
\hline 31 & Solsep reboiler & 268500 \\
\hline 32 & Solsep condensor (3 nos.)+ reflux pump & 1798500 \\
\hline 33 & 4 th stage compressor & 12373000 \\
\hline 34 & 5th stage compressor & 8341500 \\
\hline 35 & Interstage cool 5 & 241000 \\
\hline 36 & De-methanizer column & 3949500 \\
\hline 37 & De-methanizer reboiler & 177500 \\
\hline 38 & De-methanizer condenser (2 nos.)+reflux pump & 5022000 \\
\hline 39 & Ethylene column & 2351500 \\
\hline 40 & Ethylene reboiler & 452500 \\
\hline 41 & Ethylene condenser (2 nos.) & 4825500 \\
\hline & Total & 385096632 \\
\hline & Total in Million USD & \\
\hline & & (185.1 \\
\hline
\end{tabular}




\section{CHAPTER V}

\section{SAFETY ANALYSIS}

In this chapter, the details of safety analysis will be outlined for both the processes. The index chosen to measure safety is Hazard Identification and RAnking system (HIRA). After carrying out a through literature study, it can be understood that one of main reasons why companies do not measure inherent safety in the conceptual stage is because almost all available safety indices require comprehensive data. At the conceptual stage there is not much information on the process except for process flow diagram and approximate economic analysis. The advantage of using HIRA is that this index offers flexibility in neglecting those parameters that are not available, for example, location, spacing and congestion. Another advantage is that this index, though not completely qualitative, most of the operating conditions are estimated through thermodynamic and empirical models. Hence, this index will prove to be a reliable tool for safety analysis.

Further, most of the indices are based on quantification safety index, depending on possible abnormal situations that can be encountered and this requires expertise and experience to choose credible scenarios. But in this approach, the capacities of plant as such will be used for estimating the value of index. This is because the purpose of the analysis is not to calculate accurate value of risks in order to design layers of protection. Instead a rough approximate estimate of safety levels is to be determined in order to rank the equipment in terms of safety and then focus on each section to identify opportunities 
for application of ISD approaches. Hence, this top level approach requires less time for calculation and can be easily applied at early stage of design.

\section{V.1.General Assumptions}

a. For this analysis, only gas phase and vapor phase conditions and compositions will be used for the purpose of calculation. The vapor phase is more dangerous than liquid and hence has more damage potential than liquid. Hence vapor phase conditions are used to represent the extent of damage of each equipment.

b. Effects due to location of the nearest hazardous units and density of units are neglected.

c. In all unit operations, only the composition of hydrocarbons is taken into consideration.

d. For heat exchangers, the design shortcut method used yields the volume of entire equipment. But for safety calculations, instead of counting the volume occupied by hydrocarbon, the value for entire equipment volume will be considered. This is due to the lack of detailed design data available for calculation. This will slightly overestimate the measure of damage potential in heat exchangers.

e. For distillation columns and absorption towers, the conditions at the top of column will be considered for safety calculations. This is because top of column contains maximum amount of lighters in comparison with to 
bottom and most of them are in vapor phase. Only vapor load at top of column will be assumed for calculation.

f. Invariably for all equipment, the conditions at the inlet or outlet that has maximum temperature will be considered for safety analysis except for reactors.

g. Since the volumes of compressors are variable and small, the volume term in calculation of compressors and expanders are neglected.

\section{V.1.1 Units with Chemical Reactions and Physical Operations}

The procedure for calculation of Fire and explosion damage index using HIRA is different for each equipment class. Since all the equipment considered for analysis of both the plants fall under the category of either physical operations or reactors, calculation algorithm for only these two equipment class is shown. In this sub division, step by step procedure for calculating units involving chemical reaction and physical operation will be listed. The fire and explosion damage index is given by:(Khan \& Abbasi, 1998)

FEDI $=4.76 *(\text { Damage potential })^{0.333}$

Damage potential $($ Reactions $)=(\mathrm{F} 1 * \mathrm{pn} 1+\mathrm{F} * \mathrm{pn} 2+\mathrm{F} 4 * \mathrm{pn} 7 * \mathrm{pn} 8) * \mathrm{pn} 3 * \mathrm{pn} 4 * \mathrm{pn} 5 * \mathrm{pn} 6$ Damage Potential $($ Physical operations $)=(\mathrm{F} 1 * \mathrm{pn} 1+\mathrm{F} * \mathrm{pn} 2) * \mathrm{pn} 3 * \mathrm{pn} 4 * \mathrm{pn} 5 * \mathrm{pn} 6$

F1, F and F4 are energy factors and pn1-8 are penalties assigned to each operating condition. F1 is the energy factor that takes account for chemical energy. F is summation of F2 and F3, where both these sub factors account for physical energy based 
on certain physical conditions.(Khan \& Abbasi, 1998) F4 accounts for energy released due to chemical reactions.(Khan \& Abbasi, 1998) Penalties pn1 is assigned for temperature, pn2 for pressure, pn3 for quantity of chemical handled in the unit, pn4 for effect of chemical characteristics namely flammability and reactivity, pn5 for effect of location of nearest hazardous unit, pn6 for density of units, pn7 for type of reaction and pn8 for probability of side reaction.(Khan \& Abbasi, 1998) The formulas for calculating energy factors and penalties are given as follows:(Khan \& Abbasi, 1998)

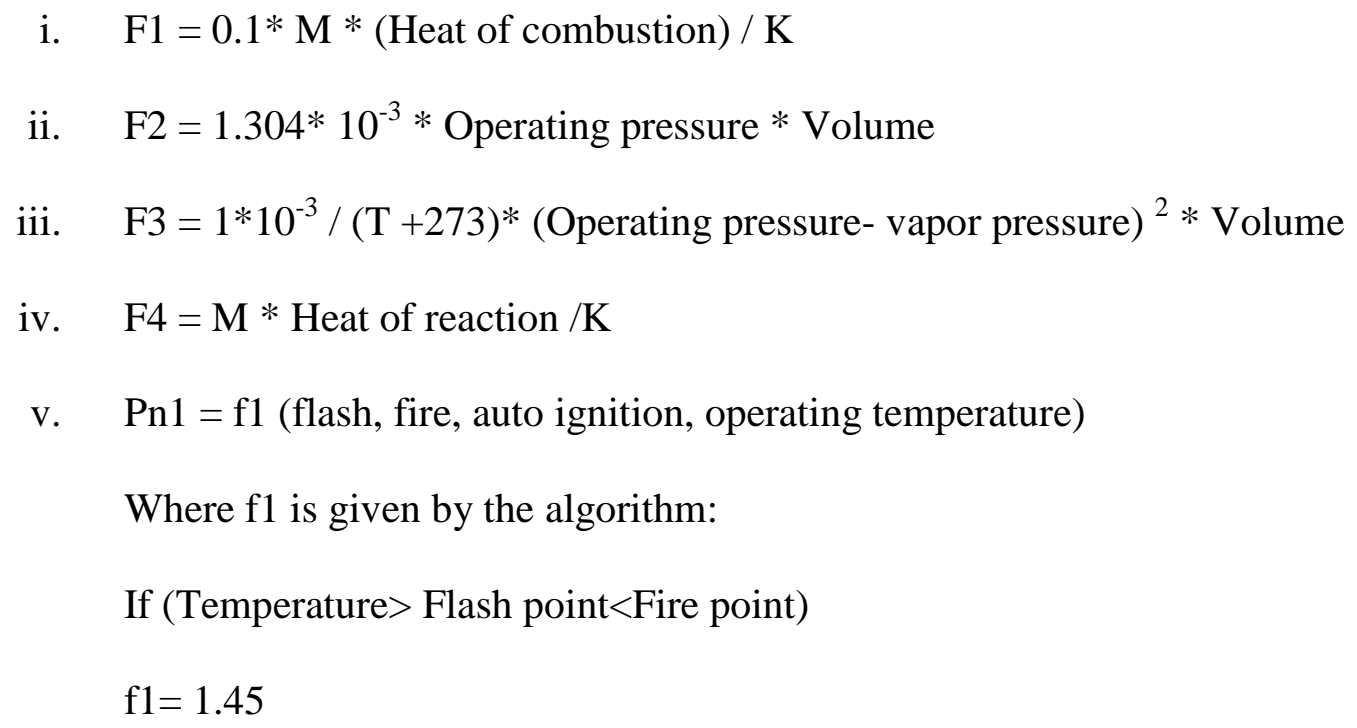

i. $\quad \mathrm{F} 1=0.1 * \mathrm{M} *$ (Heat of combustion) $/ \mathrm{K}$

ii. $\quad \mathrm{F} 2=1.304 * 10^{-3} *$ Operating pressure $*$ Volume

iii. $\quad \mathrm{F} 3=1 * 10^{-3} /(\mathrm{T}+273)^{*}(\text { Operating pressure- vapor pressure })^{2} *$ Volume

iv. $\quad \mathrm{F} 4=\mathrm{M} *$ Heat of reaction $/ \mathrm{K}$

v. Pn1 = f1 (flash, fire, auto ignition, operating temperature)

Where $\mathrm{f} 1$ is given by the algorithm:

If (Temperature $>$ Flash point $<$ Fire point)

$\mathrm{f} 1=1.45$

Else if (Temperature $>$ Fire point $<0.75$ Auto-ignition temperature)

$\mathrm{f} 1=1.75$

Else if (Temperature> 0.75 Auto-ignition temperature)

$\mathrm{f} 1=1.95$

Else

$\mathrm{f} 1=1.1$

vi. Pn2 is calculated using the following algorithm: 
If (Vapor pressure>Atmospheric pressure and operating pressure>vapor pressure)

$\operatorname{Pn} 2=1+(1-($ vapor pressure/operating pressure $)) * 0.6$

$\mathrm{F}=\mathrm{F} 2+\mathrm{F} 3$

Else

$\operatorname{Pn} 2=1+(1-($ vapor pressure/operating pressure $)) * 0.4$

$\mathrm{F}=\mathrm{F} 2$

If (Atmospheric pressure > vapor pressure and operating pressure > Atmospheric pressure)

$\operatorname{Pn} 2=1+(1-(\text { vapor pressure/operating pressure }))^{*} 0.2$

$\mathrm{F}=\mathrm{F} 3$

Otherwise

$\operatorname{Pn} 2=1.1$

$\mathrm{F}=\mathrm{F} 3$

vii. Pn3 is calculated based on weightage for chemical handled in the unit. This is based on the chemical characteristics namely flammability and reactivity. Since, both the process are steady state, flow rates are with respect to time. Hence quantity cannot be defined properly. Hence a limiting value of 1.1 is assumed for all operations.

viii. Pn4 describes the effect of chemical characteristics. It is given by the following equation:

$\mathrm{Pn} 4=1+0.25^{*}$ (NFPA flammability score + NFPA reactivity score $)$ 
ix. Pn5 is the effect due to location of nearest hazardous unit. Since this has been neglected for this case study, a minimum value of 1.2 is taken as value.

x. Pn6 is the penalty due to density of units. Since this is neglected for this case study a minimum value of 1 is assumed. The formula is given by the equation below:

Pn6 $=(1+\%$ space occupied by unit in an area of $30 \mathrm{~m}$ in radius from the unit/100)

xi. Pn7 is the penalty used for units involving chemical reactions, where the score is assigned based on the type of reaction.

xii. Pn8 is the penalty assigned to account for probability of undesired side reactions in units involving reactions.

$\mathrm{M}$ is mass flow rate with units in $\mathrm{kg} / \mathrm{sec}$, Heat of combustion in $\mathrm{J} / \mathrm{mol}$, Operating pressure in $\mathrm{kPa}$, Volume in $\mathrm{m}^{3}$, Temperature $(\mathrm{T})$ in ${ }^{0} \mathrm{C}$ and Heat of reaction in $\mathrm{kJ} / \mathrm{kg}$. $\mathrm{K}$ is a constant with value of 3.148 . The damage potential and the final fire and explosion index are measured as radius of impact in meters. In units where temperature varies as a function of length, temperature of decision was chosen to be the one that was maximum at any part of the length. The heat of combustion was calculated based on mole fraction of vapor phase in each equipment. NFPA rankings for flammability and reactivity were also calculated based on mole fractions. For equipment processing only gas, conditions at the end where the temperature is maximum is considered for calculation. 


\section{V.2. Ethane Cracking}

For safety analysis of ethane cracking technology, only the 8 main hydrocarbon compounds in the plant are considered. The detailed calculation sheet is attached in appendix. The base data on heat of combustion, flash point, auto ignition temperature and NFPA rankings are obtained from National Institute of Standards and Technology (NIST) handbook. The heat of reaction of reactors were calculated using values obtained from ASPEN simulation. Since reactors have change in composition with respect to length, the conditions at the state where maximum FEDI value is encountered is taken into consideration for calculation. After all the necessary design data were collected for calculating the safety index, the following results were obtained and are ranked in the descending order in Table 22.

Table 22: Equipment ranking based on FEDI values- Ethane cracking process.

\begin{tabular}{|c|l|l|r|}
\hline S. No & Equipment Class & Physical Units & $\begin{array}{c}\text { Fire and } \\
\text { Explosion } \\
\text { Damage } \\
\text { index }\end{array}$ \\
\hline 1 & Distillation Column & C2splitter-I & 1456 \\
\hline 2 & Distillation Column & C2splitter-II & 1456 \\
\hline 3 & Distillation Column & De-ethanizer & 1430 \\
\hline 4 & Heat Exchanger & Reboiler 2 & 1384 \\
\hline 5 & Heat Exchanger & Reboiler 1 & 1241 \\
\hline 6 & Heat Exchanger & Preheater & 1049 \\
\hline 7 & Heat Exchanger & Reboiler 3 & 1029 \\
\hline 8 & Heat Exchanger & Acetylene preheater & 1006 \\
\hline 9 & Heat Exchanger & Condenser 2-A & 976 \\
\hline 10 & Heat Exchanger & Condenser 2-B & 976 \\
\hline 11 & Tower & Caustic scrubber & 950 \\
\hline 12 & Reactor & Cracker & 945 \\
\hline
\end{tabular}


Table 22: Continued.

\begin{tabular}{|c|c|c|c|}
\hline S. No & Equipment Class & Physical Units & $\begin{array}{c}\text { Fire and } \\
\text { Explosion } \\
\text { Damage } \\
\text { index }\end{array}$ \\
\hline 13 & Reactor & Acetylene hydrogenation & 944 \\
\hline 14 & Distillation Column & De-methanizer & 932 \\
\hline 15 & Vessel & Dryer & 918 \\
\hline 16 & Heat Exchanger & Inter-stage cool4 & 912 \\
\hline 17 & Heat Exchanger & Inter-stage cool3 & 911 \\
\hline 18 & Heat Exchanger & Cool train hx2 & 911 \\
\hline 19 & Heat Exchanger & Refrigeration cooler & 911 \\
\hline 20 & Heat Exchanger & Cool train hx 1 & 910 \\
\hline 21 & Vessel & Flash drum 2 & 909 \\
\hline 22 & Compressor & 3rdstage compressor & 909 \\
\hline 23 & Compressor & 4th stage compressor & 908 \\
\hline 24 & Heat Exchanger & Inter-stage cool2 & 908 \\
\hline 25 & Vessel & Flash drum 1 & 907 \\
\hline 26 & Compressor & 2nd stage compressor & 907 \\
\hline 27 & Compressor & 1stage compressor & 897 \\
\hline 28 & Heat Exchanger & Transfer Line exchange & 896 \\
\hline 29 & Vessel & Cool-flash 1 & 804 \\
\hline 30 & Heat Exchanger & Cool train hx 5 & 792 \\
\hline 31 & Heat Exchanger & Cool train hx4 & 791 \\
\hline 32 & Heat Exchanger & Condenser 3-I-A & 774 \\
\hline 33 & Heat Exchanger & Condenser 3-I-B & 774 \\
\hline 34 & Heat Exchanger & Condenser 3-II-A & 774 \\
\hline 35 & Heat Exchanger & Condenser 3-II-B & 774 \\
\hline 36 & Heat Exchanger & Inter-stage cool $1 \mathrm{~A}$ & 713 \\
\hline 37 & Heat Exchanger & Inter-stage cool $1 \mathrm{~B}$ & 713 \\
\hline 38 & Heat Exchanger & Cool train hx3-C & 647 \\
\hline 39 & Heat Exchanger & Cool train hx3-A & 646 \\
\hline 40 & Heat Exchanger & Cool train hx3-B & 646 \\
\hline 41 & Heat Exchanger & Cool train hx6-A & 639 \\
\hline 42 & Heat Exchanger & Cool train hx6- B & 639 \\
\hline 43 & Column & Quench tower-1 & 635 \\
\hline 44 & Column & Quench tower-2 & 635 \\
\hline
\end{tabular}


Table 22: Continued.

\begin{tabular}{|c|l|l|r|}
\hline S. No & Equipment Class & Physical Units & $\begin{array}{c}\text { Fire and } \\
\text { Explosion } \\
\text { Damage } \\
\text { index }\end{array}$ \\
\hline 45 & Column & Quench tower-3 & 635 \\
\hline 46 & Vessel & Cool-flash 2 & 446 \\
\hline 47 & Heat Exchanger & Condenser 1 & 371 \\
\hline 48 & Heat Exchanger & Cool train hx9 & 362 \\
\hline 49 & Heat Exchanger & Cool train hx8 & 357 \\
\hline 50 & Heat Exchanger & Cool train hx 7 & 354 \\
\hline 51 & Vessel & Cool-flash 3 & 255 \\
\hline 52 & & Expander & 186 \\
\hline
\end{tabular}

From the results it can be seen that the $\mathrm{C} 2$ splitter columns are the more dangerous with highest impact radius, followed by de-ethanizer column and de-ethanizer reboiler. The preheater and cracker are essentially in the same unit, but since the index distinguishes different classes of equipment, they have been separated as convection section (preheater), where the feed is preheated and radiation section (cracker) where ethane dehydrogenation takes place respectively. Figure 17 shown below gives approximately the number of equipment that falls under each range of fire and explosion damage index. It can be seen that 17 out of 52 equipment fall under the category of $900<$ FEDI $<1000$, while 8 equipment fall under the range that has FEDI $>1000$. This chart gives us an approximate idea on which equipment we need to concentrate to improve safety. Effort should be taken at this stage to apply Inherent safety guidewords to modify the process and the procedure should be repeated to achieve lower impact radius. It should be noted that the value of index is a highly overestimated figure, since the units 
were not evaluated for any abnormal conditions. Hence, the magnitude does not literally imply the exact damage radius, but on a comparative basis, it indicates where each unit stands with respect to other equipment on inherent safety. Similarly those 7 equipment falling under the category of $400<$ FEDI $<200$ does not require much attention in terms of safety.

\section{Fire and Explosion Damage Index}

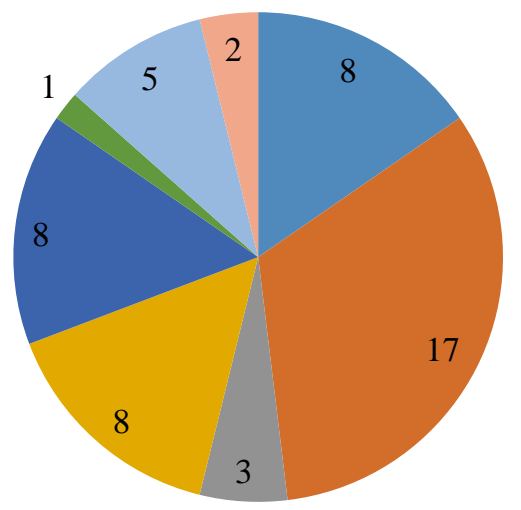

$$
\begin{aligned}
& \square \text { FEDI }>1000 \\
& \square 900<\text { FEDI }<1000 \\
& \square 800<\text { FEDI }<900 \\
& \square 700<\text { FEDI }<800 \\
& \square 600<\text { FEDI }<700 \\
& \square 500<\text { FEDI }<400 \\
& \square 400<\text { FEDI }<200 \\
& \square \text { FEDI }<200
\end{aligned}
$$

Figure 17: Distribution of equipment under various ranges of damage radiusEthane Cracking.

Figure 18 shows the semi-quantitative ranking of equipment. By using the semiquantitative chart of HIRA for deducing the final results, it can be seen that almost $83 \%$ of equipment are highly hazardous. This chart merely shows an analysis of how many equipment are highly hazardous and hence gives an overview of safety present in the 
process technology. The qualitative ranking will not be used for comparative study since it does not identify the areas of improvement accurately.

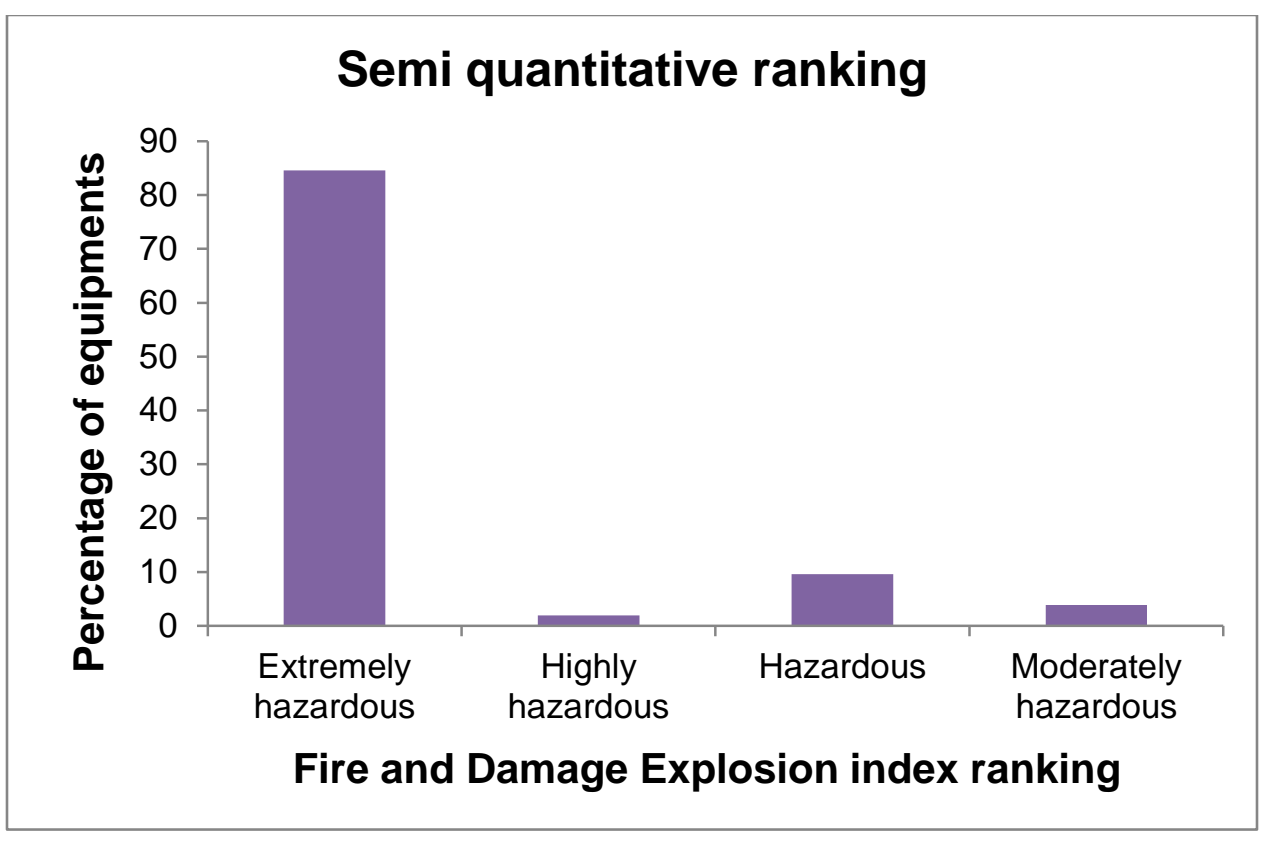

Figure 18: Semi-quantitative ranking based on HIRA method- Ethane Cracking.

Figure 19 shows the section wise ranking of top 5 most hazardous equipment of the process and this gives a detailed overview of areas of improvement in terms of safety. It can be seen that since cooling and separation has maximum number of equipment (32 nos.), this section is more hazardous because it consists of large number of dangerous equipment. The reason for large value of indices infer to be due to chemical composition, mass flow rate handled and chemical characteristics such as flammability, reactivity and heat of combustion. The general safety data sheet shows that heat of combustion values are high for ethylene, ethane, propylene, propane, butadiene 
and acetylene. It can be seen that since most of the products are purified in the separation section, the presence of the above mentioned chemicals in high quantities and in pure state, increases the impact of damage in the event of abnormal release. It can be seen within each section except for the compression section, there is difference in damage radius between units in same section. It can also be seen that magnitude of impact of $\mathrm{C} 2$ splitter column in separation section is approximately 1.5 times higher than caustic scrubber in compression section and preheater in pyrolysis section. This shows that $\mathrm{C} 2$ splitter column has be investigated first to identify the root cause of damage radius. One of the observation is that the effect of temperature and pressure difference between different units does not have a stark impact on the damage potential and this is a limitation of the index. Figure 20 showing the overall block diagram displays highest radius of impact of each unit and depicts how the damage radius varies along the process flow. 


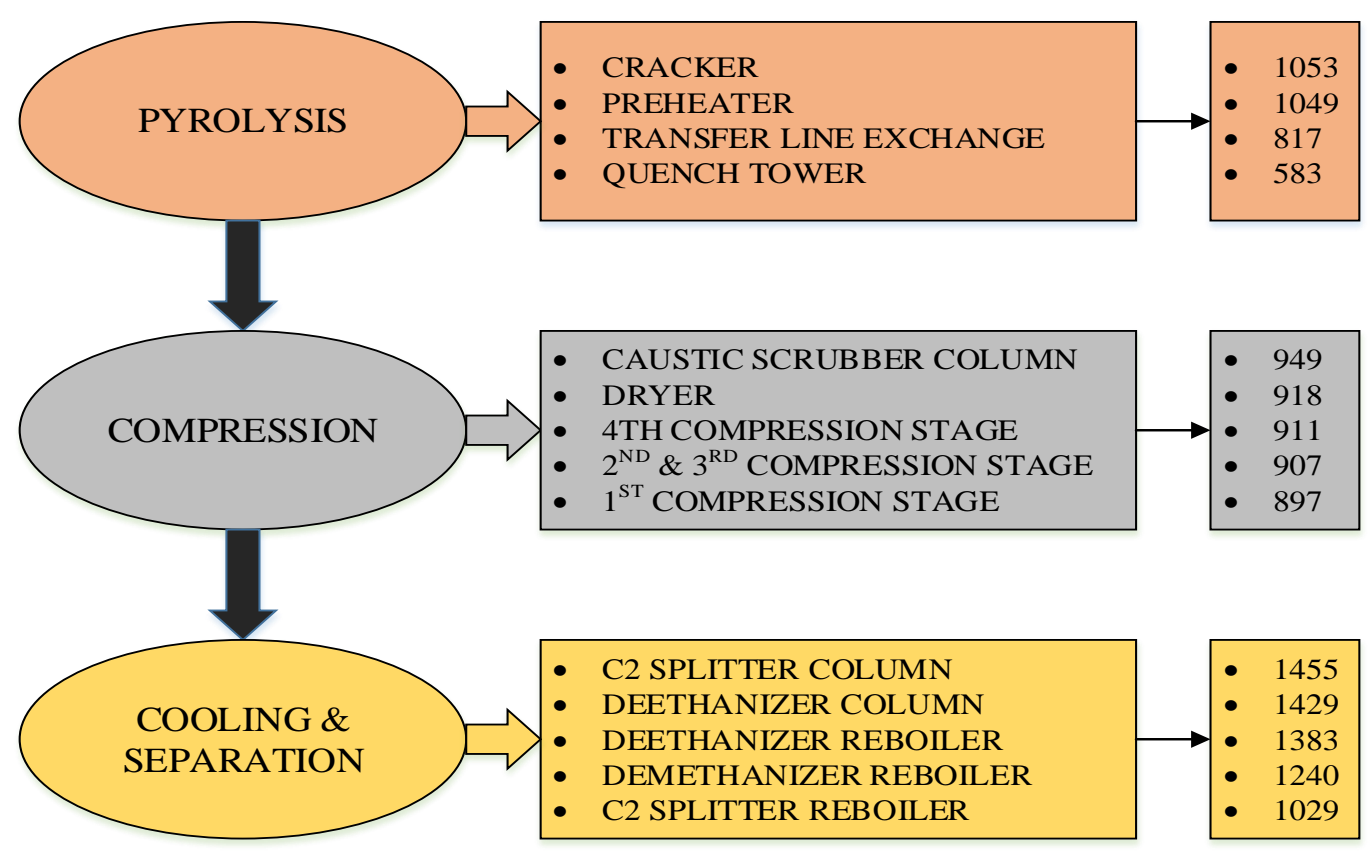

Figure 19: Section wise ranking of FEDI- Ethane Cracking.

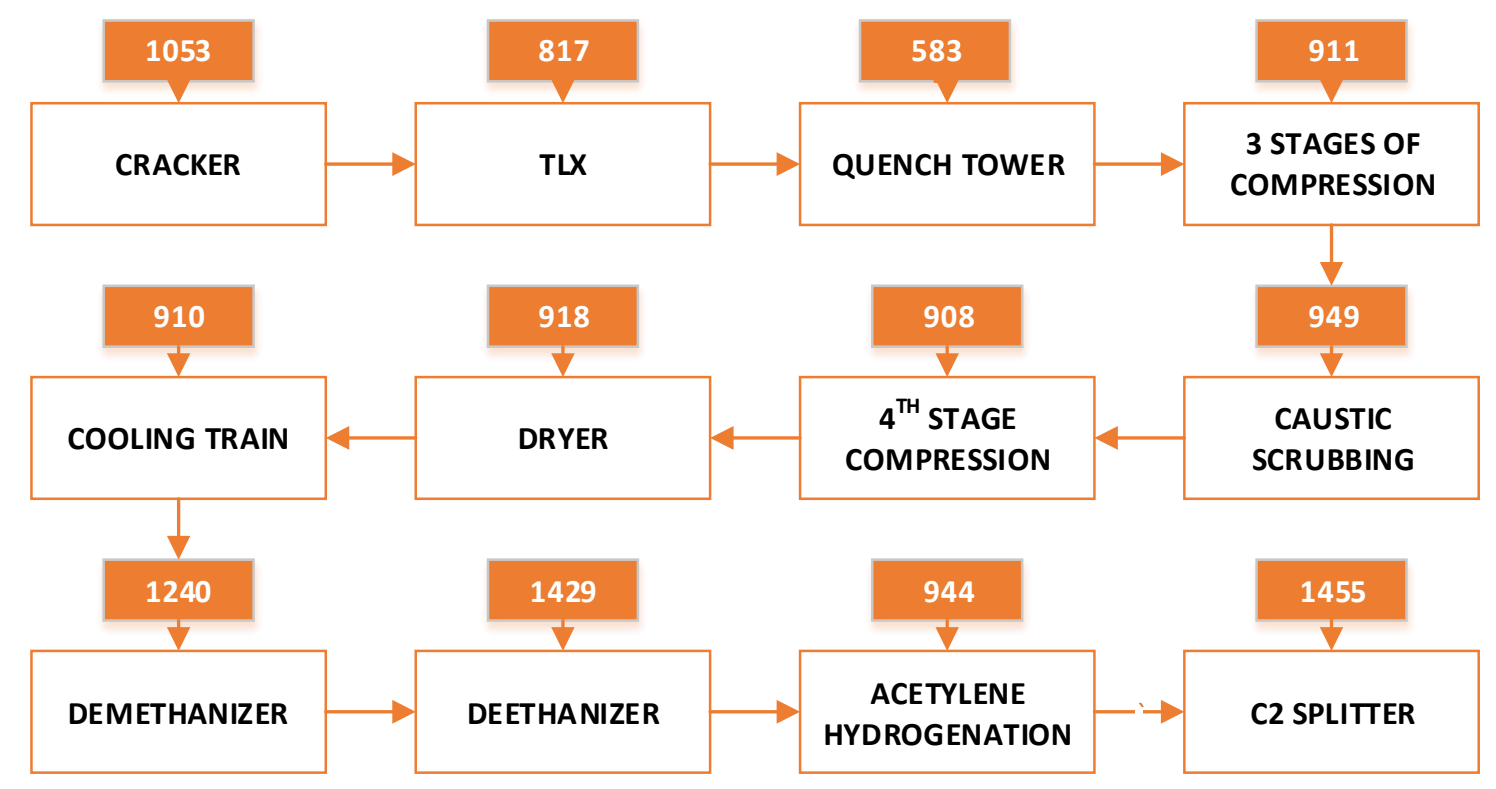

Figure 20: Overall block diagram of inherent safety levels- Ethane cracking. 


\section{V.3. Pyrolysis of Methane}

Safety analysis of GTE technology is carried out in a similar way as ethane cracking technology. The main compounds considered for calculation of safety index are methane, hydrogen, ethylene, acetylene, propadiene and carbon monoxide. Carbon monoxide is non-environmental friendly, toxic and also highly flammable. In this case study index will be calculated to account only for flammability and hence, only the flammable characteristics of carbon monoxide will be considered. The cracker is evaluated in the same way as ethane cracker. Since composition varies along the length, conditions at that state where calculated FEDI is higher is considered for analysis. Also mass release rate accounts only for hydrocarbons assumed for the safety analysis. The detailed calculation sheet is shown in appendix. Table 23 shows the equipment wise ranking in descending order. There are a total of 62 equipment in this process and the ranking table shows only the representative equipment for those that are in network of parallel equipments.

Table 23: Equipment ranking based on FEDI values- Methane Pyrolysis.

\begin{tabular}{|c|l|l|r|}
\hline S.No & Equipment Class & Physical Units & $\begin{array}{c}\text { Fire and } \\
\text { Explosion } \\
\text { Damage } \\
\text { index }\end{array}$ \\
\hline 1 & Cracker & Reactor & 1147 \\
\hline 2 & Furnace & Methane preheater & 1107 \\
\hline 3 & Heat Exchanger & Ethylene reboiler & 1104 \\
\hline 4 & Column & Ethylene column & 1104 \\
\hline 5 & Column & De-methanizer column & 1093 \\
\hline 6 & Heat Exchanger & De-methanizer reboiler & 1061 \\
\hline 7 & Compressor & 3rd stage compressor & 943 \\
\hline
\end{tabular}


Table 23: Continued.

\begin{tabular}{|c|c|c|c|}
\hline S.No & Equipment Class & Physical Units & $\begin{array}{c}\text { Fire and } \\
\text { Explosion } \\
\text { Damage } \\
\text { index }\end{array}$ \\
\hline 8 & Vessel & Cool flash 2 & 915 \\
\hline 9 & Vessel & Cool flash 1 & 910 \\
\hline 10 & Compressor & 2nd stage compressor & 910 \\
\hline 11 & Compressor & 1st stage compressor & 897 \\
\hline 12 & Heat Exchanger & Interstage cool 5 & 863 \\
\hline 13 & Compressor & 4th stage compressor & 861 \\
\hline 14 & Compressor & 5th stage compressor & 861 \\
\hline 15 & Column & Solsep column & 857 \\
\hline 16 & Heat Exchanger & Ethylene condenser (2 nos.) & 836 \\
\hline 17 & Column & Amine absorber ( 2 nos.) & 812 \\
\hline 18 & Heat Exchanger & De-methanizer condenser ( 2 nos.) & 773 \\
\hline 19 & Vessel & Pressure swing absorption & 766 \\
\hline 20 & Heat Exchanger & Intercool stage 3 ( 2 nos.) & 752 \\
\hline 21 & Vessel & Flash net 1 & 752 \\
\hline 22 & Column & NMP absorption (3 nos.) & 748 \\
\hline 23 & Vessel & Flash net 7 & 658 \\
\hline 24 & Vessel & Flash net 2 & 647 \\
\hline 25 & Heat Exchanger & Intercool stage 2 (3 nos.) & 633 \\
\hline 26 & Vessel & Flash net 6 & 601 \\
\hline 27 & Heat Exchanger & Flash stage cool 6 & 599 \\
\hline 28 & Heat Exchanger & Solsep condenser (3 nos.) & 586 \\
\hline 29 & Heat Exchanger & Intercool stage 1 (4 nos.) & 567 \\
\hline 30 & Heat Exchanger & Flash stage 1 heater & 562 \\
\hline 31 & Vessel & Flash net 3 & 560 \\
\hline 32 & Vessel & Flash net 5 & 556 \\
\hline 33 & Heat Exchanger & Flash stage cool 5 & 554 \\
\hline 34 & Heat Exchanger & Flash stage cool 4 & 532 \\
\hline 35 & Heat Exchanger & Flash stage 2 heater & 443 \\
\hline 36 & Heat Exchanger & Flash stage 3 heater & 388 \\
\hline 37 & Vessel & Flash net 4 & 356 \\
\hline 38 & Column & Spray tower (10 nos.) & 349 \\
\hline 39 & Acetylene hydrogenation & Reactor & 210 \\
\hline 40 & Heat Exchanger & Solsep reboiler & 33 \\
\hline 41 & Furnace & Oxygen preheater & 17 \\
\hline
\end{tabular}


From the safety analysis results, we can see that Cracker/ reactor is most hazardous unit operation in the process. This is followed by methane preheater and then ethylene reboiler. Though the residence time of cracker is small leading to a small volume equipment, the amount of gas processed and operating temperature are high. Pyrolysis, Compression, Solvent Separation and Product separation section consists of 4, 12, 19 and 6 equipment respectively. Though the pyrolysis section consists of only 4 equipment, the magnitude of damage for 2 equipment, is very high. Hence, pyrolysis section may be considered more hazardous.

The number of equipment for different range of FEDI values were plotted. This is shown in Figure 21. It can be seen that 6 out of 62 equipment (around 9.5\%) have damage radius more than 1000 meters. More number of equipment fall under the category of 500- 600 and 200-400 range of FEDI values. Necessary area of focus needs to be given to those equipment in the higher range for safety improvement. It should be noted that cracker reactor is also highly energy intensive and most hazardous. A semi quantitative ranking based on HIRA ranking methodology is plotted to gain insight into the whole process. This is shown in Figure 22. It can be seen that almost $75 \%$ of equipment in the process are extremely hazardous. Proper ISD approaches should be applied to these equipment to find out opportunities for enhancing safety. Since GTE technology is a relatively new technology, there exists huge benefits of analyzing the process at this stage to make it inherently safer and process efficient. 


\section{Fire and Explosion Damage Index}

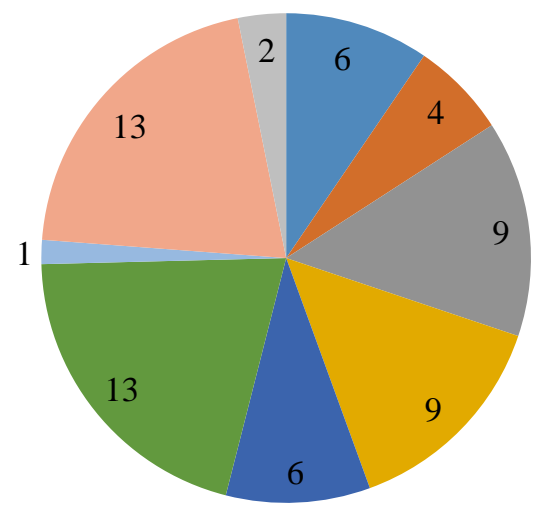

$$
\begin{aligned}
& \square \text { FEDI }>1000 \\
& \square 900<\mathrm{FEDI}<1000 \\
& \square 800<\mathrm{FEDI}<900 \\
& \square 700<\mathrm{FEDI}<800 \\
& \square 600<\mathrm{FEDI}<700 \\
& \square 500<\mathrm{FEDI}<600 \\
& 400<\mathrm{FEDI}<500 \\
& \square 200<\mathrm{FEDI}<400 \\
& \square \mathrm{FEDI}<200
\end{aligned}
$$

Figure 21: Distribution of equipment under various ranges of danage radiusMethane pyrolysis.

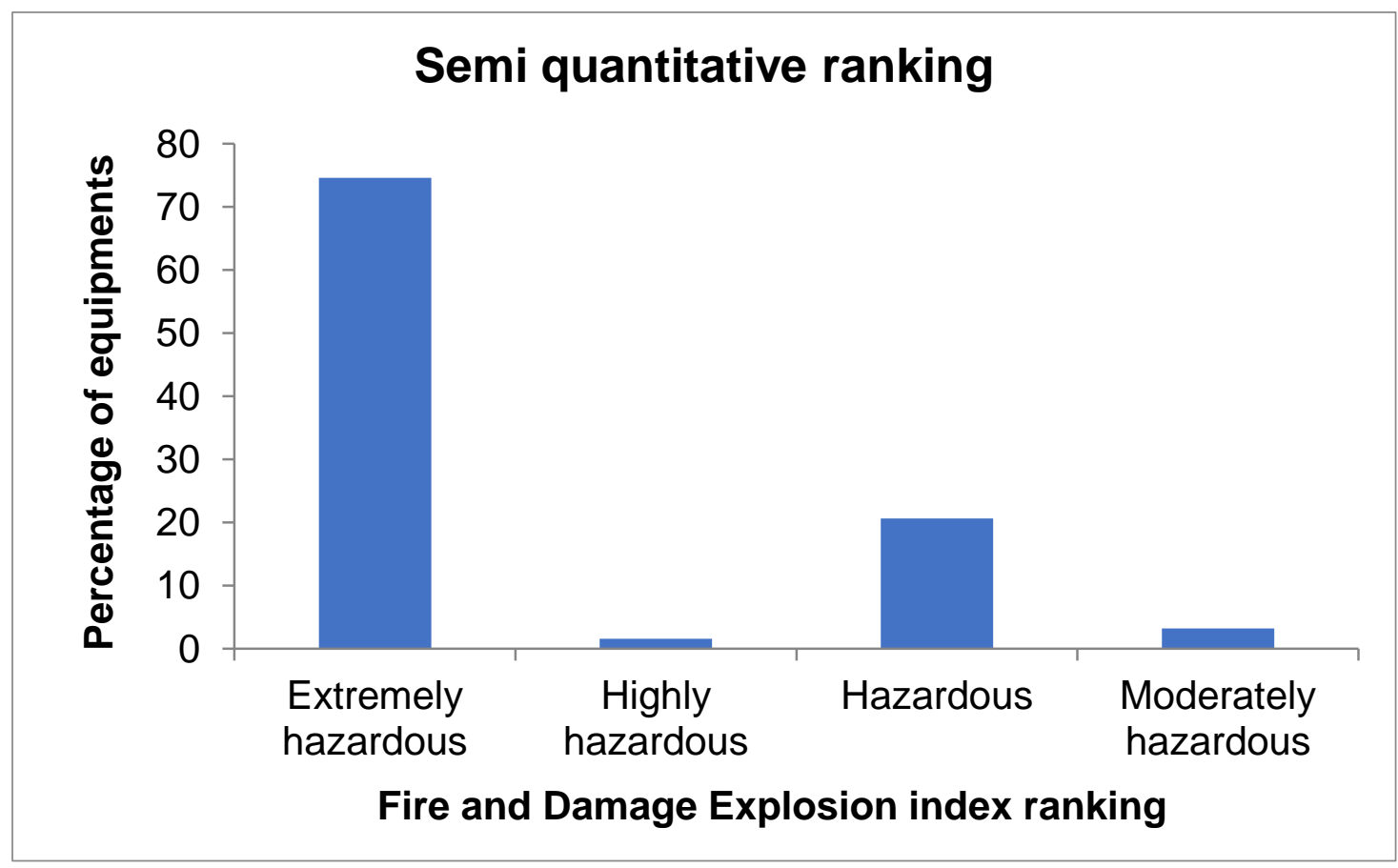

Figure 22: Semi-quantitative ranking based on HIRA method- Methane pyrolysis. 
The section wise ranking of equipment is illustrated by Figure 23. It can be seen that in the pyrolysis section, cracker has highest damage potential followed by methane preheater. The remaining equipment in the pyrolysis section are safer. Analysis of compression section shows that all the compressors have an impact radius around $900 \mathrm{~m}$. The $3^{\text {rd }}$ compressor is highest because of increase in acetylene concentration and other lighters. In the solvent separation section, the SOLSEP column has highest damage potential, followed by flash stages that have higher mole percent of hydrocarbon in their vapor streams. Similarly, in product separation section ethylene column and reboiler are more hazardous than de-methanizer column.

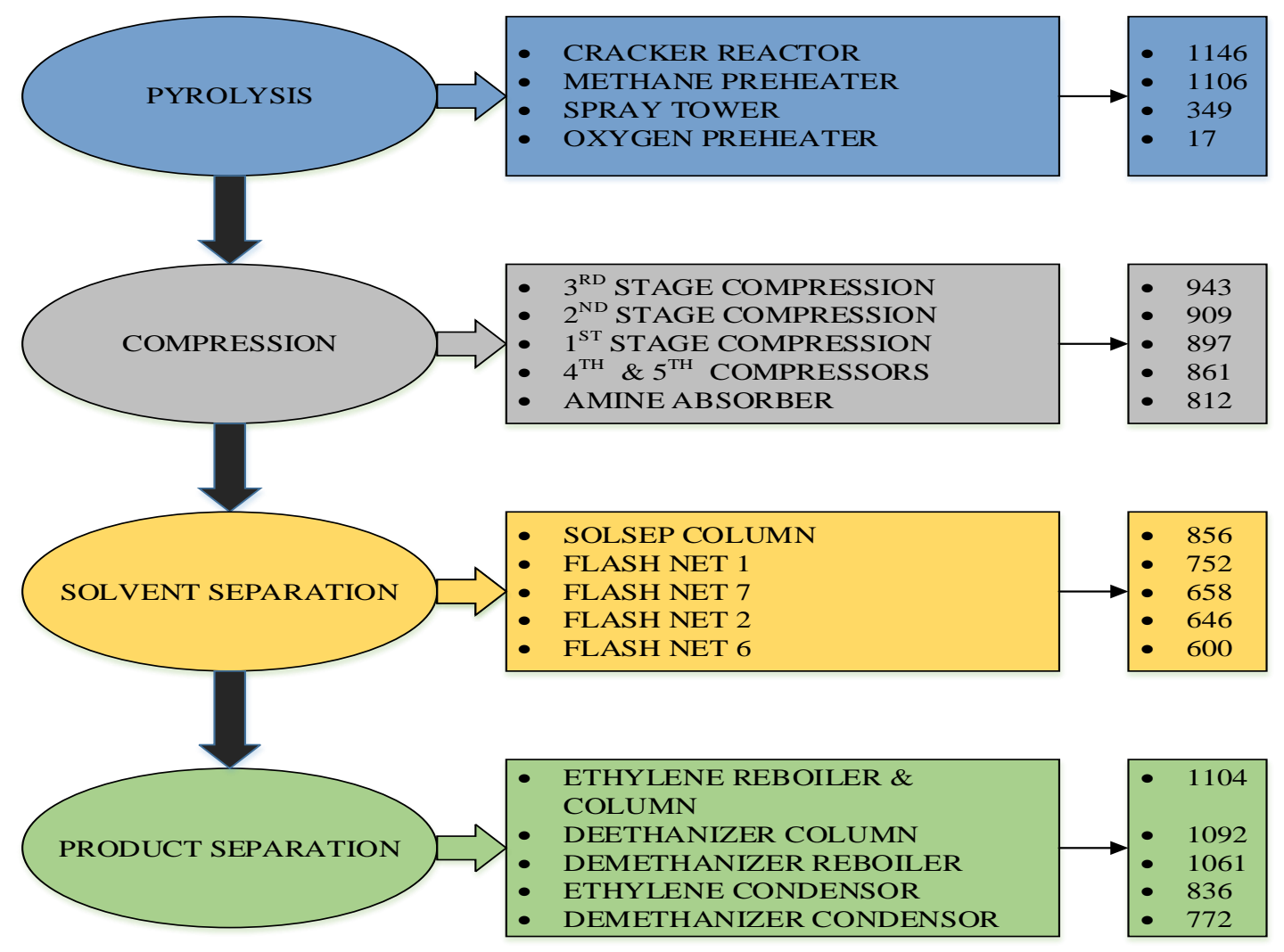

Figure 23: Section wise ranking of FEDI- Methane Pyrolysis. 
From the figure, it can be inferred that almost all the high ranked equipment in each section have same radius of impact. Once again, the magnitude does not reflect the exact damage index but instead sheds some knowledge about the parameters that affect the impact radius. The main parameters that affect the impact radius are flammability, heat of combustion, gas composition, mass flow rate and penalties for temperature and pressure.

The block diagram displayed in Figure 24 shows how the impact radius varies along the process flow. It can be seen that starting from cracker, the FEDI value decreases at Spray tower and the increases. This is because Spray tower section consists of 10 parallel networks of equipment due to design considerations. This once again proves that reduction in size increases safety. It can be well noted that the safety index of acetylene hydrogenation is very low in the range of 200 . This is because the hydrogenation reaction is carried out in liquid phase and only the vapor phase containing hydrogen is considered for analysis. Starting from solvent separation the FEDI values increase due to increase in concentration of pure hydrocarbons. 


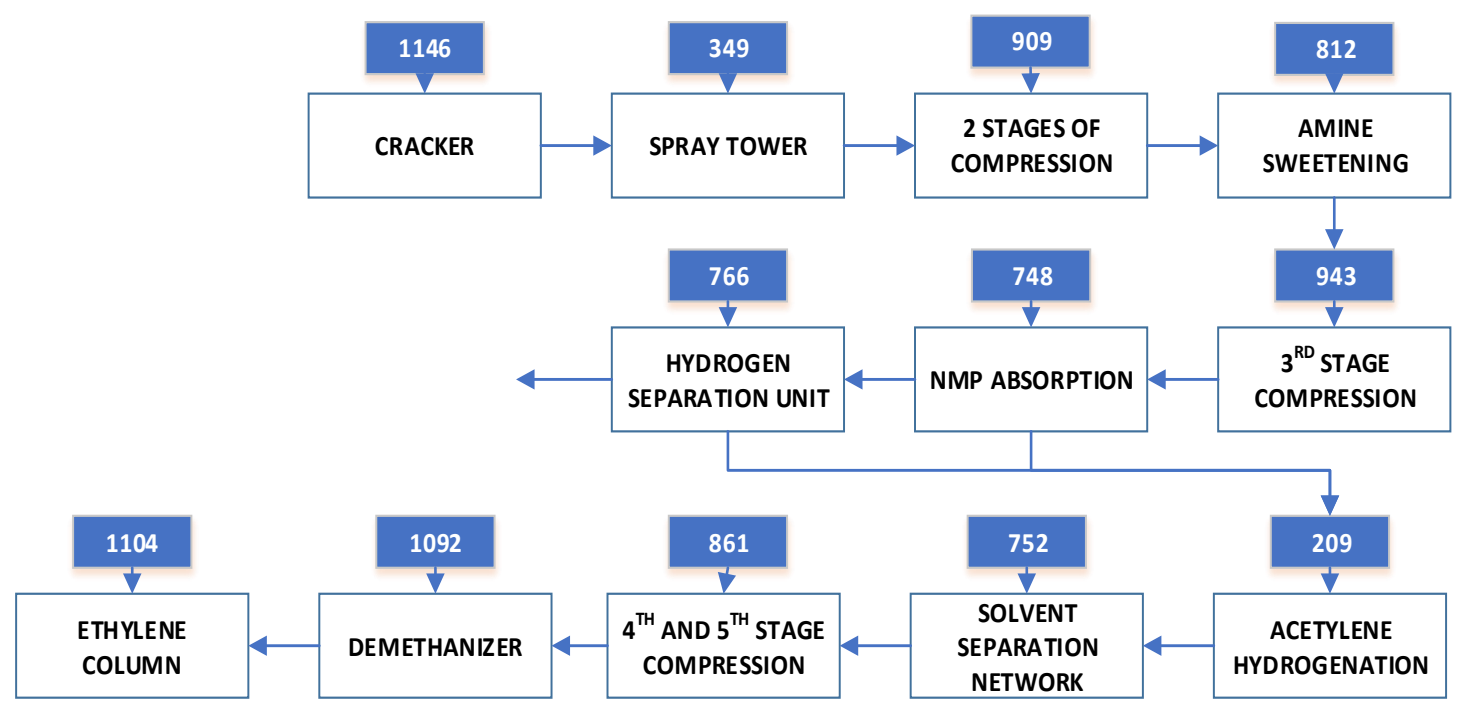

Figure 24: Overall block diagram of inherent safety levels- Methane pyrolysis. 


\section{CHAPTER VI}

\section{RESULTS AND DISCUSSION}

From the previous chapters, results of techno-economic and safety analysis were discussed separately for each base case. In this chapter, the overall objective of this research is achieved by comparing both the processes to identify the superior process that balances process performance, economics of operation and inherent safety. Each analysis was performed by applying same techniques and assumptions so that a reasonable comparison can be made. For the same reason, ethylene production rate of 830,000 Tonnes/annum is considered as the basis of process simulation for both the plants. The final results are obtained by comparing the key performance indicators of each metrics.

\section{VI.1. Process Metrics}

The key process metrics that are compared are process yield, specific consumption of raw material, conversion, minimum energy requirements and specific energy consumption. Both the plants are optimized and simulated to produce $99.9 \mathrm{wt} \%$ pure ethylene. The results of the analysis are shown below in Table 24. From the comparative table, it can be clearly seen that process performance of ethane cracking technology is better than the methane pyrolysis. The process yield of methane pyrolysis is considerably low because of the requirement of part of the natural gas to be used as fuel in order to generate enough heat required to crack methane. Hence, this also 
increases the specific consumption of raw material of natural gas to produce ethylene. Another reason for the specific consumption of methane to be very high is because the methane crackers are once through reactors. Since most of the methane is burned, recovery of methane in the final product purification level is relatively insignificant and hence, there is no feed recycle unlike ethane cracking process, where unconverted ethane is recovered and recycled back to the reactor. It can also be seen that the product recovery in ethane cracking technology is higher than methane pyrolysis. This is dictated by optimized use of external solvent and energy required for separation.

Table 24: Comparison of process performance metrics.

\begin{tabular}{|c|l|c|c|c|}
\hline S.No & \multicolumn{1}{|c|}{ Parameters } & $\begin{array}{c}\text { Ethane } \\
\text { Cracking }\end{array}$ & $\begin{array}{c}\text { Methane } \\
\text { Pyrolysis }\end{array}$ & UOM \\
\hline 1 & Process yield of ethylene & 85 & 25 & $\%($ mass basis) \\
\hline 2 & $\begin{array}{l}\text { Specific consumption of raw } \\
\text { material }\end{array}$ & 1.2 & 4 & $\begin{array}{c}\text { Tonne of raw } \\
\text { material/tonne } \\
\text { of product }\end{array}$ \\
\hline 3 & Conversion of raw material & 60 & 33 & $\%$ (mass basis) \\
\hline 4 & Product recovery & 99 & 96 & $\%($ mass basis) \\
\hline 5 & Minimum energy requirements & 2446 & 6252 & MMBtu/hr \\
\hline 6 & Minimum heating requirements & 1112 & 1244 & MMBtu/hr \\
\hline 7 & Minimum cooling requirements & 1200 & 4546 & MMBtu/hr \\
\hline 8 & Specific energy consumption & 26 & 66 & $\begin{array}{c}\text { MMBtu/tonne } \\
\text { of ethylene }\end{array}$ \\
\hline
\end{tabular}

In terms of energy requirements, it is clear that ethane cracking requires less energy than methane pyrolysis. The underlying fact is that majority of the energy requirements in methane pyrolysis is contributed by quench water in the reactor, which 
is used for bringing down the temperature of the reactor immediately to stop carbon decomposition reaction. Since this requires very less residence time, large amounts of cooling water needs to be used and this increases cooling requirements of quench water. The reasons can be attributed mainly due to process chemistry requiring high temperatures for producing acetylene and insufficient heat recovery systems. This paves way for modification in the process chemistry such that acetylene is produced at less intensive operating conditions or heat recovery systems be introduced such that a proper heat integration network is formed that will significantly reduce external energy consumption.

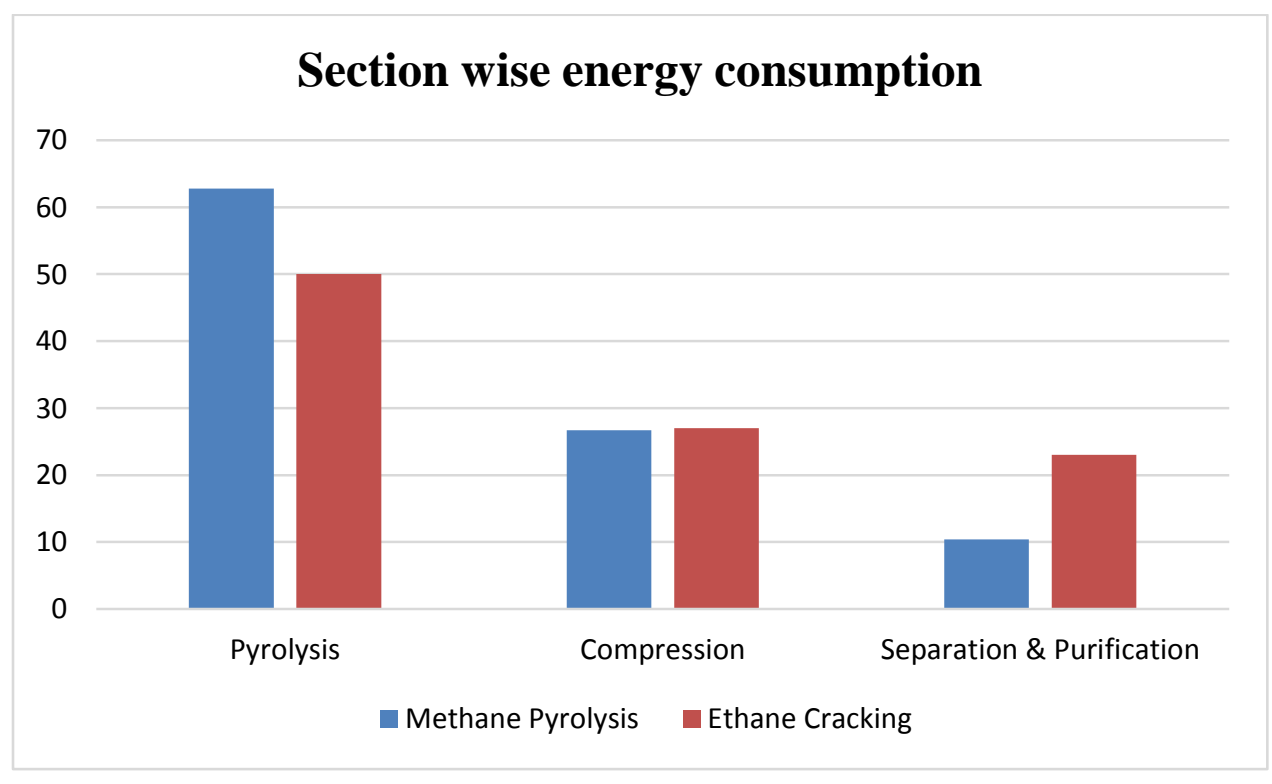

Figure 25: Comparison of section-wise energy consumption. 
A section wise comparison of specific energy consumption is illustrated by Figure 25. In the pyrolysis section, Methane pyrolysis has contribution to specific energy consumption when compared to ethane cracking process. This is attributed to high reactor temperature and cooling requirements. Input to specific energy consumptions of compression section are almost same for both the plants. It can be seen that percentage of specific energy consumed is higher for ethane cracking process when compared to methane pyrolysis. The reason can be attributed due to cryogenic operations required for separation of purification of products in ethane cracking technology. It is to be noted that solvent separation and product purification sections in methane pyrolysis plant have been clubbed into separation and purification section.

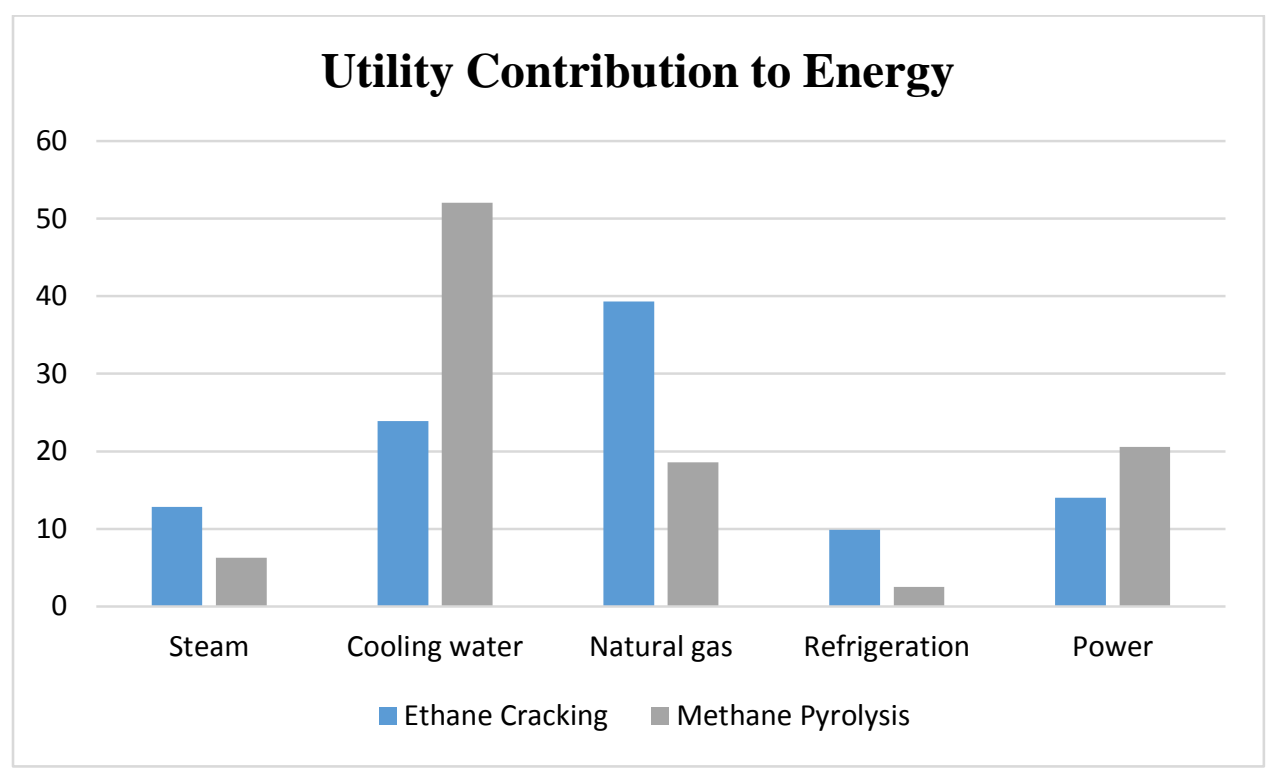

Figure 26: Comparison of utility consumption. 
Figure 26 shows individual contribution of each utility to the total energy requirements is shown below. Methane pyrolysis utilizes almost $50 \%$ of energy requirements from cooling water, followed by power required for compression. Ethane cracking technology utilizes more natural gas for energy requirements, followed by steam and power. It can be clearly seen that refrigeration demands in ethane cracking process is higher than methane pyrolysis, leading to higher energy cost.

\section{VI.2. Economic Metrics}

The main cost metrics that decide which process is more economically viable are cost of energy, raw material cost, total operating cost and fixed capital cost. In order to justify comparison of both the processes, same cost of utility have been chosen. The prices of raw material are taken as an average value of natural gas and natural gas liquids trends in the EIA website. The results of the economic comparison are shown below in Table 25.

Table 25: Comparison of economic metrics.

\begin{tabular}{|c|l|r|r|l|}
\hline S.No & \multicolumn{1}{|c|}{ Parameters } & \multicolumn{1}{|c|}{$\begin{array}{c}\text { Ethane } \\
\text { Cracking }\end{array}$} & \multicolumn{1}{|c|}{$\begin{array}{l}\text { Methane } \\
\text { Pyrolysis }\end{array}$} & \multicolumn{1}{|c|}{ UOM } \\
\hline 1 & Energy Cost & 526.6 & 598.5 & Million \$/year \\
\hline 2 & Raw material cost & 195.2 & 803.1 & Million \$/year \\
\hline 3 & Total operating cost & 721.8 & 1421.7 & Million \$/year \\
\hline 4 & Fixed Capital Cost & 870.8 & 385.1 & Million \$/year \\
\hline 5 & EGP & 1141.1 & 533.1 & Million \$/year \\
\hline
\end{tabular}


From the table, it can be seen that Ethane cracking process has more economic advantage over methane pyrolysis process. The total operating cost of methane pyrolysis is almost twice that of ethane cracking process. This is because of the high rates of natural gas consumption and external solvent makeup involved in the process. Also, the study does not include cost of a separate air separation unit, but instead accounts for cost of oxygen as a raw material. Addition of air separation unit will increase the fixed cost but there will be no significant reduction in the total operating cost. It can be seen that the fixed capital cost of Methane pyrolysis is much lower than ethane cracking. This is because, the reaction chemistry involved is not much complex and does not involve much hydrocarbons that require rigorous separation processes. The use of selective absorption of acetylene and conversion of acetylene to ethylene in liquid phase, has decreased the fixed cost considerably due to ease of separation of product from the solvent. Also the fixed capital cost of methane pyrolysis may be an underestimation of the actual cost since other minor unit operations such as pumps, blowers, and other utility unit operations have not been accounted in the calculation. Nevertheless, the huge difference in fixed capital cost of both plants emphasize that this error of underestimation can be neglected thus, proving that fixed capital cost of methane pyrolysis is lower than ethane cracking process.

Another important analysis that can be inferred from cost of energy is that though the minimum energy requirements of methane pyrolysis plant were very high, the operating cost of both the plants are almost same. This is because the utility price of cooling water is cheaper and even though requirement of cooling water is very high in 
this plant, the low price offsets the energy cost. Whereas in the ethane cracking technology, refrigeration demands are very high leading to increase in energy cost because the cost of refrigeration is $\$ 20$ / MMBtu when compared to cooling water cost of \$2/ MMBtu. Moreover off- gas generation in GTE process is very high thus, reducing external fuel consumption required for furnaces and boilers. Also, it can be understood that Economic gross potential of ethylene from ethane cracking is much higher than from methane pyrolysis, once again showing that raw material consumption of methane is very high in the second process.

\section{VI.3. Safety Metrics}

The individual plant safety metrics for each equipment were evaluated and analyzed. The comparative study was done based on highest ranking of equipment that are more hazardous, section wise ranking of equipment and proportion of hazardous equipment in the entire process. All the safety assumptions made were applied equally to both the plants. Design data required for safety analysis were also evaluated in the similar way for both the processes. Table 26 given below shows top 5 equipment with highest FEDI rankings in each plant.

Table 26: Comparison of inherent safety levels.

\begin{tabular}{|c|l|c|c|c|}
\hline \multirow{2}{*}{ Ranking } & \multicolumn{2}{|c|}{ Ethane Cracking } & \multicolumn{2}{c|}{ Methane Pyrolysis } \\
\cline { 2 - 5 } & \multicolumn{1}{|c|}{ Equipment } & FEDI & Equipment & FEDI \\
\hline 1 & C2splitter & $\mathbf{1 4 5 4}$ & Cracker reactor & $\mathbf{1 1 4 7}$ \\
\hline 2 & De-ethanizer & 1430 & Methane preheater & 1107 \\
\hline
\end{tabular}


Table 26: Continued.

\begin{tabular}{|c|l|c|l|c|}
\hline \multirow{2}{*}{ Ranking } & \multicolumn{2}{|c|}{ Ethane Cracking } & \multicolumn{2}{c|}{ Methane Pyrolysis } \\
\cline { 2 - 5 } & \multicolumn{1}{|c|}{ Equipment } & FEDI & Equipment & FEDI \\
\hline 3 & De-ethanizer reboiler & 1384 & Ethylene reboiler & 1104 \\
\hline 4 & De-methanizer reboiler & 1241 & Ethylene column & 1104 \\
\hline 5 & Cracker reactor & 1053 & De-methanizer column & 1093 \\
\hline
\end{tabular}

From the results, it is evident that Methane pyrolysis process is relatively inherently safer than the ethane cracking process, since the magnitude of impact of $1^{\text {st }}$ ranked equipment of methane pyrolysis is lower than the one in ethane cracking process. The main parameters that attribute to this difference in impact are mass of flammable chemical handled, chemical characteristics of chemicals, temperature, heat of combustion of each chemical and gas composition. It is to be noted that C2splitter in ethane cracking operates at 19 bar pressure and $-31{ }^{\circ} \mathrm{C}$ top temperature, while reactor in methane pyrolysis operates at $1500{ }^{\circ} \mathrm{C}$ and 1 bar pressure. Effects of temperature, partial pressure, chemical composition and mass flow rate have a pronounced effect on above mentioned equipment.

Similarly due to above mentioned parameters, it can be seen that Ethane cracker has less damage radius than methane pyrolysis. The acetylene hydrogenation reactor in ethane cracking process has an FEDI value of 944 meters while the one in methane pyrolysis has a value of 209 meters. This stark difference can be contributed to the consideration of only vapor phase since acetylene hydrogenation in ethane cracking is gas phase reaction whereas in methane pyrolysis, it is governed by liquid phase reaction. 
This shows an example of reduction in process intensification thus proving that inherent safety approach of design is effective.

The section wise ranking of both the plants are shown below in Table 27. From the results, it is evident that pyrolysis section of ethane cracking is less hazardous than methane pyrolysis plant. Transfer line exchange and Spray tower have similar purpose of operation in both the processes. The huge difference in the value of FEDI for both the equipment can be attributed mainly to the operating temperature. The compression section of both the plants have almost same impact radius. Compressors in methane pyrolysis plant rank higher than the ones in ethane cracking plant.

In the separation and purification section, it can be observed that the most hazardous equipment in both the technologies have similar operating conditions and are involved in separation of product. The difference in damage radius of ethylene column in methane pyrolysis and C2splitter column in ethane cracking is due to large vapor load rate present in C2splitter. C2splitter separates ethylene from ethane while ethylene column separates ethylene from Propadiene. Since ethane and ethylene are close boiling points, separation requires large number of trays and reflux ratios and hence, the vapor load of the column is high. The separation of ethylene from Propadiene is relatively easy and this leads to less vapor load. Another factor to be considered is the quantity of feed mixture handled.

The above analysis in the section wise ranking gives insight into the process and this enables easy interpretation of process with safety. This aids in selecting a suitable separation method and also allocation of units in the process flow. 
Table 27: Section-wise comparison of FEDI values.

\begin{tabular}{|c|c|c|c|c|}
\hline \multirow{2}{*}{ Section } & \multicolumn{2}{|c|}{ Ethane Cracking } & \multicolumn{2}{|c|}{ Methane Pyrolysis } \\
\hline & Equipment & FEDI & Equipment & FEDI \\
\hline \multirow{3}{*}{ Pyrolysis } & Cracker reactor & 1053 & Cracker Reactor & 1147 \\
\hline & Preheater & 1049 & Methane Preheater & 1106 \\
\hline & Transfer Line exchange & 817 & Spray Tower & 349 \\
\hline \multirow{3}{*}{ Compression } & Caustic scrubber & 949 & $\begin{array}{l}\text { 3rd stage } \\
\text { compression }\end{array}$ & 943 \\
\hline & Dryer & 918 & $\begin{array}{l}\text { 2nd stage } \\
\text { compression }\end{array}$ & 909 \\
\hline & 4th stage compression & 911 & $\begin{array}{l}\text { 1st stage } \\
\text { compression }\end{array}$ & 897 \\
\hline \multirow{3}{*}{$\begin{array}{c}\text { Separation } \\
\text { and } \\
\text { Purification }\end{array}$} & C2 splitter column & 1455 & $\begin{array}{l}\text { Ethylene column } \\
\text { \& reboiler }\end{array}$ & 1106 \\
\hline & De-ethanizer column & 1429 & $\begin{array}{l}\text { De-methanizer } \\
\text { column }\end{array}$ & 1092 \\
\hline & De-methanizer reboiler & 1383 & $\begin{array}{l}\text { De-methanizer } \\
\text { reboiler }\end{array}$ & 1061 \\
\hline
\end{tabular}

From the semi quantitative charts shown in previous chapters, it can be observed that approximately $86 \%$ of equipment in ethane cracking process are extremely hazardous while $76 \%$ of equipment in methane pyrolysis are extremely hazardous. This again proves that methane pyrolysis is inherently safer than ethane cracking process. Moreover, the number of equipment in the higher range of FEDI (>800 meters) is higher in ethane cracking process than in methane pyrolysis process. This analysis can be helpful in providing focus on those areas where process improvement needs to be achieved. From the above discussed safety analysis it can also be inferred that splitting equipment for design considerations caused significant reduction in damage radius. This proves effectiveness of inherent safety design principles. 
From the above comparative study it can be understood that a top level comparative study of process, economics and safety can provide significant insights into the process for improvement in all of the above mentioned areas. The approach used for this research has proved to be effective in identifying grey areas and has also enabled easy interpretation of the results thereby, clearly revealing the root causes of discrepancies in metrics. The analysis shows that ethane cracking process is better in terms of process performance and economics while methane pyrolysis is better in terms of inherent safety. This proves the current trends of new projects proposed for installation of ethane crackers to produce ethylene. Ethane cracking technology is a wellestablished, saturated technology and the opportunities for process improvement are very less. Meanwhile, gas to ethylene process is a relatively new technology where there exists huge opportunities for improvement. Though process performance and economics parameters of this technology are poor when compared to ethane cracking process, appropriate process modifications and material and heat integration can be applied to improve the process such that safety of the process is improved. 


\section{CHAPTER VII}

\section{CONCLUSION AND RECOMMENDATIONS}

In this research, a top level techno-economic and safety analysis of two technologies producing ethylene, namely the ethane steam cracking and gas to ethylene processes (Methane pyrolysis) was carried out. The results obtained from this analysis show that the ethane cracking process is more process efficient and economically superior while the gas to ethylene is more inherently safer. The approach adopted for carrying out the analysis was aimed at identifying areas of process improvement and key safety parameters at a preliminary stage of design while weighing the economic advantages. The results clearly prove that ethane to ethylene cracking technology is more widely adapted due to process and economic benefits. At the same time it is inferred that the new gas to ethylene technology has more scope of process improvement and requires detail analysis on the process to improve operating efficiency. The early stage approach used in this thesis has served to reason out different options available for producing a chemical utilizing minimum process information and this can help take better future decisions that accounts for technology, cost as well as inherent safety.

From the general methodology of evaluation and results obtained from the study, it is evident that safety has a direct impact on energy consumption and operating cost. This enables easy interpretation of process modifications if safety is measured along with other parameters in the preliminary stages. The limitations of this approach will be availability of suitable indices that can measure inherent safety and huge amount of time 
and resource spent on evaluation methods at preliminary stage. The study can be expanded to identify different safety indices that measure inherent safety needing minimum process information and the results can be compared to support the decision making process. Finally, time and resources invested at the initial stage can prove to be worthy by choosing inherently safer and economically superior process.

Based on the results obtained, the following observations and recommendations are made that would address the methods of measurement of different metrics, identification of key performance variables and root causes of hazards.

i. The safety index, HIRA chosen is identified to be flexible in eliminating those factors that are not essential at the early stage and hence can serve as a suitable index for measuring inherent safety.

ii. Inclusion of safety analysis in the traditional techno-economic comparison of two processes provides more insight into the technology and sparks novel ideas for improving or integrating technologies to achieve better decision making. Though the gas to ethylene process does not have a good process or economic potential, low inherent safety levels of the process creates more necessity to improve the process in terms of cost and technology.

iii. The assumptions made for safety calculations namely accounting only for vapor phase, can be modified to suit different application of process based on solid or fluid handling capability. 
iv. It is observed that the index has a subtle impact to changes in temperature and pressure, unless the operating conditions are variable with respect to flash point and auto ignition temperature. This does not give vital information about weak areas since most of chemicals in hydrocarbon industry are operated above flash points and the magnitude of temperature modification will not be properly reflected in safety index.

v. Similarly, since assumption of vapor phase is made for all unit operations, the role of pressure deviations will not be effected unless operating pressure is lesser than atmospheric pressure. This can be overcome by assuming mixed phase but it can prove to be difficult for evaluating complex operations such as absorption and distillation columns.

vi. The magnitude of damage potential does not merely point out the direct damage radius but it indicates the ranking of each equipment with other. This kind of analysis will help in identifying those equipment which require more attention in terms of safety and energy consumption.

vii. The above observations indicate that there is a need for invention of new safety indices that quantitatively measure process parameters while requiring less process information.

viii. The areas identified for process improvement should be analyzed further by applying four main design principles of inherent safety design, namely minimize, moderate, simplify and substitute. 
ix. The cooling and separation section of ethane cracking process needs to be studied further for possible alterations in process flow to reduce the damage radius of distillation columns. It is found that C2splitter is the most hazardous equipment hence, substitution of another separation process or splitting of parallel streams should be analyzed for reducing energy consumption as well as improving safety.

x. Ethane cracking technology has other separation schemes such as front end de-propanizer, front end de-ethanizer and front end acetylene hydrogenation.(Takaoka, 1967) The scheme used for this study was front end de-methanizer. This study can be expanded to analyze all different schemes for inherent safety and choose that separation scheme that is inherently safer.

xi. The advantage of using methane pyrolysis technology is that it is a simple process and has an energy efficient and inherently safer product separation process when compared to ethane cracking process. The front end part of the process involving production of acetylene is the portion that needs focus on safety and process improvement. Studies show that different types of heat transfer methods can be used for pyrolysis of methane. All of these methods also have high energy demands due to large requirements of reaction temperatures, but a study can be done to compare different processes that can yield less impact on safety and energy consumption. 
xii. Since majority of the operating cost of methane pyrolysis plant is due to large consumption of natural gas, this technology can prove to be cost efficient in places where natural gas is stranded thus, reducing much of raw material cost.

xiii. Alternatively, methane pyrolysis technology can prove to be feasible on being coupled with plants that produce either of raw materials (oxygen or methane) or utilize the off gas generated in the process to produce some other value added chemical. This either offsets the cost of raw material or increases the product value thus, causing an increase in economic gross potential.

xiv. Since off-gas generated in methane pyrolysis process has large amounts of hydrogen and carbon monoxide, a feasibility study of integrating syngas to gasoline or Fischer Tropsch process can be studied. Hence, methane pyrolysis might have an economic potential on a plants-coupled basis than as a stand-alone plant.

xv. Heat integration and material integration techniques can be applied to identify areas that can be pinched for reducing the minimum requirements of heating and cooling duties thereby reducing energy consumption and also the number of equipments. 


\section{REFERENCES}

Abedi, A. A. (2007). Economical analysis of a new gas to ethylene technology. (Master of Science Thesis), Texas A\&M University, College Station, Texas.

AichE. (1994). Procedure for Risk Analysis Calculations Dow's Fire \& Explosion Index Hazard Classification Guide (Seventh ed., pp. 3-7). Hoboken, NJ, USA: John Wiley \& Sons, Inc.

Anderson, E. L. (1967). U.S. Patent No. 3,335,198. Washington DC: U.S. Patent and Trademark Office.

Bauer, P. E., \& Maciel Filho, R. (2004). Incorporation of environmental impact criteria in the design and operation of chemical processes. Brazilian Journal of Chemical Engineering, 21, 405-414.

Bond, G. C., \& Wells, P. B. (1966). The hydrogenation of acetylene: II. The reaction of acetylene with hydrogen catalyzed by alumina-supported palladium. Journal of Catalysis, 5(1), 65-73. doi: http://dx.doi.org/10.1016/S0021-9517(66)80126-4

Branan, C. R. (2012). Rules of Thumb for Chemical Engineers (5 ed.). Oxford, UK: Elsevier Science.

Browning, J. B. (1993). Union Carbide: Disaster at Bhopal. In J. Gottschalk (Ed.), Crisis: Inside stories of managing image under siege (pp. 365-382). Detroit: Visible Ink. 
Burr, B., \& Lyddon, L. (2008). A comparison of physical solvents for acid gas removal. Paper presented at the 87th Annual Gas Processors Association Convention, Grapevine, TX.

Cantrell, J., Bullin, J., McIntyre, G., Butts, C., \& Cheatham, B. (2013). Consider GTL as an economic alternative for stranded natural gas and ethane. Hydrocarbon processing, 92(10), 77-80.

Center for Chemical Process, S. (2008a). The Concept of Inherent Safety Inherently Safer Chemical Processes: A Life Cycle Approach (Second ed., pp. 9-19). Hoboken, NJ, USA: John Wiley \& Sons, Inc.

Center for Chemical Process, S. (2008b). Introduction Inherently Safer Chemical Processes: A Life Cycle Approach (Second ed., pp. 1-8). Hoboken, NJ, USA: John Wiley \& Sons, Inc.

Chang, J. (2014). New projects may raise US ethylene capacity by $52 \%$, PE by $47 \%$. ICIS News. Retrieved from http://www.icis.com/resources/news/2014/01/16/9744545/new-projects-mayraise-us-ethylene-capacity-by-52-pe-by-47-1

Chapel, D. G., Mariz, C. L., \& Ernest, J. (1999, October 4-6). Recovery of CO2 from flue gases: commercial trends. Paper presented at the Canadian Society of Chemical Engineers Annual Meeting, Saskatoon, Saskatchewan, Canada.

Chuang, K., \& Nandakumar, K. (2000). Tray columns: design Encyclopedia of Separation Science (pp. 1135-1140). San Diego: Academic Press. 
Coker, A. K. (2007). Ludwig's applied process design for chemical and petrochemical plants (Fourth ed. Vol. 1). Burlington, MA, USA: Elsevier Gulf Professional Pub.

Dennis, C. H. (2012). 1nherently Safer Design: The Fundamentals. CEP, 40-42. Retrieved from AIChE website: http://www.aiche.org/resources/publications/cep/2012/january

Edwards, D. W., \& Lawrence, D. (1993). Assessing the inherent safety of chemical process routes: Is there a relation between plant costs and inherent safety? Process Safety and Environmental Protection, 71(B4), 252-258.

El-Halwagi, M. M. (2012). Sustainable design through process integration: fundamentals and applications to industrial pollution prevention, resource conservation, and profitability enhancement. Waltham, MA, USA: Elsevier.

Froment, G. P., Van de Steene, B. O., Van Damme, P. S., Narayanan, S., \& Goossens, A. G. (1976). Thermal cracking of ethane and ethane-propane mixtures. Industrial \& Engineering Chemistry Process Design and Development, 15(4), 495-504.

Gattis, S. C., Peterson, E. R., \& Johnson, M. M. (2004). The ÉCLAIRS Process for Converting Natural Gas to Hydrocarbon Liquids: Dallas: SYNFUELS Int. Inc.

Gupta, J. P. (2002). The Bhopal gas tragedy: could it have happened in a developed country? Journal of Loss Prevention in the Process Industries, 15(1), 1-4. doi: http://dx.doi.org/10.1016/S0950-4230(01)00025-0 
Hall, K. R. (2005). A new gas to liquids (GTL) or gas to ethylene (GTE) technology. Catalysis Today, 106(1-4), 243-246. doi: http://dx.doi.org/10.1016/j.cattod.2005.07.176

Hammond, C., \& Ham, V. (2009). Caustic Tower Operation-Considerations for Effective Performance. Paper presented at the AIChE, Ethylene Producers' Conference, Houston, Texas.

Heikkilä, A.-M., Hurme, M., \& Järveläinen, M. (1996). Safety considerations in process synthesis. Computers \& chemical engineering, 20, S115-S120.

Holmen, A. (2009). Direct conversion of methane to fuels and chemicals. Catalysis Today, 142(1), 2-8.

Holmen, A., Olsvik, O., \& Rokstad, O. A. (1995). Pyrolysis of natural gas: chemistry and process concepts. Fuel Processing Technology, 42(2-3), 249-267. doi: http://dx.doi.org/10.1016/0378-3820(94)00109-7

ICIS. (2015). Ethylene \& Propylene Supply and Demand. Retrieved February 25, 2015, from http://www.icis.com/services/analysis/analysis-supply-and-demanddatabase/

Jain, S., Moharir, A., Li, P., \& Wozny, G. (2003). Heuristic design of pressure swing adsorption: a preliminary study. Separation and Purification Technology, 33(1), $25-43$.

Khan, F. I., \& Abbasi, S. (1998). Multivariate hazard identification and ranking system. Process Safety Progress, 17(3), 157-170. 
Khan, F. I., \& Amyotte, P. R. (2003). How to make inherent safety practice a reality. The Canadian Journal of Chemical Engineering, 81(1), 2-16.

Khan, F. I., Husain, T., \& Abbasi, S. (2001). Safety weighted hazard index (SWeHI): a new, user-friendly tool for swift yet comprehensive hazard identification and safety evaluation in chemical process industrie. Process Safety and Environmental Protection, 79(2), 65-80.

Khan, F. I., Sadiq, R., \& Amyotte, P. R. (2003). Evaluation of available indices for inherently safer design options. Process Safety Progress, 22(2), 83-97.

Kletz, T. A. (1985). Inherently safer plants. Plant/Operations Progress, 4(3), 164-167.

Kletz, T. A. (2006). Accident investigation: keep asking “why?”. Journal of Hazardous Materials, 130(1), 69-75.

Lewis, D. (1979). The Mond Fire, Explosion and Toxicity Index-a Development of the Dow Index. Paper presented at the Proceedings of the AIChE on loss prevention symposium, New York, USA.

Maher, S. T., Norton, K. D., \& Surmeli, S. (2012). Design an inherently safer plant. Chemical Engineering Progress, 108(1), 43-47.

Noureldin, M. M., Elbashir, N. O., \& El-Halwagi, M. M. (2013). Optimization and selection of reforming approaches for syngas generation from natural/shale gas. Industrial \& Engineering Chemistry Research, 53(5), 1841-1855.

Olivier Ducreux, \& Nedez, C. (2011). Air and gas Drying with AxsorbTM Activated Alumina. Retrieved from Axens website: 
http://usa.axens.net/en/component/axensdocuments/875/air-and-gas-drying-with$\underline{\text { axsorb-activated-alumina/english.html }}$

Pässler, P., Hefner, W., Buckl, K., Meinass, H., Meiswinkel, A., Wernicke, H.-J., . . . Mayer, D. (2012). Acetylene Ullmann's Encyclopedia of Industrial Chemistry. Weinheim: Wiley-VCH Verlag GmbH \& Co. KGaA,.

Peramanu, S., Cox, B. G., \& Pruden, B. B. (1999). Economics of hydrogen recovery processes for the purification of hydroprocessor purge and off-gases. International Journal of Hydrogen Energy, 24(5), 405-424. doi: http://dx.doi.org/10.1016/S0360-3199(98)00105-0

Ren, T., Patel, M., \& Blok, K. (2006). Olefins from conventional and heavy feedstocks: Energy use in steam cracking and alternative processes. Energy, 31(4), 425-451.

Ries, H. C. (1966). Acetylene Process Economics program. Menlo Park, California: Stanford Research Institute.

S2S-A Gateway for Plant and Process Safety. (2003). Layer of Protection Model. Retrieved February 25, 2015, from http://www.safety$\underline{\text { s2s.eu/modules.php?name }=\mathrm{s} 2 \mathrm{~s} \_ \text {wp } 4 \& \mathrm{idpart}=2 \& \mathrm{op}=\mathrm{v} \& \mathrm{idp}=750}$

Shah, R. K., \& Sekulić, D. a. P. (2003). Fundamentals of heat exchanger design. Hoboken, NJ, USA: John Wiley \& Sons

Sundaram, K. M., \& Froment, G. F. (1977). Modeling of thermal cracking kinetics-I: Thermal cracking of ethane, propane and their mixtures. Chemical Engineering Science, 32(6), 601-608. doi: http://dx.doi.org/10.1016/0009-2509(77)80225-X 
Tabe-Mohammadi, A., Villaluenga, J. P. G., Kim, H. J., Chan, T., \& Rauw, V. (2001). Effects of polymer solvents on the performance of cellulose acetate membranes in methanol/methyl tertiary butyl ether separation. Journal of applied polymer science, 82(12), 2882-2895.

Takaoka, S. (1967). Ethylene Process Economics Program. Menlo park, California: Stanford Research Institute.

Thomas K. Swift, Martha G. Moore, \& Sanchez, E. (2011). Shale Gas and New petrochemicals Investment: Benefits for the Economy, Jobs, and US Manufacturing Economics \& Statistics: American Chemistry Council.

True, W. R. (2013). Global ethylene capacity poised for major expansion. Oil \& gas journal, 111(7), 90-95.

Wolf, E. E. (1992). Methane conversion by oxidative processes. New York, NY (United States): Van Nostrand Reinhold Co., Inc.

Wood, D. A., Nwaoha, C., \& Towler, B. F. (2012). Gas-to-liquids (GTL): A review of an industry offering several routes for monetizing natural gas. Journal of Natural Gas Science and Engineering, 9(0), 196-208. doi: http://dx.doi.org/10.1016/j.jngse.2012.07.001 


\section{APPENDIX}

Table 28: Safety data of chemicals

\begin{tabular}{|c|c|c|c|c|c|c|}
\hline Chemicals & $\begin{array}{l}\text { Fire } \\
\text { point }\end{array}$ & $\begin{array}{l}\text { Autoignition } \\
\text { Temperature }\end{array}$ & $\begin{array}{l}\text { Flash } \\
\text { Point }\end{array}$ & $\begin{array}{l}\text { NFPA } \\
-F\end{array}$ & $\begin{array}{l}\text { NFPA } \\
-\mathrm{R} \\
\end{array}$ & $\begin{array}{l}\text { Heat of } \\
\text { Combustion }\end{array}$ \\
\hline & & Deg C & Deg C & & & $\mathrm{KJ} / \mathrm{mol}$ \\
\hline Hydrogen & -190 & 570 & -200 & 4 & 0 & -286 \\
\hline Ethane & -125 & 515 & -135 & 4 & 0 & -1561 \\
\hline Methane & -177.9 & 580 & -187.9 & 4 & 0 & -891.1 \\
\hline Propane & -94 & 470 & -104 & 4 & 0 & -2219.7 \\
\hline Ethylene & -126 & 490 & -136 & 4 & 2 & -1410.9 \\
\hline Propylene & -98 & 458 & -108 & 4 & 1 & -2057.8 \\
\hline Butadiene & -75 & 415 & -85 & 4 & 2 & -2540.4 \\
\hline Acetylene & -8 & 300 & -18 & 4 & 3 & -1299.6 \\
\hline Propadiene & -86 & 453.85 & -96 & 4 & 1 & -1913.4 \\
\hline $\begin{array}{l}\text { Carbon } \\
\text { monoxide }\end{array}$ & -181 & 609 & -191 & 4 & 2 & -284 \\
\hline
\end{tabular}




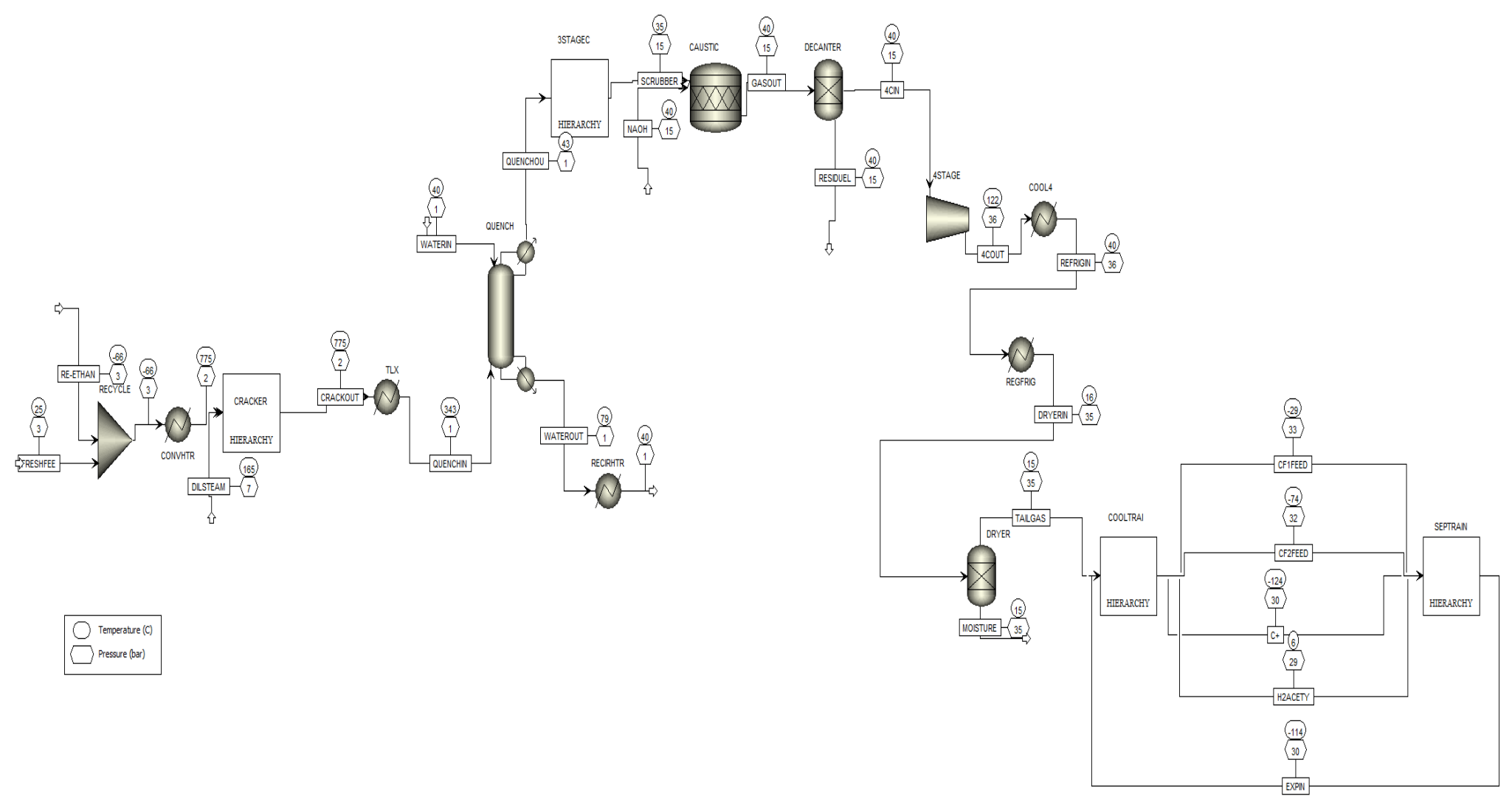

Figure 27: ASPEN Flowsheet- Ethane Cracking - Overall Process 


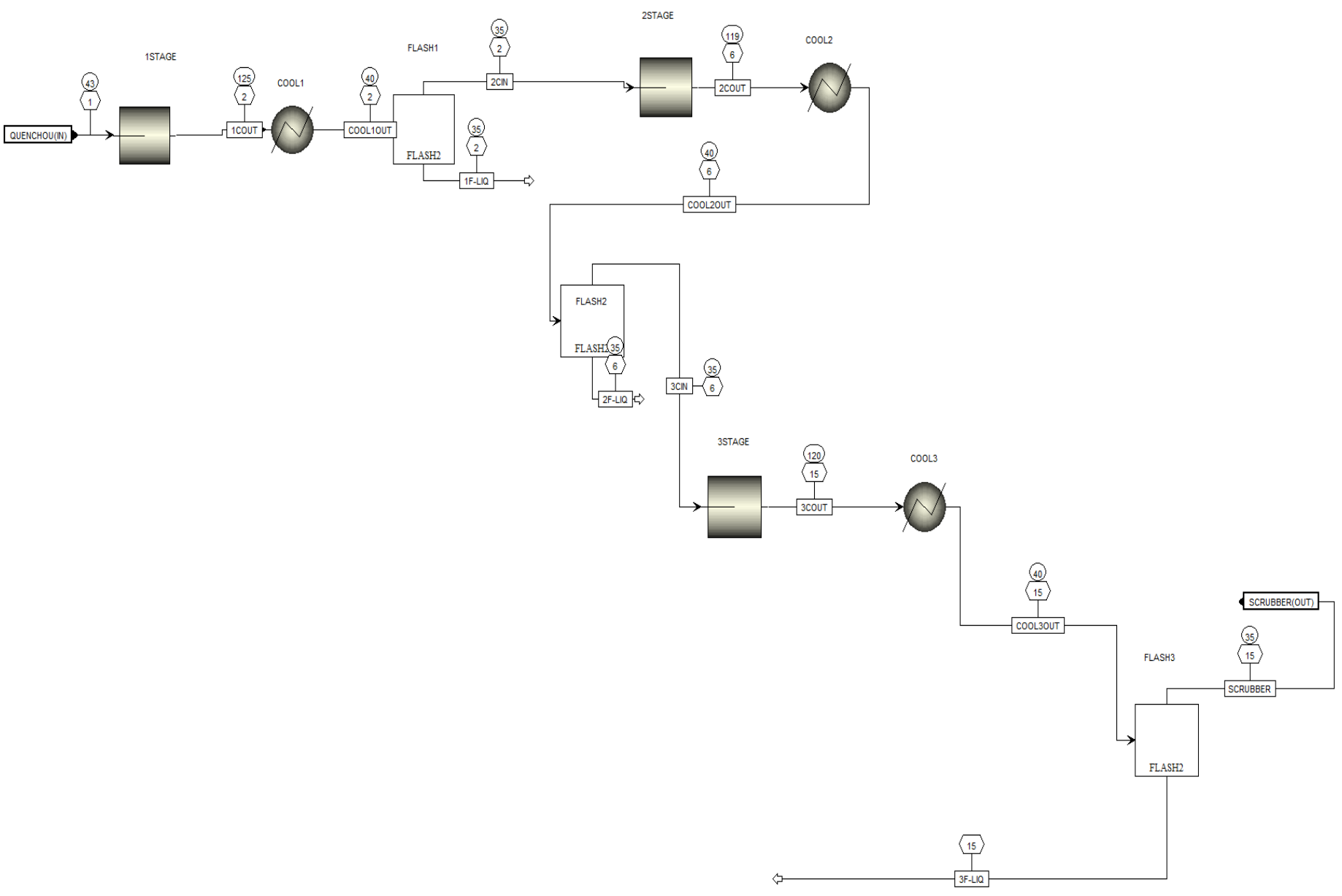

Figure 28: ASPEN Flowsheet: Ethane Cracking- Compression Section 


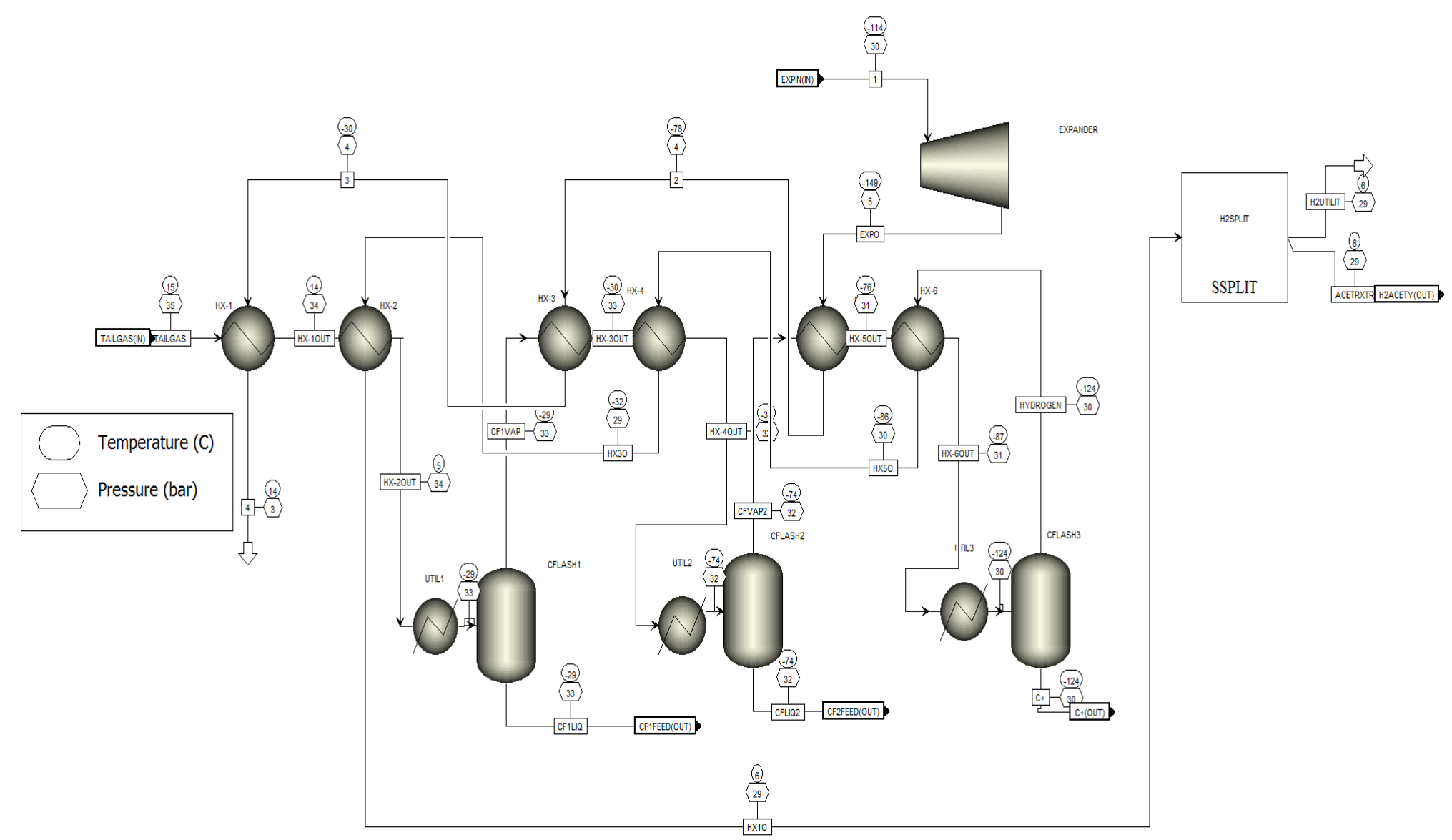

Figure 29: ASPEN Flowsheet- Ethane Cracking- Cooling train 


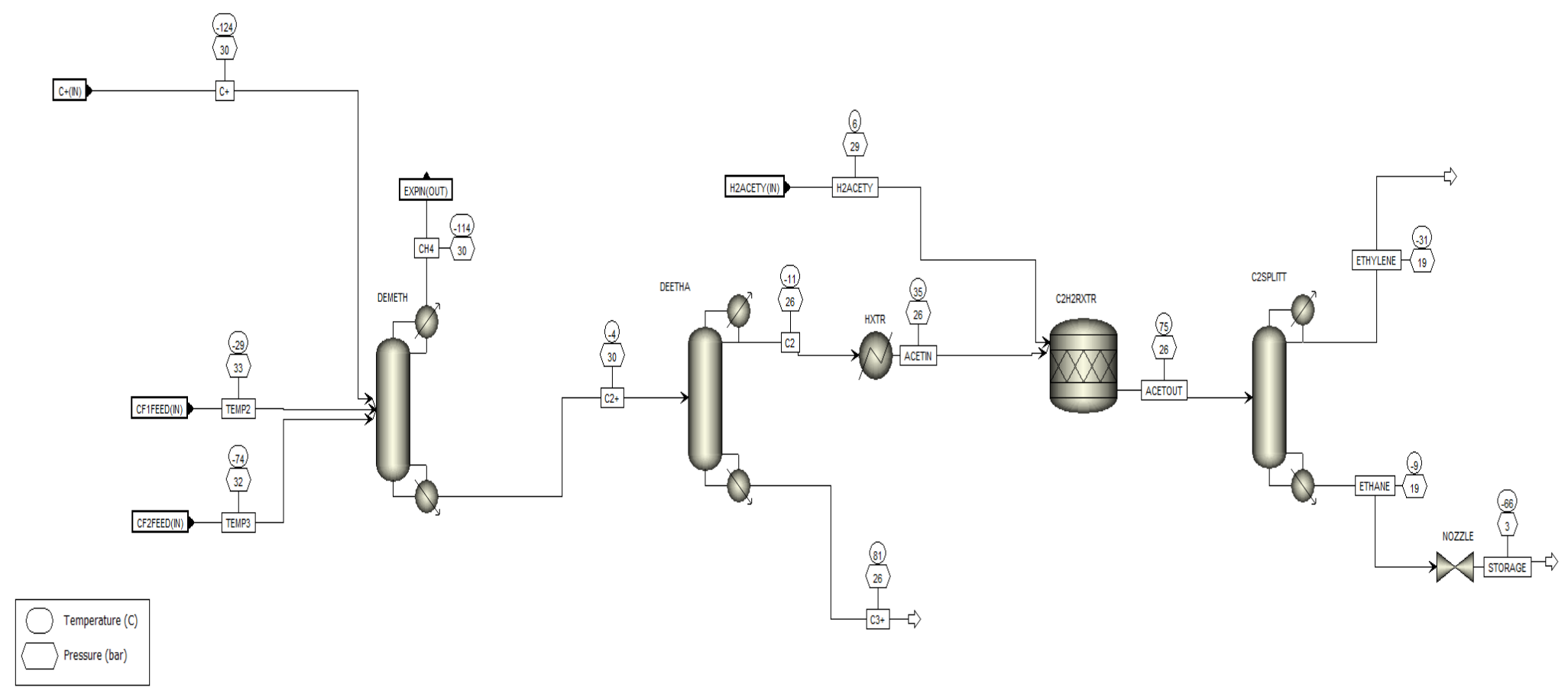

Figure 30: ASPEN Flowsheet- Ethane Cracking- Separation Section 


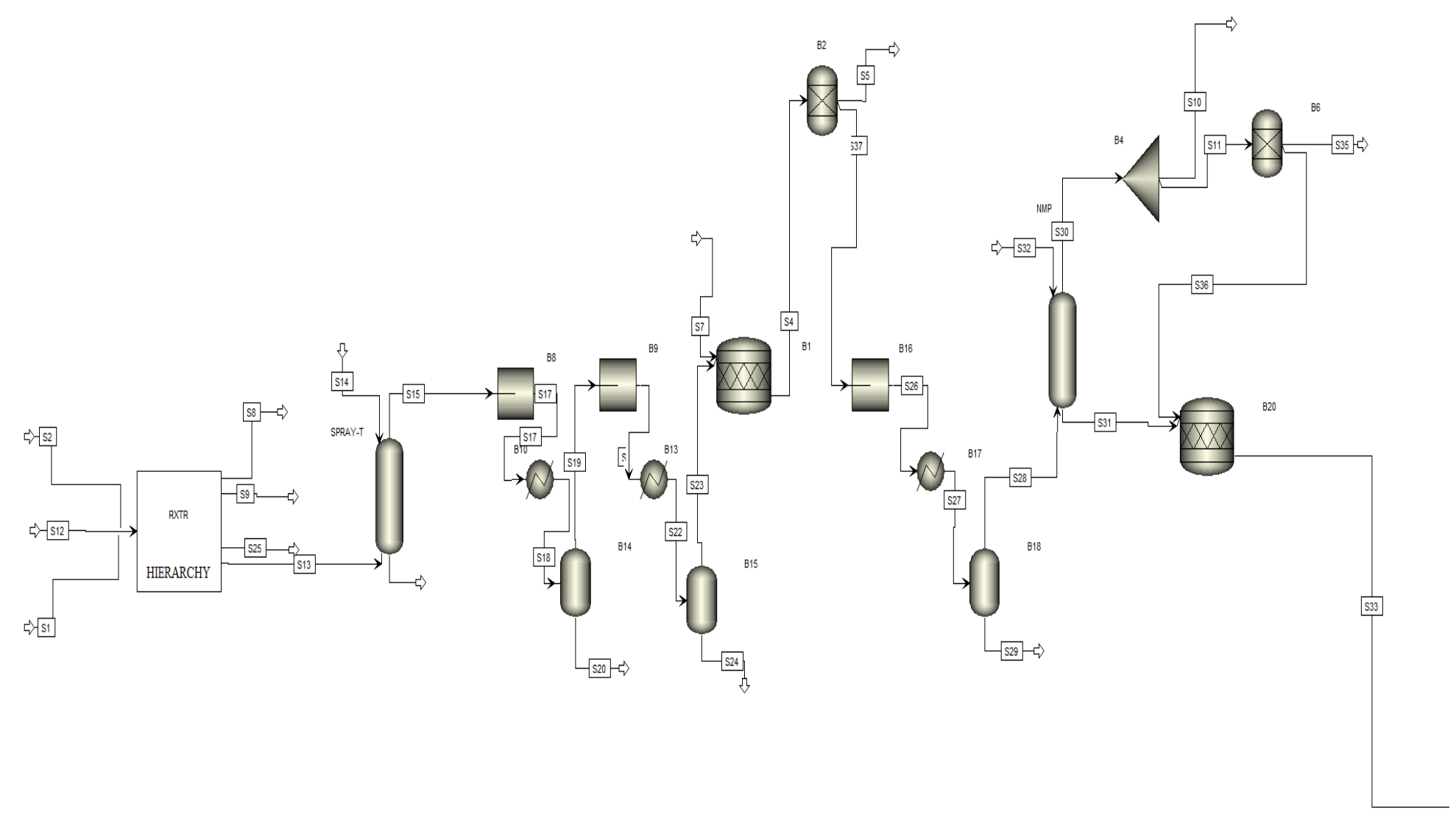

Figure 31: ASPEN Flowsheet- Gas to Ethylene - Pyrolysis and Compression Section 


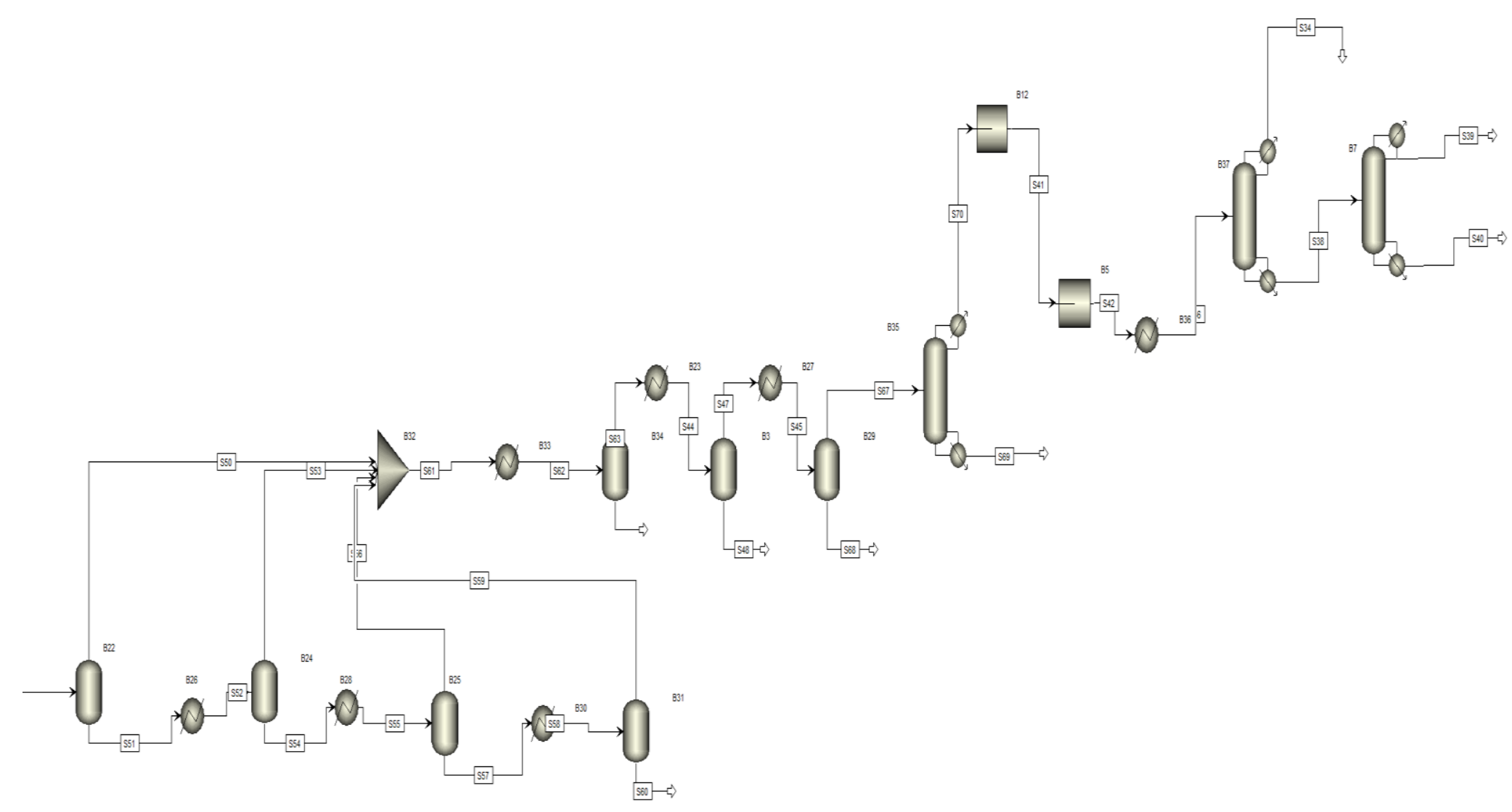

Figure 32: ASPEN Flowsheet - Gas to Ethylene- Solvent Separation and Product Separation Section 
Table 29: Safety calculation sheet of physical units- Ethane Cracking

\begin{tabular}{|c|c|c|c|c|c|c|c|c|c|c|c|c|c|c|c|c|c|c|c|c|c|c|c|c|c|c|}
\hline $\begin{array}{l}\text { S.N } \\
0\end{array}$ & Physical Units & $\begin{array}{l}\text { Mass } \\
\text { flow } \\
\text { rate } \\
(\mathrm{kg} / \mathrm{s})\end{array}$ & $\begin{array}{c}\text { Heat of } \\
\text { combust } \\
\text { ion } \\
(\mathrm{J} / \mathrm{mol})\end{array}$ & 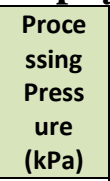 & $\begin{array}{l}\text { Volum } \\
e(m 3)\end{array}$ & $\begin{array}{l}\text { Tempe } \\
\text { rature } \\
\text { (degC) }\end{array}$ & $\begin{array}{c}\text { NFA } \\
\text { ranki } \\
\text { ng } \\
\text { Reacti } \\
\text { vity }\end{array}$ & $\begin{array}{l}\text { NFPA } \\
\text { rapking } \\
\text { flamm } \\
\text { ability }\end{array}$ & F1 & F2 & \begin{tabular}{|l|} 
Hydroge \\
$n$ mol \\
frac
\end{tabular} & $\begin{array}{l}\text { Ethylene } \\
\text { mol frac }\end{array}$ & $\begin{array}{l}\text { Methan } \\
\text { e mol } \\
\text { frac }\end{array}$ & $\begin{array}{l}\text { Propane } \\
\text { mol frac }\end{array}$ & $\begin{array}{l}\text { Acetylene } \\
\text { mol frac }\end{array}$ & $\begin{array}{l}\text { Butadiene } \\
\text { mol frac }\end{array}$ & $\begin{array}{l}\text { Ethane mol } \\
\text { frac }\end{array}$ & $\begin{array}{l}\text { Propyle } \\
\text { ne mol } \\
\text { frac }\end{array}$ & pn1 & pn2 & pn3 & pn4 & pn5 & pn6 & $\begin{array}{l}\text { Damage } \\
\text { Potential }\end{array}$ & FEDI \\
\hline 1 & Preheater & 51 & 1552152 & 300 & 0.2 & 775 & 0.0 & 4.0 & 2530355 & 118 & 0 & $2.01 E-02$ & $3.84 E-26$ & $2.82 \mathrm{E}-08$ & 0 & $1.05 E-12$ & 0.9762 & $6.12 \mathrm{E}-06$ & 1.95 & 1.4 & 1.1 & 2.0 & 1 & 1 & 10889697 & 1049 \\
\hline 2 & \begin{tabular}{|l|l|}
$\begin{array}{l}\text { Transfer L } \\
\text { exchange }\end{array}$ \\
\end{tabular} & 51 & 788187 & 160 & 2.6 & 840 & 0.6 & 3.0 & 1265206 & 796 & 0.2668 & 0.2653 & $2.26 \mathrm{E}-02$ & $8.45 E-00$ & $4.14 E-03$ & $2.76 E-03$ & 0.1893 & $3.71 E-03$ & 1.95 & 1.4 & 1.1 & 1.9 & 1 & 1 & 5141118 & 817 \\
\hline 3 & Quench tower-1 & 17 & 788187 & 110 & 247.5 & 343 & 0.6 & 3.0 & 421735.3 & 51884 & 0.2668 & 0.2653 & 2.26E- 02 & $8.45 \mathrm{E}-04$ & 4.14E- 03 & $2.76 \mathrm{E}-03$ & 0.1893 & $3.71 \mathrm{E}-03$ & 1.95 & 1.4 & 1.1 & 1.9 & 1 & 1 & 1864230 & 583 \\
\hline 4 & Quench tower-2 & 17 & 788187 & 110 & 247.5 & 343 & 0.6 & 3.0 & 421735.3 & 51884 & 0.2668 & 0.2653 & 2.26E-02 & $8.45 \mathrm{E}-04$ & 4.14E- 03 & $2.76 \mathrm{E}-03$ & 0.1893 & $3.71 \mathrm{E}-03$ & 1.95 & 1.4 & 1.1 & 1.9 & 1 & 1 & 1864230 & 583 \\
\hline 5 & Quench tower-3 & 17 & 788187 & 110 & 247.5 & 343 & 0.6 & 3.0 & 421735.3 & 51884 & 0.2668 & 0.2653 & 2.26E- 02 & $8.45 \mathrm{E}-04$ & 4.14E- 03 & $2.76 \mathrm{E}-03$ & 0.1893 & $3.71 \mathrm{E}-03$ & 1.95 & 1.4 & 1.1 & 1.9 & 1 & 1 & 1864230 & 583 \\
\hline 6 & \begin{tabular}{|l} 
1stage \\
compressor
\end{tabular} & 55 & 963468 & 240 & & 125.2 & 0.7 & 3.7 & 1688840 & 0 & 0.3261 & 0.3243 & $2.77 E-02$ & $1.03 \mathrm{E}-03$ & $5.06 \mathrm{E}-03$ & $3.37 \mathrm{E}-03$ & 0.2314 & 54E-03 & 1.75 & 1.4 & 1.1 & 2.1 & 1 & 1 & 6801830 & 897 \\
\hline 7 & \begin{tabular}{|l} 
Inter-stage cool \\
$1 \mathrm{~A}$ \\
\end{tabular} & 28 & 963468 & 240 & 5.3 & 125.2 & 0.7 & 3.7 & 844420 & 2437 & 0.3261 & 0.3243 & 77E-02 & $1.03 E-03$ & $5.06 \mathrm{E}-03$ & $37 \mathrm{E}-03$ & 0.2314 & $54 \mathrm{E}-03$ & 1.75 & 1.4 & 1.1 & 2.1 & 1 & 1 & 3408766 & 713 \\
\hline 8 & \begin{tabular}{|l} 
Inter- \\
$1 \mathrm{~B}-$
\end{tabular} & 28 & 963468 & 240 & 5.3 & 125.2 & 0.7 & 3.7 & 844420 & 2437 & 0.3261 & 0.3243 & $2.77 \mathrm{E}-02$ & $1.03 \mathrm{E}-03$ & $5.06 \mathrm{E}-03$ & $3.37 \mathrm{E}-03$ & 0.2314 & $4.54 \mathrm{E}-03$ & 1.75 & 1.4 & 1.1 & 2.1 & 1 & 1 & 3408766 & 713 \\
\hline 9 & Flash drum 1 & 52 & 1019824 & 240 & 0.9 & 35 & 0.7 & 3.9 & 1694487 & 401 & 0.3452 & 0.3433 & $2.93 \mathrm{E}-02$ & $1.09 \mathrm{E}-03$ & $5.35 E-03$ & $3.57 \mathrm{E}-03$ & 0.2449 & $4.80 \mathrm{E}-03$ & 1.75 & 1.4 & 1.1 & 2.2 & 1 & 1 & 7034283 & 907 \\
\hline 10 & \begin{tabular}{|l|} 
2nd stage \\
compressor \\
\end{tabular} & 52 & 1019824 & 600 & & 119 & 0.7 & 3.9 & 1694487 & 0 & 0.3452 & 0.3433 & 2.93E- 02 & $1.09 \mathrm{E}-03$ & $5.35 E-03$ & $3.57 \mathrm{E}-03$ & 0.2449 & $4.80 \mathrm{E}-03$ & 1.75 & 1.4 & 1.1 & 2.2 & 1 & 1 & 7033096 & 907 \\
\hline 11 & Inter-stage cool2 & 52 & 1019824 & 600 & 5.7 & 119 & 0.7 & 3.9 & 1694487 & 6462 & 0.3452 & 0.3433 & $2.93 \mathrm{E}-02$ & $1.09 \mathrm{E}-03$ & $5.35 E-03$ & $3.57 \mathrm{E}-03$ & 0.2449 & $4.80 \mathrm{E}-03$ & 1.75 & 1.4 & 1.1 & 2.2 & 1 & 1 & 7054551 & 908 \\
\hline 12 & Flash drum 2 & 52 & 1032146 & 600 & 0.2 & 35 & 0.7 & 4.0 & 1695926 & 203 & 0.3494 & 0.3474 & 2.96E- 02 & $1.11 E-03$ & 5.42E- -03 & $3.61 \mathrm{E}-03$ & 0.2479 & $4.866-03$ & 1.75 & 1.4 & 1.1 & 2.2 & 1 & 1 & 7085283 & 909 \\
\hline 13 & \begin{tabular}{|l|} 
3rdstage \\
compressor
\end{tabular} & 52 & 1032146 & 1500 & & 120 & 0.7 & 4.0 & 1695926 & 0 & 0.3494 & 0.3474 & 2.96E- 02 & $1.11 \mathrm{E}-03$ & $5.42 E-03$ & $3.61 \mathrm{E}-03$ & 0.2479 & $4.866-03$ & 1.75 & 1.4 & 1.1 & 2.2 & 1 & 1 & 7084654 & 909 \\
\hline 14 & Inter-stage cool3 & 52 & 1032146 & 1500 & 4.2 & 77 & 0.7 & 4.0 & 1695926 & 12021 & 0.3494 & 0.3474 & $2.96 \mathrm{E}-02$ & $1.11 \mathrm{E}-03$ & $5.42 \mathrm{E}-03$ & $3.61 \mathrm{E}-03$ & 0.2479 & $4.86 \mathrm{E}-03$ & 1.75 & 1.4 & 1.1 & 2.2 & 1 & 1 & 7124827 & 911 \\
\hline & Flash drum 3 & & & No & & LLQUID & & & & & & & & & & & & & & & & 1.0 & 1 & 1 & & \\
\hline 15 & Caustic scrubber & 52 & 1032146 & 1500 & 105.4 & 40 & 0.7 & 4.0 & 1690552 & 301400 & 0.3494 & 0.3474 & $2.96 \mathrm{E}-02$ & 1.11E- 03 & 5.42E- -03 & $3.61 \mathrm{E}-03$ & 0.2479 & $4.866-03$ & 1.75 & 1.4 & 1.1 & 2.2 & 1 & 1 & 8069473 & 950 \\
\hline 16 & $\begin{array}{l}\text { 4insoge } \\
\text { compressor }\end{array}$ & 52 & 1032146 & 3600 & & 122 & 0.7 & 4.0 & 1690552 & 0 & 0.3494 & 0.3474 & $2.96 \mathrm{E}-02$ & $1.11 \mathrm{E}-03$ & $5.42 \mathrm{E}-03$ & $3.61 \mathrm{E}-03$ & 0.2479 & $4.866-03$ & 1.75 & 1.4 & 1.1 & 2.2 & 1 & 1 & 7062206 & 908 \\
\hline 17 & Inter-stage cool4 & 52 & 1032146 & 3600 & 3.4 & 122 & 0.7 & 4.0 & 1690552 & 23203 & 0.3494 & 0.3474 & $2.96 \mathrm{E}-02$ & $1.11 \mathrm{E}-03$ & $5.42 \mathrm{E}-03$ & $3.61 \mathrm{E}-03$ & 0.2479 & $4.86 \mathrm{E}-03$ & 1.75 & 1.4 & 1.1 & 2.2 & 1 & 1 & 7139749 & 912 \\
\hline 18 & cooler & 52 & 1032146 & 3550 & 2.3 & 40 & 0.7 & 4.0 & 1690552 & 15558 & 0.3494 & 0.3474 & $2.96 \mathrm{E}-02$ & $1.11 \mathrm{E}-03$ & $5.42 E-03$ & $3.61 \mathrm{E}-03$ & 0.2479 & $4.86 \mathrm{E}-03$ & 1.75 & 1.4 & 1.1 & 2.2 & 1 & 1 & 7114201 & 911 \\
\hline 19 & Dryer & 51 & 1043266 & 3500 & 8.2 & 15 & 0.7 & 4.0 & 1691460 & 54646 & 0.3532 & 0.3511 & $2.99 \mathrm{E}-02$ & 1.12E -03 & $5.48 \mathrm{E}-03$ & $3.65 \mathrm{E}-03$ & 0.2506 & $4.91 \mathrm{E}-03$ & 1.75 & 1.4 & 1.1 & 2.2 & 1 & 1 & 7290748 & 918 \\
\hline 20 & Cool train $\mathrm{h} \times 1$ & 51 & 1043266 & 3450 & 0.1 & 15 & 0.7 & 4.0 & 1691460 & 654 & 0.3532 & 0.3511 & $2.99 \mathrm{E}-02$ & $1.12 E-03$ & $5.48 \mathrm{E}-03$ & $3.65 \mathrm{E}-03$ & 0.2506 & $4.91 \mathrm{E}-03$ & 1.75 & 1.4 & 1.1 & 2.2 & 1 & 1 & 7109261 & 910 \\
\hline 21 & Cool train $\mathrm{h} \times 2$ & 51 & 1043266 & 3400 & 0.7 & 14 & 0.7 & 4.0 & 1691460 & 4253 & 0.3532 & 0.3511 & $2.99 \mathrm{E}-02$ & $1.12 \mathrm{E}-03$ & $5.48 \mathrm{E}-03$ & $3.65 \mathrm{E}-03$ & 0.2506 & $4.91 \mathrm{E}-03$ & 1.75 & 1.4 & 1.1 & 2.2 & 1 & 1 & 7121360 & 911 \\
\hline 22 & Cool train $\mathrm{h} \times 3-\mathrm{A}$ & 17 & 1043266 & 3350 & 8.0 & 5 & 0.7 & 4.0 & 563820 & 51253 & 0.3532 & 0.3511 & $2.99 \mathrm{E}-02$ & $1.12 E-03$ & $5.48 \mathrm{E}-03$ & $3.65 \mathrm{E}-03$ & 0.2506 & $4.91 \mathrm{E}-03$ & 1.75 & 1.4 & 1.1 & 2.2 & 1 & 1 & 2541302 & 646 \\
\hline 23 & Cool train $\mathrm{h} \times 3-\mathrm{B}$ & 17 & 1043266 & 3350 & 8.0 & 5 & 0.7 & 4.0 & 563820 & 51253 & 0.3532 & 0.3511 & 2.99E-02 & $1.12 E-03$ & $5.48 \mathrm{E}-03$ & $3.65 \mathrm{E}-03$ & 0.2506 & $4.91 \mathrm{E}-03$ & 1.75 & 1.4 & 1.1 & 2.2 & 1 & 1 & 2541302 & 646 \\
\hline 24 & Cool train $\mathrm{h} \times 3-\mathrm{C}$ & 17 & 1043266 & 3350 & 8.3 & 5 & 0.7 & 4.0 & 563820 & 52806 & 0.3532 & 0.3511 & $2.99 \mathrm{E}-02$ & $1.12 \mathrm{E}-03$ & $5.48 \mathrm{E}-03$ & $3.65 \mathrm{E}-03$ & 0.2506 & $4.91 \mathrm{E}-03$ & 1.75 & 1.4 & 1.1 & 2.2 & 1 & 1 & 2546523 & 647 \\
\hline 25 & Cool train $\mathrm{h} \times 4$ & 37 & 946011 & 3300 & 0.1 & -29 & 0.7 & 4.0 & 1115733 & 544 & 0.4268 & 0.3254 & $3.40 \mathrm{E}-02$ & $4.56 \mathrm{E}-04$ & $4.78 \mathrm{E}-03$ & $5.74 \mathrm{E}-04$ & 0.2057 & $2.32 \mathrm{E}-03$ & 1.75 & 1.4 & 1.1 & 2.2 & 1 & 1 & 4656384 & 791 \\
\hline 26 & Cool train $\mathrm{h} \times 5$ & 37 & 946011 & 3250 & 1.1 & -29.7 & 0.7 & 4.0 & 1115733 & 6733 & 0.4268 & 0.3254 & $3.40 \mathrm{E}-02$ & $4.56 \mathrm{E}-04$ & $4.78 \mathrm{E}-03$ & $5.74 \mathrm{E}-04$ & 0.2057 & $2.32 \mathrm{E}-03$ & 1.75 & 1.4 & 1.1 & 2.2 & 1 & 1 & 4677039 & 792 \\
\hline 27 & Cool train hx6-A & 19 & 946011 & 3200 & 6.1 & -33 & 0.7 & 4.0 & 557866.6 & 37062 & 0.4268 & 0.3254 & $3.40 \mathrm{E}-02$ & $4.56 \mathrm{E}-04$ & $4.78 \mathrm{E}-03$ & $5.74 \mathrm{E}-04$ & 0.2057 & $2.32 \mathrm{E}-03$ & 1.75 & 1.4 & 1.1 & 2.2 & 1 & 1 & 2450974 & 639 \\
\hline 28 & Cool train hx6- & 19 & 946011 & 3200 & 6.1 & -33 & 0.7 & 4.0 & 557866.6 & 37062 & 0.4268 & 0.3254 & $3.40 \mathrm{E}-02$ & $4.56 \mathrm{E}-04$ & $4.78 \mathrm{E}-03$ & $5.74 \mathrm{E}-04$ & 0.2057 & $2.32 \mathrm{E}-03$ & 1.75 & 1.4 & 1.1 & 2.2 & 1 & 1 & 2450974 & 639 \\
\hline 29 & Cool train $\mathrm{h} \times 7$ & 7 & 472554 & 3150 & 0.1 & -74 & 0.2 & 4.0 & 105337.2 & 535 & 0.819 & 0.1005 & $4.30 \mathrm{E}-02$ & $9.93 \mathrm{E}-06$ & $1.06 \mathrm{E}-03$ & $1.86 \mathrm{E}-06$ & $3.63 \mathrm{E}-02$ & 7.05E-05 & 1.75 & 1.4 & 1.1 & 2.1 & 1 & 1 & 417582 & 354 \\
\hline 30 & Cool train $\mathrm{h} \times 8$ & 7 & 472554 & 3100 & 0.6 & -76 & 0.2 & 4.0 & 105337.2 & 3616 & 0.819 & 0.1005 & $4.30 \mathrm{E}-02$ & $9.93 E-06$ & $1.06 E-03$ & $1.86 \mathrm{E}-06$ & $3.63 \mathrm{E}-02$ & 7.05E-05 & 1.75 & 1.4 & 1.1 & 2.1 & 1 & 1 & 427313 & 357 \\
\hline 31 & Cool train hx9 & 7 & 472554 & 3050 & 1.7 & -87 & 0.2 & 4.0 & 105337.2 & 9775 & 0.819 & 0.1005 & $4.30 \mathrm{E}-02$ & $9.93 E-06$ & $1.06 E-03$ & $1.86 \mathrm{E}-06$ & $3.63 \mathrm{E}-02$ & 7.05E-05 & 1.75 & 1.4 & 1.1 & 2.1 & 1 & 1 & 446768 & 362 \\
\hline
\end{tabular}




\section{Table 29: Continued}

\begin{tabular}{|c|c|c|c|c|c|c|c|c|c|c|c|c|c|c|c|c|c|c|c|c|c|c|c|c|c|c|}
\hline $\begin{array}{l}\text { S.N } \\
0\end{array}$ & Physical Units & $\begin{array}{l}\text { Mass } \\
\text { flow } \\
\text { rate } \\
(\mathrm{kg} / \mathrm{s})\end{array}$ & $\begin{array}{c}\text { Heat of } \\
\text { combust } \\
\text { ion } \\
(\mathrm{J} / \mathrm{mol})\end{array}$ & $\begin{array}{c}\text { Proce } \\
\text { ssing } \\
\text { Press } \\
\text { ure } \\
\text { (kPa) }\end{array}$ & $\begin{array}{l}\text { Volum } \\
\text { e (m3) }\end{array}$ & $\begin{array}{l}\text { mpe } \\
\text { ture } \\
\text { egC) }\end{array}$ & \begin{tabular}{|c|} 
NFPA \\
ranki \\
ng \\
Reacti \\
vity \\
\end{tabular} & $\begin{array}{l}\text { NFPA } \\
\text { ranking } \\
\text { flamm } \\
\text { ability }\end{array}$ & F1 & F2 & $\begin{array}{l}\text { droge } \\
\text { nnol } \\
\text { c }\end{array}$ & $\begin{array}{l}\text { ylene } \\
\text { If frac }\end{array}$ & $\begin{array}{l}\text { Methan } \\
\text { e m mol } \\
\text { frac }\end{array}$ & $\begin{array}{l}\text { Propane } \\
\text { mol frac }\end{array}$ & $\begin{array}{l}\text { cetylene } \\
\text { ol frac }\end{array}$ & $\begin{array}{l}\text { Butadiene } \\
\text { mol frac }\end{array}$ & $\begin{array}{l}\text { Ethane mol } \\
\text { frac }\end{array}$ & $\begin{array}{l}\text { Propyle } \\
\text { ne mol } \\
\text { frac }\end{array}$ & pn1 & pn2 & pn3 & pn4 & pn5 & pn6 & & FEDI \\
\hline 32 & Cool-flash 1 & 37 & 946011 & 3300 & 9.3 & -29 & 0.7 & 4.0 & 1115733 & 58229 & 0.4268 & 0.3254 & $3.40 \mathrm{E}-02$ & 4.56E-04 & 4.78E-03 & $5.74 E-04$ & 0.2057 & $2.32 \mathrm{E}-03$ & 1.75 & 1.4 & 1.1 & 2.2 & 1 & 1 & 4848899 & 802 \\
\hline 33 & olfflash 2 & 7 & 472554 & 3150 & 7.6 & -74 & 0.2 & 4.0 & 105337.2 & 105511 & 0.819 & 0.1005 & $4.30 \mathrm{E}-02$ & $9.93 \mathrm{E}-06$ & $1.06 E-03$ & $1.86 \mathrm{E}-06$ & $3.63 \mathrm{E}-02$ & $7.05 E-05$ & 1.75 & 1.4 & 1.1 & 2.1 & 1 & 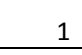 & 749152 & 430 \\
\hline 34 & ol-flash 3 & 3 & 320385 & 3000 & 2 & -124 & 0.0 & 4.0 & 27415.64 & 12912 & 0.9522 & $8.74 E-03$ & $3.77 E-02$ & $1.30 \mathrm{E}-08$ & 4.91E- 05 & 1.17E- -10 & $1.30 \mathrm{E}-03$ & $1.52 E-07$ & 1.75 & 1.4 & 1.1 & 2.0 & 1 & 1 & 145642 & 249 \\
\hline 35 & oander & 1 & 657733 & 3000 & & -113 & 0.0 & 4.0 & 15763.93 & 0 & 0.3868 & $1.31 E-03$ & 0.6119 & $1.43 E-20$ & $1.33 \mathrm{E}-06$ & $8.62 E-30$ & $3.83 \mathrm{E}-07$ & $5.21 E-18$ & 1.75 & 1.4 & 1.1 & 2.0 & 1 & 1 & 60711 & 186 \\
\hline 36 & methanizer & 5 & 834438 & 3000 & 404.8 & -113.9 & 0.0 & 4.0 & 121299.7 & 14537 & 0.10499 & $1.32 \mathrm{E}-02$ & 0.8818 & $2.68 \mathrm{E}-18$ & $2.91 \mathrm{E}-05$ & $1.29 \mathrm{E}-26$ & $9.16 \mathrm{E}-06$ & $5.42 E-16$ & 1.75 & 1.4 & 1.1 & 2.0 & 1 & 1 & 7620879 & 932 \\
\hline 37 & denser 1 & 5 & 834438 & 3000 & 0.5 & -113.9 & 0.0 & 4.0 & 121299.7 & 3140 & 0.10499 & $1.32 \mathrm{E}-02$ & 0.8818 & 2.68E-18 & $2.91 \mathrm{E}-05$ & $1.29 \mathrm{E}-26$ & $9.16 \mathrm{E}-06$ & $5.42 E-16$ & 1.75 & 1.4 & 1.1 & 2.0 & 1 & 1 & 478250 & 371 \\
\hline 38 & oiler 1 & 86 & 1465095 & 3000 & 0.7 & -4.3 & 1.3 & 4.0 & 4016716 & 4142 & $1.65 \mathrm{E}-14$ & 0.64074 & $2.37 E-04$ & $5.93 E-04$ & $9.06 \mathrm{E}-03$ & $8.65 \mathrm{E}-04$ & 0.34547 & $3.04 E-03$ & 1.75 & 1.4 & 1.1 & 2. & 1 & 1 & 18018124 & 1241 \\
\hline 39 & ethanizer & 83 & 472028 & 2600 & 590.2 & -9.4 & 1.2 & 4.0 & 3900781 & 924862 & $1.29 \mathrm{E}-15$ & 0.57697 & $8.14 E-05$ & $2.81 E-08$ & $9.05 \mathrm{E}-03$ & $15 E-17$ & 0.4139 & $6.14 \mathrm{E}-06$ & 1.75 & 1.4 & 1.1 & 2. & 1 & 1 & 27573827 & 1430 \\
\hline 40 & ndenser 2-A & 42 & 472028 & 2600 & 8.3 & -9. & 1.2 & 4.0 & 1950391 & 40948 & $\begin{array}{l}1.29 \mathrm{E}-15 \\
\end{array}$ & 57697 & $8.14 E-05$ & $81 E-08$ & $9.05 \mathrm{E}-03$ & $15 E-17$ & 0.4139 & $6.14 \mathrm{E}-06$ & 1.75 & 1.4 & 1.1 & 2. & 1 & 1 & 762361 & 976 \\
\hline 41 & denser 2-B & 42 & 1472028 & 2600 & 8.3 & -9.4 & 1.2 & 4.0 & 1950391 & 40948 & $\begin{array}{l}1.29 \mathrm{E}-15 \\
\end{array}$ & 57697 & $8.14 E-05$ & $81 E-08$ & $9.05 \mathrm{E}-03$ & $6.15 \mathrm{E}-17$ & 0.4139 & $6.14 \mathrm{E}-06$ & 1.75 & 1.4 & 1.1 & 2. & 1 & 1 & 762361 & 976 \\
\hline 42 & P & 85 & 2126055 & 2600 & 3.3 & 75.5 & 1.0 & 4.0 & 44275 & 382 & $5.46 E-41$ & 2.25E- 04 & $5 E-16$ & 1867 & 2.93E- 04 & 21078 & 0.10529 & 0.56474 & 1.75 & 1.4 & 1.1 & 2.2 & 1 & 1 & 24988861 & 1384 \\
\hline 43 & & 46 & 52 & 2600 & 1.3 & 75 & 1.2 & 4.0 & 0246 & 45 & 84E-05 & 858 & 2E- 04 & $\mathrm{E}-08$ & 0 & $E-12$ & 4.4137 & $14 \mathrm{E}-06$ & 1.75 & 1.4 & 1.1 & 2.3 & 1 & 1 & 02201 & 1006 \\
\hline 44 & C2splitter-1 & 79 & 1411128 & 1900 & 851.5 & -30.7 & 2.0 & 4.0 & 3561307 & 83449 & $8.23 \mathrm{E}-05$ & 0.99491 & $7.51 E-04$ & $4.77 E-46$ & $0.00 E+00$ & $1.46 E-80$ & $4.26 \mathrm{E}-03$ & $4.34 E-38$ & 1.75 & 1.4 & 1.1 & 2.5 & 1 & 1 & 28980557 & 1454 \\
\hline 45 & 2splitter-II & 79 & 1411128 & 1900 & 851.5 & -30.7 & 2.0 & 4.0 & 3561307 & 3083449 & $23 \mathrm{E}-05$ & 0.99491 & 1E-04 & $4.77 E-46$ & $0.00 E+00$ & $1.46 E-80$ & $4.26 \mathrm{E}-03$ & 4.34E-38 & 1.75 & 1.4 & 1.1 & 2.5 & 1 & 1 & 28980557 & 1454 \\
\hline 46 & ndenser 3-I-A & 20 & 28 & 1900 & 6.2 & -30.7 & 2.0 & 4.0 & 26.5 & 52 & $3 E-05$ & 8491 & $E-04$ & -46 & $0.00 E+00$ & E-80 & $E-03$ & 4E-38 & 1.75 & 1.4 & 1.1 & 2.5 & 1 & 1 & 6304 & 774 \\
\hline 47 & r3-1-B & 20 & & 1900 & 6.2 & -30.7 & 2.0 & 4.0 & & 52 & $E-05$ & 491 & $=04$ & $=46$ & $E+00$ & E-80 & $=03$ & 4E-38 & 1.75 & 1.4 & 1.1 & 2.5 & 1 & 1 & 66304 & 774 \\
\hline 48 & tenser 3-II-A & 20 & & 1900 & 6 & -30.7 & 2.0 & 4.0 & 0326.5 & 352 & BE-05 & 8491 & E-04 & E-46 & $0 E+00$ & $6 E-80$ & E-03 & 4E-38 & 1.75 & 1.4 & 1.1 & 2.5 & 1 & & 366304 & 774 \\
\hline 49 & tenser 3-1 & 20 & 28 & 1900 & 6.2 & -30.7 & & 4.0 & 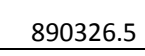 & & & & & & & & & & & & & & & & & \\
\hline & & & & & & & & & & & & & & & & & & & & & & & & & & \\
\hline
\end{tabular}

Table 30: Safety calculation sheet of physical units- Methane Pyrolysis

\begin{tabular}{|c|c|c|c|c|c|c|c|c|c|c|c|c|c|c|c|c|c|c|c|c|c|c|c|c|c|c|c|}
\hline $\begin{array}{l}\text { S.N } \\
0 \\
\end{array}$ & ysical Units & $\begin{array}{c}\text { Mass } \\
\text { flow } \\
\text { rate } \\
(\mathrm{kg} / \mathrm{s})\end{array}$ & $\begin{array}{c}\text { Heat of } \\
\text { combusti } \\
\text { on } \\
(\mathrm{J} / \mathrm{mol})\end{array}$ & $\begin{array}{c}\begin{array}{c}\text { Processi } \\
\text { ng } \\
\text { Pressure } \\
\text { (kPa) }\end{array} \\
\end{array}$ & $\begin{array}{c}\text { Volu } \\
\text { me } \\
\text { (m3) }\end{array}$ & $\begin{array}{c}\text { Tempera } \\
\text { ture } \\
\text { (degc) }\end{array}$ & $\begin{array}{c}\text { NFPA } \\
\text { ranking } \\
\text { Reactiv } \\
\text { ity } \\
\end{array}$ & $\begin{array}{l}\text { NFPA } \\
\text { ranking } \\
\text { flamm } \\
\text { ability }\end{array}$ & F1 & F2 & $\begin{array}{c}\text { Methan } \\
\text { e mole } \\
\text { frac }\end{array}$ & $\begin{array}{c}\text { co mol } \\
\text { frac }\end{array}$ & $\underset{\text { frac }}{\mathrm{CO} 2 \mathrm{~mol}}$ & $\begin{array}{c}\text { Acetylen } \\
\text { e mol } \\
\text { frac }\end{array}$ & $\begin{array}{c}\text { Hydrog } \\
\text { en mol } \\
\text { frac }\end{array}$ & $\begin{array}{c}\text { Oxygen } \\
\text { mol } \\
\text { frac }\end{array}$ & $\begin{array}{c}\text { water } \\
\text { mole } \\
\text { frac }\end{array}$ & $\begin{array}{c}\text { ethylen } \\
\text { e mol } \\
\text { frac }\end{array}$ & $\begin{array}{c}\text { propadi } \\
\text { ene mol } \\
\text { frac }\end{array}$ & n1 & $\begin{array}{l}\text { pn } \\
2\end{array}$ & $\begin{array}{l}\text { pn } \\
3\end{array}$ & pn4 & n5 & pn6 & & FEDI \\
\hline 1 & & 105 & 100 & 150 & 0.26 & 600 & 0.00 & 4.0 & 083 & 74.3 & & & & & 0 & 0 & 0 & 0 & 0 & 1.95 & 1.4 & 1.1 & 2 & 1 & 1 & 4786 & 1107 \\
\hline 2 & Oxygen pre & 136 & $c$ & 150 & 0.11 & 600 & 0.00 & 0.0 & 0 & 29.9 & & 0 & 0 & & 0 & 1 & 0 & 0 & 0 & 1.1 & 1.4 & \begin{tabular}{|l}
1.1 \\
\end{tabular} & 1 & 1 & 1 & 46 & 17 \\
\hline 3 & & 14 & 224876 & 100 & 167.2 & 80 & 0. & 2.2 & 100431.5 & 669.4 & -02 & .15 & & -02 & 3106 & 0 & 4326 & $\mathrm{EE}-03$ & E-03 & 1.75 & 1.4 & 1.1 & 1.7 & 1 & 1 & 00562 & 349 \\
\hline 4 & & 140 & 7470 & 230 & & 143 & 0.8 & 3.6 & 35558 & 0 & E-02 & 0.2518 & $\mathrm{E}-02$ & $E-02$ & 5214 & 0 & $E-02$ & E-03 & 3E-03 & 1.75 & 1.4 & 1.1 & 2.1 & 1 & 1 & 798200 & 897 \\
\hline 5 & \begin{tabular}{|l} 
Intercoc \\
nos.)
\end{tabular} & 35 & 377470 & 230 & 8.1 & 143 & 0.8 & 3.6 & 421389.5 & 3582.1 & 7E-02 & 0.2518 & 4.6E-02 & $8.0 \mathrm{E}-02$ & 0.5214 & 0 & $4.8 \mathrm{E}-02$ & $3.4 \mathrm{E}-03$ & $3.3 E-03$ & 1.75 & 1.4 & 1.1 & 2.1 & 1 & 1 & 1711107 & 566 \\
\hline 6 & Cool flash 1 & 140 & 388056 & 230 & 1.9 & 35 & 0.8 & 3.7 & 1732820 & 824.2 & $4.8 E-02$ & 0.2589 & 4.7E-02 & $8.2 E-02$ & 0.536 & 0 & $2.11-02$ & $3.5 \mathrm{E}-03$ & $3.4 \mathrm{E}-03$ & 1.75 & 1.4 & 1.1 & 2.1 & 1 & 1 & 7094064 & 905 \\
\hline
\end{tabular}




\section{Table 30: Continued}

\begin{tabular}{|c|c|c|c|c|c|c|c|c|c|c|c|c|c|c|c|c|c|c|c|c|c|c|c|c|c|c|c|}
\hline $\begin{array}{l}S . N \\
0\end{array}$ & ysical Units & $\begin{array}{l}\text { Mass } \\
\text { flow } \\
\text { rate } \\
(\mathrm{kg} / \mathrm{s})\end{array}$ & $\begin{array}{c}\text { Heat of } \\
\text { combusti } \\
\text { on } \\
(\mathrm{J} / \mathrm{mol})\end{array}$ & $\begin{array}{c}\text { Processi } \\
\text { ng } \\
\text { Pressure } \\
\text { (kPa) }\end{array}$ & $\begin{array}{c}\text { Volu } \\
\text { me } \\
\text { (m3) } \\
\end{array}$ & $\begin{array}{c}\text { Tempera } \\
\text { ture } \\
\text { (degC) }\end{array}$ & $\begin{array}{c}\text { NFPA } \\
\text { ranking } \\
\text { Reactiv } \\
\text { ity }\end{array}$ & $\begin{array}{l}\text { NFPA } \\
\text { ranking } \\
\text { flamm } \\
\text { ability }\end{array}$ & $F 1$ & $F 2$ & $\begin{array}{c}\text { Methan } \\
\text { e mole } \\
\text { frac }\end{array}$ & $\begin{array}{c}\mathrm{comol} \\
\text { frac }\end{array}$ & $\begin{array}{c}\mathrm{CO} 2 \mathrm{~mol} \\
\mathrm{frac}\end{array}$ & $\begin{array}{c}\text { Acetylen } \\
\text { e mol } \\
\text { frac }\end{array}$ & $\begin{array}{c}\text { Hydrog } \\
\text { en mol } \\
\text { frac }\end{array}$ & $\begin{array}{c}\text { Oxygen } \\
\text { mol } \\
\text { frac }\end{array}$ & \begin{tabular}{|c|} 
water \\
mole \\
frac
\end{tabular} & $\begin{array}{c}\text { ethylen } \\
\text { e mol } \\
\text { frac }\end{array}$ & $\begin{array}{c}\text { propadi } \\
\text { ene mol } \\
\text { frac }\end{array}$ & $\mathrm{pn} 1$ & $p_{2}^{p n}$ & $\begin{array}{l}\text { pn } \\
3\end{array}$ & pn4 & pn5 & pn6 & $\begin{array}{l}\text { amage } \\
\text { otential }\end{array}$ & FEDI \\
\hline 7 & $\begin{array}{l}\text { stage } \\
\text { npressor }\end{array}$ & 140 & 56 & 529 & & 143 & 18 & 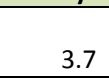 & 820 & 0 & -02 & 589 & $=02$ & 02 & 0.536 & 0 & $\mathrm{E}-02$ & E-03 & -03 & 1.75 & 1.4 & $\begin{array}{l}1.1 \\
\end{array}$ & 2.1 & 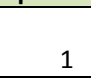 & - & 1365 & 909 \\
\hline 8 & $\begin{array}{l}\text { Intercool stage } 2 \text { (3 } \\
\text { nos.) }\end{array}$ & 46 & 388056 & 529 & 7.2 & 143 & 0.8 & 3.7 & 7606.8 & 7275 & $4.8 \mathrm{E}-02$ & .2589 & 4.7E-02 & $.2 \mathrm{E}-02$ & 0.536 & 0 & 2.1E- 02 & 3.5E-03 & 3.4E-03 & 1.75 & 1.4 & 1.1 & 2.1 & 1 & 1 & 387606 & 633 \\
\hline 9 & of flash 2 & 140 & 2616 & 529 & 0.8 & 35 & 0.8 & 8.8 & 53189 & 792.3 & $9 \mathrm{E}-02$ & 2619 & $4.8 \mathrm{E}-02$ & $3 \mathrm{E}-02$ & 0.5423 & 0 & 2E-03 & 5E-03 & $.5 E-03$ & 1.75 & 1.4 & 1.1 & 2.1 & 1 & 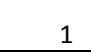 & 221822 & 915 \\
\hline 10 & & 70 & 6291 & 500 & 339 & 35 & 0.8 & 4.0 & 9463.9 & 3383 & 5.1E-02 & 2777 & 0 & $8 E-02$ & 0.575 & 0 & 0 & 7E-03 & 7E-03 & 1.75 & 1.4 & 1.1 & 2.2 & 1 & 1 & 049725 & 812 \\
\hline 11 & $\begin{array}{l}\text { 玍 sta } \\
\text { compror }\end{array}$ & 140 & 416291 & 1250 & & 152 & 0.8 & 4.0 & 858928 & 0 & $5.1 \mathrm{E}-02$ & 2777 & 0 & $.8 \mathrm{E}-02$ & 0.575 & 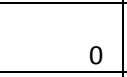 & 0 & 3.7E- 03 & $.7 E-03$ & 1.75 & 1.4 & 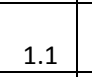 & 2.2 & 1 & 1 & 900445 & 943 \\
\hline 12 & $\begin{array}{l}\text { Int } \\
\text { no }\end{array}$ & 70 & 16291 & 1250 & 6.94 & 152 & 0.8 & 4.0 & 9463.9 & 5529.6 & 5.1E- -02 & 2777 & 0 & $8.8 E-02$ & 0.575 & 0 & 0 & 7E-03 & $.7 E-03$ & 1.75 & 1.4 & 1.1 & 2.2 & 1 & 1 & 4006423 & 752 \\
\hline 13 & & 46 & 416291 & 1200 & 168.2 & 35 & 0.8 & 4.0 & 9642.6 & 6499.6 & E-02 & 777 & 0 & E- 02 & 575 & 0 & 0 & E-03 & ZE-03 & 1.75 & 1.4 & 1.1 & 2.2 & 1 & 1 & 841221 & 748 \\
\hline 14 & $\begin{array}{l}\text { Pressure swing } \\
\text { absorption }\end{array}$ & 16 & 325480 & 1200 & 466.7 & -47 & 0.6 & 4.0 & 67241.8 & 1067344 & $5.4 \mathrm{E}-02$ & 0.3034 & 0 & E-03 & 0.6354 & 0 & 0 & $2.4 \mathrm{E}-03$ & $6 E-17$ & 1.75 & 1.4 & 1.1 & 2.2 & 1 & 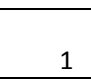 & 4238637 & 766 \\
\hline 15 & Flash net 1 & 11 & 8719 & 1000 & 59.4 & 88 & 1.6 & 3.4 & 2322.5 & 34920.6 & 5E-02 & 6E-02 & 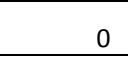 & 0 & $6.3 \mathrm{E}-03$ & 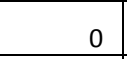 & 0 & 0.7068 & $44 E-03$ & 1.75 & 1.4 & \begin{tabular}{ll|}
1.1 \\
\end{tabular} & 2.2 & 1 & 1 & 005965 & 752 \\
\hline 16 & $\begin{array}{l}\text { Flash stage } 1 \\
\text { heater }\end{array}$ & 11 & 1078719 & 950 & 4.3 & 100 & 1.6 & 3.4 & 82322.5 & 7856.5 & 4.5E-02 & 7.6E-02 & 0 & 0 & $6.3 \mathrm{E}-03$ & 0 & 0 & 0.7068 & $9.4 \mathrm{E}-03$ & 1.75 & 1.4 & 1.1 & 2.2 & 1 & 1 & 673458 & 562 \\
\hline 17 & th net 2 & 6 & 9952 & 800 & 358.3 & 100 & 1.4 & 2.9 & 7991.1 & 46266.8 & $6 \mathrm{E}-02$ & AE-02 & $\underline{0}$ & 0 & 9.9E-04 & 0 & 0 & 0.6699 & $.3 E-02$ & 1.75 & 1.4 & 1.1 & 2.1 & 1 & 1 & 546776 & 646 \\
\hline 18 & & 6 & 999952 & 750 & 4.7 & 110 & 1.4 & 2.9 & 197991.1 & 6650.6 & $2.6 E-02$ & 2.4E-02 & 0 & 0 & 9.9E-04 & 0 & 0 & 0.6699 & .3E-02 & 1.75 & 1.4 & 1.1 & 2.1 & 1 & 1 & 315410 & 442 \\
\hline 19 & shnet 3 & 6 & 766989 & 600 & 352.4 & 110 & 1.1 & 2.2 & 151519 & 03004.4 & $1.1 E-02$ & 9E-03 & 0 & 0 & $1.0 \mathrm{EE}-04$ & t & 0 & 0.5138 & $1.6 \mathrm{E}-02$ & 1.75 & 1.4 & 1.1 & 1.8 & 1 & 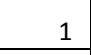 & 1650622 & 559 \\
\hline 20 & & 6 & 766989 & 550 & 6.6 & 120 & 1.1 & 2.2 & 1519 & 6934.6 & -02 & E-03 & 0 & 0 & 04 & 0 & 0 & .5138 & -02 & 1.75 & 1.4 & 1.1 & 1.8 & 1 & 1 & 547046 & 387 \\
\hline 21 & Flash net 4 & 0.62 & 183850 & 400 & 299 & 120 & 0.2 & 0.5 & 3646.905 & 227996.2 & $1.1 E-03$ & $2 E-04$ & 0 & 0 & $2 \mathrm{E}-06$ & 0 & 0 & 0.115 & $1.1 \mathrm{E}-02$ & 1.75 & 1.4 & 1.1 & 1.2 & 1 & 1 & 425215 & 356 \\
\hline 22 & Flash stage coc & 29 & 501474 & 400 & 1.72 & 113 & 0.7 & 1.5 & 475509 & 1311.7 & $1.3 \mathrm{E}-02$ & $1.6 \mathrm{E}-02$ & 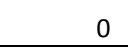 & 0 & $\begin{array}{l}1.2 E-03 \\
\end{array}$ & 0 & 0 & 0.3285 & $1.2 E-02$ & 1.75 & 1.4 & 1.1 & 1.5 & 1 & 1 & 1417108 & 532 \\
\hline 23 & Flash net 5 & 29 & 549390 & 384 & 9.21 & 102 & 0.8 & 1.6 & 519441.3 & 6742.6 & $1.46-02$ & $1.8 \mathrm{E}-02$ & 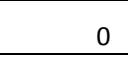 & 0 & $1.3 \mathrm{E}-03$ & 0 & 0 & 0.36 & $1.3 \mathrm{E}-02$ & 1.75 & 1.4 & 1.1 & 1.6 & 1 & 1 & 1613398 & 555 \\
\hline 24 & Flash stage cor & 29 & 549390 & 368 & 2.5 & 102 & 0.8 & 1.6 & 519441.3 & 1737.0 & $1.4 E-02$ & $1.8 \mathrm{E}-02$ & - & 0 & $1.3 \mathrm{E}-03$ & 0 & 0 & 0.36 & $1.3 \mathrm{E}-02$ & 1.75 & 1.4 & 1.1 & 1.6 & 1 & 1 & 1601088 & 554 \\
\hline 25 & Flash net 6 & 29 & 651214 & 368 & 14.8 & 95 & 0.9 & 1.9 & 612093.4 & 10405.3 & $1.66-02$ & $2.1 E-02$ & 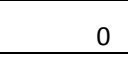 & 0 & $1.5 \mathrm{E}-03$ & 0 & 0 & 0.427 & $1.5 \mathrm{E}-02$ & 1.75 & 1.4 & 1.1 & 1.7 & 1 & 1 & 2039761 & 600 \\
\hline 26 & Flash stage co & 29 & 651214 & 350 & 2.8 & 95 & 0.9 & 1.9 & 612093.4 & 1891.2 & $1.6 \mathrm{E}-02$ & $2.1 \mathrm{EE}-02$ & 0 & 0 & $1.5 \mathrm{E}-03$ & 0 & 0 & 0.427 & $1.5 \mathrm{E}-02$ & 1.75 & 1.4 & 1.1 & 1.7 & 1 & 1 & 2017367 & 598 \\
\hline 27 & Flash net 7 & 29 & 793451 & 350 & 14 & 85 & 1.1 & 2.3 & 740535.3 & 9377.0 & 2E-02 & $2.6 E-02$ & - & 0 & $1.9 E-03$ & 0 & 0 & 0.5207 & $1.7 \mathrm{E}-02$ & 1.75 & 1.4 & 1.1 & 1.9 & 1 & 1 & 2682732 & 658 \\
\hline 28 & Solsep column & 78 & 759707 & 300 & 200 & -15.36 & 0.5 & 1.7 & 1906080 & 114608.1 & 2.7E-04 & $8.2 E-05$ & 0 & 0 & $1.4 E-06$ & 0 & 0 & 7.6E-02 & 0.3410 & 1.75 & 1.4 & 1.1 & 1.5 & 1 & 1 & 5923762 & 856 \\
\hline 29 & & 0.10 & 805 & 30 & 3.8 & 119 & 0 & 0.0 & 2.693631 & 217.9 & $6.5 E-10$ & $3.9 E-12$ & 0 & 0 & $3.0 E-15$ & 0 & 0 & $4.8 \mathrm{E}-06$ & 4.2E-04 & 1.75 & 1.4 & 1.1 & 1.0 & 1 & 1 & 340 & 33 \\
\hline 30 & & 26 & 707 & 300 & 7.5 & -15.36 & 0.5 & 1.7 & 5360 & 4294.2 & E-04 & $=05$ & 0 & 0 & IE-06 & 0 & 0 & $\mathrm{E}-02$ & 3410 & 1.75 & 1.4 & 1.1 & 1.5 & 1 & 1 & 394151 & 586 \\
\hline 31 & & 29 & 13 & 1200 & & 33 & 1.9 & 4.0 & 4037 & 0 & 02 & -02 & 0 & 0 & $=03$ & 0 & 0 & .8895 & -02 & 1.75 & 1.4 & 1.1 & 2.5 & 1 & 1 & 019808 & 861 \\
\hline 32 & $\begin{array}{l}\text { 5th stage } \\
\text { compressor }\end{array}$ & 29 & 1354873 & 3000 & & 112 & 1.9 & 4.0 & 1264037 & 0 & $3.4 E-02$ & AE-02 & 0 & 0 & $3.2 E-03$ & 0 & 0 & 0.8895 & $.9 E-02$ & 1.75 & 1.4 & 1.1 & 2.5 & 1 & 1 & 19808 & 861 \\
\hline 33 & & 29 & 1354873 & 3000 & 1.4 & 112 & 1.9 & $4 . c$ & 1264037 & 09.9 & $3.4 E-02$ & $E-02$ & 0 & 0 & $3.2 E-03$ & 0 & 0 & 0.8895 & $2.9 \mathrm{E}-02$ & 1.75 & 1.4 & 1.1 & 2.5 & 1 & 1 & 6051087 & 862 \\
\hline 34 & & 54 & 1120406 & 30 & 19 & -88 & 1.1 & 4.0 & 1928348 & 91145 & 44 & -02 & 0 & 0 & E-04 & 0 & 0 & 0.5053 & $E-05$ & 1.75 & 1.4 & $\begin{array}{l} \\
\end{array}$ & 2.3 & 1 & 1 & 12295381 & 1092 \\
\hline 35 & & 51 & 1426951 & 3000 & 0.45 & -12 & 2 & 4.0 & 46824 & 60.9 & 7.4E- -05 & $=09$ & 0 & 0 & 4E-16 & 0 & 0 & & $2 E-02$ & 1.75 & 1.4 & 1.1 & 2.5 & 1 & 1 & 11267742 & 1061 \\
\hline 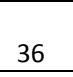 & $\begin{array}{l}\text { De-methanizer } \\
\text { condenser }(2 \text { nos.) }\end{array}$ & 27 & 1120406 & 3000 & 5.8 & -88 & 1.1 & 4.0 & 964174.2 & 33160.6 & 0.44 & $5.5 E-02$ & 0 & 0 & 1.7E-04 & 0 & 0 & & $1.9 E-05$ & 1.75 & 1.4 & 1.1 & 2.3 & 1 & 1 & 4348417 & 772 \\
\hline
\end{tabular}


Table 30: Continued

\begin{tabular}{|c|c|c|c|c|c|c|c|c|c|c|c|c|c|c|c|c|c|c|c|c|c|c|c|c|c|c|c|}
\hline $\begin{array}{l}S . N \\
0\end{array}$ & Physical Units & $\begin{array}{c}\text { Mass } \\
\text { flow } \\
\text { rate } \\
(\mathrm{kg} / \mathrm{s}) \\
\end{array}$ & $\begin{array}{c}\text { Heat of } \\
\text { combusti } \\
\text { on } \\
(\mathrm{J} / \mathrm{mol})\end{array}$ & $\begin{array}{c}\text { Processi } \\
\text { ng } \\
\text { Pressure } \\
\text { (kPa) } \\
\end{array}$ & $\begin{array}{c}\text { Volu } \\
\text { me } \\
\text { (m3) } \\
\end{array}$ & $\begin{array}{c}\text { Tempera } \\
\text { ture } \\
\text { (degC) }\end{array}$ & $\begin{array}{c}\text { NFPA } \\
\text { ranking } \\
\text { Reactiv } \\
\text { ity }\end{array}$ & $\begin{array}{c}\text { NFPA } \\
\text { ranking } \\
\text { flamm } \\
\text { ability }\end{array}$ & $F 1$ & F2 & $\begin{array}{c}\text { Methan } \\
\text { e mole } \\
\text { frac }\end{array}$ & $\begin{array}{c}c \text { co mol } \\
\text { frac }\end{array}$ & $\begin{array}{c}\mathrm{CO} 2 \mathrm{~mol} \\
\text { frac }\end{array}$ & $\begin{array}{c}\text { Acetylen } \\
\text { e mol } \\
\text { frac }\end{array}$ & $\begin{array}{c}\begin{array}{c}\text { Hydrog } \\
\text { en mol } \\
\text { frac }\end{array}\end{array}$ & $\begin{array}{c}\text { Oxygen } \\
\text { mol } \\
\text { frac }\end{array}$ & $\begin{array}{c}\text { water } \\
\text { mole } \\
\text { frac }\end{array}$ & $\begin{array}{l}\text { ethylen } \\
\text { e mol } \\
\text { frac }\end{array}$ & $\begin{array}{c}\text { propadi } \\
\text { ene mol } \\
\text { frac }\end{array}$ & pn1 & $\begin{array}{l}\text { pn } \\
\end{array}$ & $\begin{array}{l}\text { pn } \\
3 \\
\end{array}$ & pn4 & pn5 & pn6 & $\begin{array}{l}\text { Damage } \\
\text { Potential } \\
\end{array}$ & FEDI \\
\hline 37 & Ethylene column & 49 & 1410968 & 2500 & 105 & -20.59 & 2 & 4.0 & 2234360 & 501533 & $2.3 E-05$ & 4.7E-10 & 0 & 0 & 0 & 0 & 0 & 0.9999 & $2.6 \mathrm{E}-05$ & 1.75 & 1.4 & 1.1 & 2.5 & 1 & 1 & 12683657 & 1104 \\
\hline 38 & Ethylene reboiler & 48 & 1911795 & 2500 & 2 & 77 & 1 & 4.0 & 2920917 & 9799.7 & 1.2E-12 & $9.3 E-21$ & 0 & 0 & 0 & 0 & 0 & $3.0 E-03$ & 0.9969 & 1.75 & 1.4 & \begin{tabular}{|l|}
1.1 \\
\end{tabular} & 2.3 & 1 & 1 & 12689282 & 1104 \\
\hline 39 & $\begin{array}{l}\text { Ethylene } \\
\text { condenser ( } 2 \text { nos.) }\end{array}$ & 24 & 1410968 & 2500 & 7 & -20.69 & 2 & 4.0 & 1117180 & 33319.5 & 2.3E-05 & 4.7E-10 & 0 & 0 & 0 & 0 & 0 & 0.9999 & $2.6 \mathrm{E}-05$ & 1.75 & 1.4 & 1.1 & 2.5 & 1 & 1 & 5504664 & 836 \\
\hline
\end{tabular}

\section{Table 31: Safety calculation of reactors- Ethane Cracking}

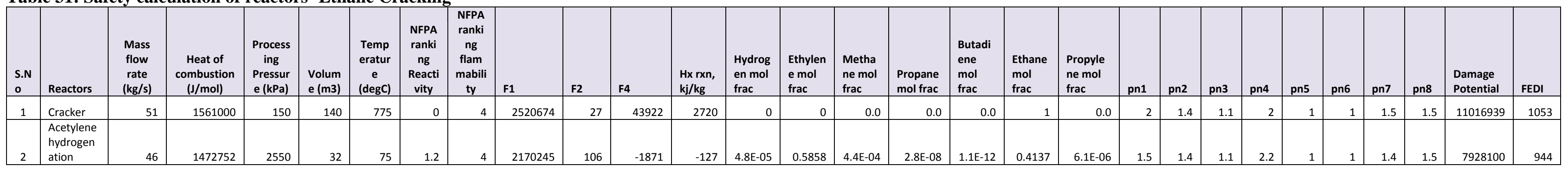

Table 32: Safety calculation of reactors- Methane Pyrolysis

\begin{tabular}{|c|c|c|c|c|c|c|c|c|c|c|c|c|c|c|c|c|c|c|c|c|c|c|c|c|}
\hline S.No & Reactors & $\begin{array}{l}\text { Mass } \\
\text { flow } \\
\text { rate } \\
(\mathrm{kg} / \mathrm{s})\end{array}$ & $\begin{array}{c}\text { Heat of } \\
\text { combustion } \\
(\mathrm{J} / \mathrm{mol})\end{array}$ & $\begin{array}{l}\text { Processing } \\
\text { Pressure } \\
\text { (kPa) }\end{array}$ & $\begin{array}{c}\text { Volume } \\
(\mathrm{m} 3)\end{array}$ & $\begin{array}{l}\text { Temperatu } \\
\text { re (degc) }\end{array}$ & $\begin{array}{c}\text { NFPA } \\
\text { ranking } \\
\text { Reactivit } \\
y\end{array}$ & $\begin{array}{c}\text { NFPA } \\
\text { ranking } \\
\text { flammabil } \\
\text { ity }\end{array}$ & F1 & F2 & F4 & 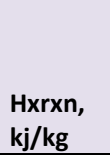 & $\begin{array}{l}\text { Methan } \\
\text { e mole } \\
\text { frac }\end{array}$ & $\begin{array}{l}\text { Hydroge } \\
\mathrm{n} \mathrm{mol} \\
\mathrm{frac}\end{array}$ & pn1 & pn2 & pn3 & pn4 & pn5 & pn6 & pn7 & pn8 & $\begin{array}{l}\text { Damage } \\
\text { Potential }\end{array}$ & FEDI \\
\hline 1 & Cracker & 105 & 891100 & 100 & 47 & 1488 & 0 & 4 & 2972220 & 6.2 & 316810 & 9498 & 1 & 0 & 1.95 & 1.4 & 1.1 & 2 & 1 & 1 & 1.45 & 1.45 & 14216252 & 1146 \\
\hline 2 & $\begin{array}{l}\text { Acetylene } \\
\text { hydrogenation }\end{array}$ & 1.9 & 286000 & 1150 & 1057 & 88 & 0 & 4 & 17196 & 1585 & 3648 & 6067 & 0 & 1 & 1.75 & 1.4 & 1.1 & 2 & 1 & 1 & 1.35 & 1.45 & 86802 & 209 \\
\hline
\end{tabular}

